\title{
WestVirginiaUniversity
}

THE RESEARCH REPOSITORY @ WVU

Graduate Theses, Dissertations, and Problem Reports

2019

\section{Characteristics and patterns of opioid-related overdoses among veterans}

\author{
Sara Catherine Warfield \\ West Virginia University, scwarfield@mix.wvu.edu
}

Follow this and additional works at: https://researchrepository.wvu.edu/etd

Part of the Epidemiology Commons, Health Services Research Commons, and the Substance Abuse and Addiction Commons

\section{Recommended Citation}

Warfield, Sara Catherine, "Characteristics and patterns of opioid-related overdoses among veterans" (2019). Graduate Theses, Dissertations, and Problem Reports. 3902.

https://researchrepository.wvu.edu/etd/3902

This Dissertation is protected by copyright and/or related rights. It has been brought to you by the The Research Repository @ WVU with permission from the rights-holder(s). You are free to use this Dissertation in any way that is permitted by the copyright and related rights legislation that applies to your use. For other uses you must obtain permission from the rights-holder(s) directly, unless additional rights are indicated by a Creative Commons license in the record and/ or on the work itself. This Dissertation has been accepted for inclusion in WVU Graduate Theses, Dissertations, and Problem Reports collection by an authorized administrator of The Research Repository @ WVU.

For more information, please contact researchrepository@mail.wvu.edu. 


\title{
Characteristics and patterns of opioid-related overdoses among veterans
}

\author{
Sara C. Warfield, MPH \\ Dissertation Submitted to the West Virginia University \\ School of Public Health \\ In Partial Fulfillment of the Requirements for the Degree of: \\ Doctor of Philosophy \\ in \\ Public Health
}
Robert M. Bossarte, Ph.D., Chair
Christa Lilly, Ph.D.
Mike Brumage, MD, MPH
Thomas Hulsey, Sc.D.
Department of Epidemiology
Morgantown, West Virginia
2019

Keywords: Opioid overdoses, veterans, nonfatal overdose, repeat overdose, Veterans Health Administration 


\section{ABSTRACT \\ Characteristics and patterns of opioid-related overdoses among veterans}

\section{Sara C. Warfield}

BACKGROUND AND OBJECTIVES: The United States is in the midst of an opioid overdose crisis and is now considered a public health emergency. Given the alarming rise in opioid overdose deaths, there is an urgent need to understand the characteristics and risks associated with opioid overdoses. The objectives of this study were 1) to compare factors associated with different type of opioid overdose, 2) to determine the conditional probability of repeat overdose among veterans with a prior overdose event and corresponding probability of mortality for each overdose event and, 3) to identify cause-specific mortality rate of those who experienced a nonfatal overdose during our study period.

METHODS: Using clinical records and mortality files of more than 10.5 million veterans, we extracted data among those with a documented opioid overdose between January 1, 2011 and December 31, 2015. During this time, 13,333 veterans had at least one documented opioid overdose of any intent.

RESULTS: Study 1. Patients who were younger in age (18-44 OR [odds ratio] 7.19, 45-64 OR 4.78) had significantly higher odds of a fatal index overdose and experiencing a repeat overdose (18-44 OR 2.13, 45-64 OR 1.78). Having one or more chronic pain diagnoses was both associated with experiencing a fatal index overdose (OR 3.96) or repeat overdose (OR 1.15). A diagnosis associated with mental health or substance abuse or dependence was significantly associated with experiencing a repeat overdose, (OR 1.54 and 1.25 respectively). Receipt of medication-assisted therapy (MAT) more than one year prior (OR 1.28) to the first (i.e. index) overdose was significantly associated with increased odds of a fatal overdose whereas receiving counseling services prior to index overdose was protective of experiencing a fatal index overdose. Study 2. One fifth of the study sample had a repeat overdose during the study period, with a conditional probability that increased linearly for each subsequent overdose event. The conditional probability of repeat overdose went from $21.1 \%$ on the second overdose to $43.2 \%$ for five or more overdoses. Mortality was highest among the first documented overdose. Study 3. Overall, veterans with a prior nonfatal overdose more often died from any cause in comparison to their veteran peers and had approximately 26 times the mortality rate to the general U.S. population. Veterans with a prior nonfatal overdose had a higher risk of death from substances (aHR [adjusted Hazard Ratio] 5.0, 95\% CI [confidence interval]: 4.4-5.8), including a higher risk of death from drugs (aHR 6.9; 95\% CI 5.8-8.1) and alcohol (aHR 2.7, 95\% CI 2.1-3.6). For cause-specific mortalities assessed between veterans in our cohort and the general U.S. population, the standardized mortality rate ratio (SMR) was 114 times higher for deaths associated with substances (95\% CI: 98.8-128.7), 107 times higher for deaths associated with hepatitis (95\% CI: 65.5-152.7) and 68 times higher for deaths associated with liver cancers $(95 \%$ CI: 47.9-88.7). Overall, veterans in our overdose cohort had an elevated mortality rate than the general public for all the specific causes of death assessed.

CONCLUSION: Although risk factors for opioid overdoses are well studied, there appears to be differences between the type of opioid overdoses documented in a clinical setting. Given that mortality is highest on the first documented overdose suggests that prevention efforts should be further support to reach those patients at highest risk. Furthermore, given that the probability of 
experiencing a repeat overdose increases with each overdose event suggest that healthcare settings should be prepared to handle an influx in patients, specifically those with mental health diagnoses. Moreover, given the elevated risk of death from all-causes, specifically those associated with substances suggests the need for an integrated healthcare approach.

Understanding risks factors, type of overdose, and cause-specific mortality among patients with an opioid overdose could help to inform healthcare interventions and potentially lead to better patient outcomes. 


\section{Dedication}

To both of my parents, Randy and Courtney, who always instilled the importance of education but more importantly showed me how to be the voice for those who may not be able to speak.

To all of my family and friends who have been supportive of me, including my second family at the Injury Control Research Center. This experience would not have been the same without you, I deeply cherish you all.

I am also especially grateful for West Virginia University, in particular the School of Public Health, for supporting me and giving me so many opportunities. I will forever be grateful for the numerous opportunities that I have been able to be part.

Last but certainly not least, I dedicate this to my friend, Nick Dibble. You touched the lives of so many people with your wit, humor and love. This epidemic has taken so many lives but yours hit me the hardest. 


\section{Acknowledgements}

To Rob Bossarte, my mentor, advisor, and the chair of my committee, thank you for encouraging me and pushing me to dive deeper into this topic. Without your mentorship, my dissertation and educational experience throughout the entire PhD program would not have been as meaningful. I will forever be grateful for your mentorship and guidance.

I am so thankful for the rest of my committee for their time, energy, support, and fruitful input. I would like to thank Dr. Mike Brumage for his unwavering support to this project in addition to his many other responsibilities. His passion to combat the current public health crisis is inspiring. I am deeply grateful for Dr. Christa Lily for her constant support, feedback, and input on my dissertation. I would also like to thank Dr. Thomas Hulsey for his time and support throughout this process.

To the Center of Excellence (CoE) for Suicide Prevention (Department of Veterans Affairs) who supported the development of this project. I would like to specifically thank Dr. Elizabeth Karras, the Director of Research at the CoE, for her continued support in this project. In addition I would like to thank other members at the COE, specifically Brady Stephens, Tom Brown and Cathy Kane.

This dissertation was also partially supported by the WVU Injury Control Research Center (funded by the Centers for Disease Control and Prevention, grant number 3R49CE002109). 


\section{TABLE OF CONTENTS}

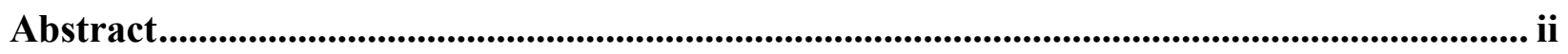

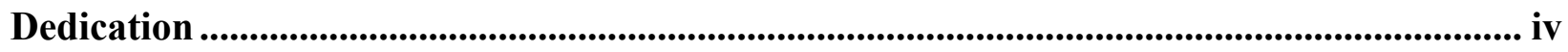

Acknowledgements .............................................................................................................................

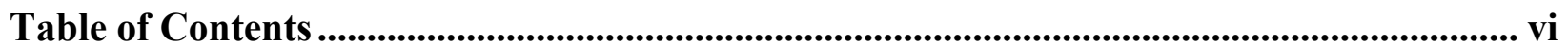

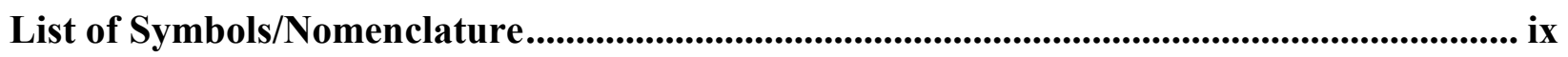

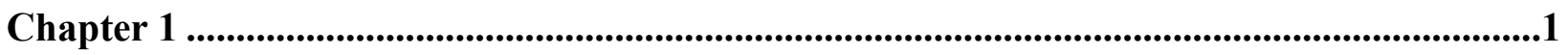

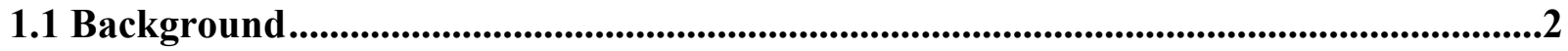

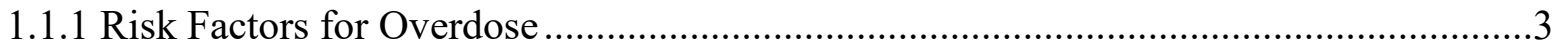

1.1.2 Epidemiology of Overdose and Veterans Who Use VHA Services.............................3

1.1.3 VHA and Electronic Health Records .....................................................................5

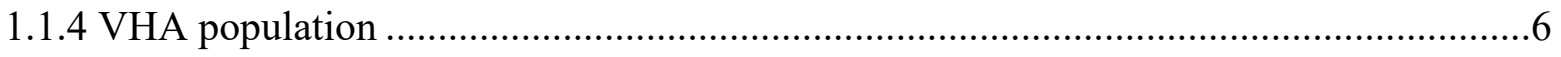

1.1.5 Current Prevention Efforts ................................................................................ 7

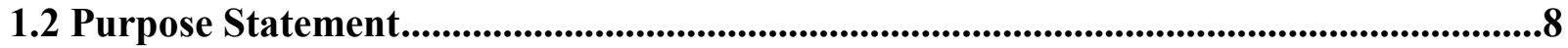

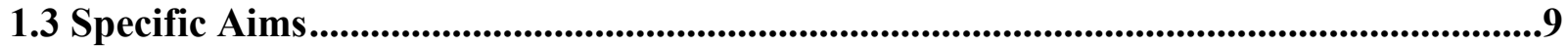

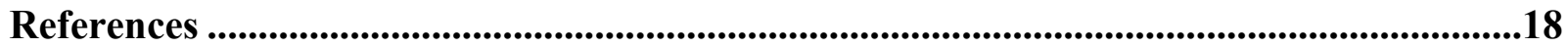

Tables and Figures ............................................................................................................23

Table 1: Risk factors for opioid overdose................................................................................24

Figure 1: Process Flow for CDW .............................................................................26

Figure 2: Sample Design for the Opioid Overdose Cohort...................................................27

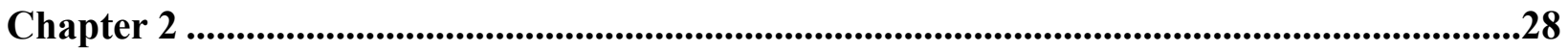

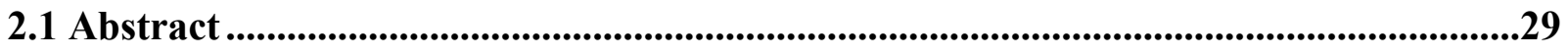

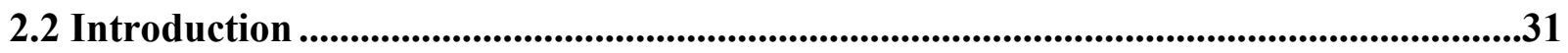

2.3 Methods

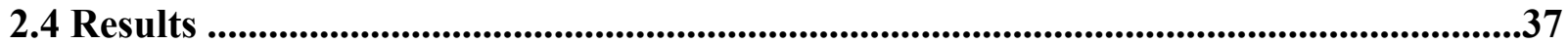

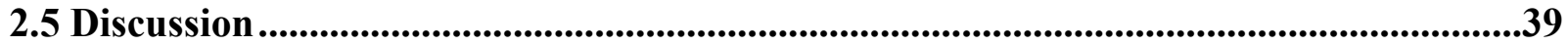

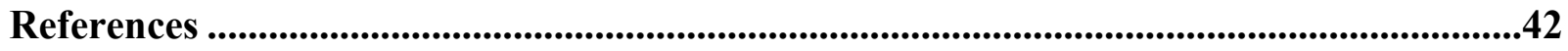

Tables and figures .............................................................................................................46

Table 1: Demographic and diagnostic characteristics of veterans with a documented

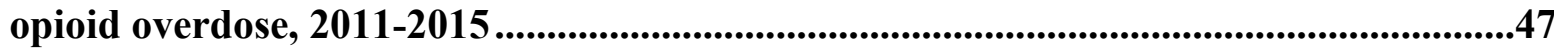


Table 2: Bivariate analysis of demographic and diagnostic characteristics by type of opioid overdose among veterans, 2011-2015.

Table 3: Multinomial regression analysis of factors associated with type of opioid overdoses among Veterans, 2011-2015 ....................................................................57

Supplemental Table: Corresponding ICD-9 and ICD-10 Codes for Variables .............58

Chapter 3 .60

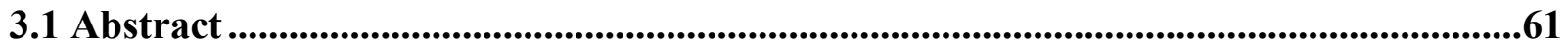

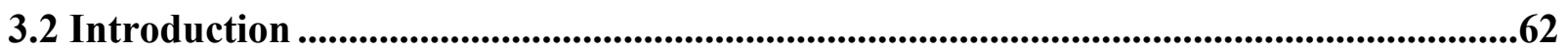

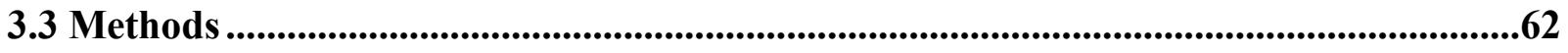

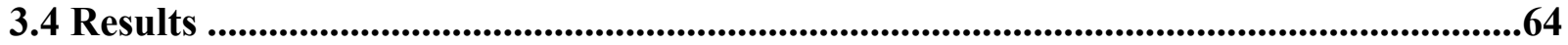

3.5 Discussion ..............................................................................................................................64

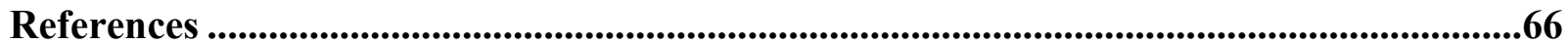

Tables and figures

Table 1: Repeated opioid overdoses and subsequent mortality among patients between

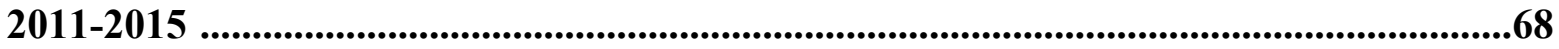

Figure 1: Mortality for each opioid overdose event recorded, 2011-2015 ......................69

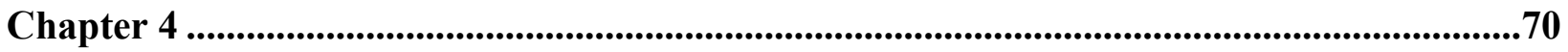

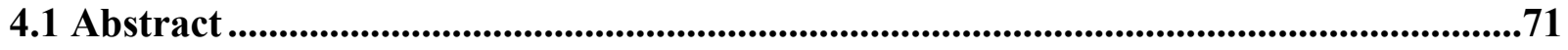

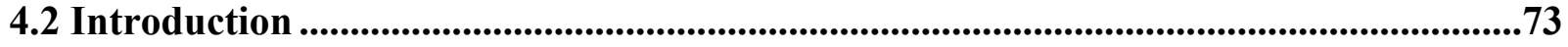

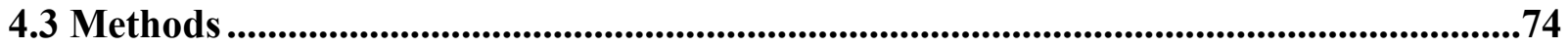

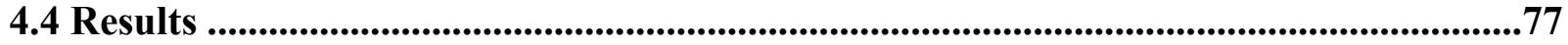

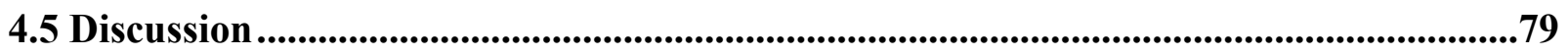

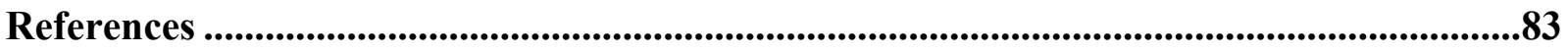

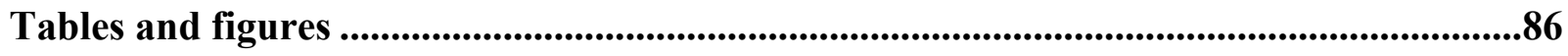

Table 1: Mortality rate (per 10,000 person-years) among veterans with a nonfatal index $\mathrm{OD}(\mathrm{n}=\mathbf{8 , 3 7 0 )}$ compared to a $5 \%$ stratified random sample of veterans........... .87

Table 2: Standardized Mortality Ratios, observed, and expected number of deaths for veterans with a nonfatal index overdose for all causes and selected causes.....................88

Supplemental Table: ICD-10 Codes for cause-specific mortality .....................................89

Chapter 5 ............................................................................................................................................90

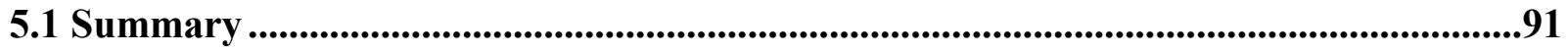

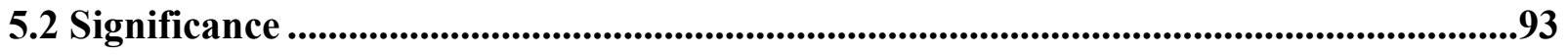

5.3 Future research ...............................................................................................................95

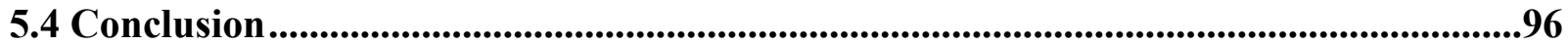




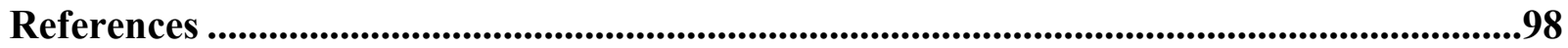

Appendix A

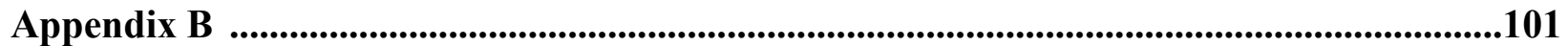

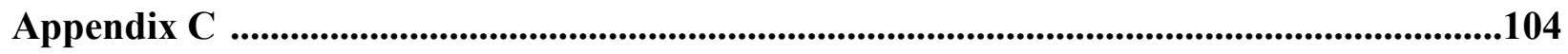

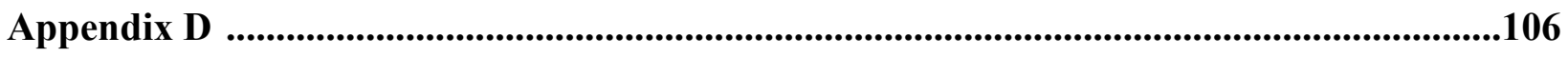




\section{List of Abbreviations and Nomenclature}

\begin{tabular}{|c|c|}
\hline $\mathrm{ADD}$ & Attention deficit disorder \\
\hline $\mathrm{CDC}$ & Centers for Disease Control and Prevention \\
\hline CDW & Corporate Data Warehouse \\
\hline DoD & Department of Defense \\
\hline EHR & Electronic health record \\
\hline HIV & Human immunodeficiency virus \\
\hline IDU & Injection drug use \\
\hline ICD-9 & International Classification of Disease, Ninth Edition \\
\hline ICD-10 & International Classification of Disease, Tenth Edition \\
\hline MAT & Medication-Assisted Treatment \\
\hline MME & Morphine Milligram Equivalence \\
\hline NDI & National Death Index \\
\hline OEND & Opioid Overdose Education and Naloxone Distribution program \\
\hline OSI & Opioid safety initiative \\
\hline OUD & Opioid use disorder \\
\hline OD & Overdose \\
\hline PDMP & Prescription drug monitoring program \\
\hline PTSD & Post-traumatic stress disorder \\
\hline PWID & Person(s) who inject drugs \\
\hline $\mathrm{SDoH}$ & Social determinants of health \\
\hline SDR & Suicide Data Repository \\
\hline SMR & Standardized mortality rate ratio \\
\hline
\end{tabular}


SSN

STORM

SUD

US

VA

VHA

WHO

WONDER
Social Security Number

Stratification Tool for Opioid Risk Mitigation

Substance Use Disorder

United States

Department of Veteran Affairs

Veterans Health Administration

World Health Organization

Wide-Ranging Online Data for Epidemiologic Research 


\section{Chapter 1}




\section{Chapter 1. Introduction}

\subsection{Background}

Opioid overdoses have surged in the past decade and deaths from overdose are now considered one of our country's most serious public health crises. Between 2007 and 2017 there were more than 507,000 overdose deaths in the United States; with more than half of these involving opioids [1-4]. Concurrent with the rise in overdose deaths, hospitalizations related to opioid abuse and misuse have also been on the rise [5, 6]. Between 2009 and 2014, opioid overdoses resulting in inpatient hospital admission increased more than $60 \%$, emergency department visits nearly doubled [5] and costs associated with overdose morbidity and mortality have been estimated to exceed $\$ 22$ billion annually $[7,8]$.

Despite the impact associated with opioid overdose on the healthcare system, few studies have examined information available from electronic health records in conjunction with vital records to examine risk for opioid overdose or to inform prevention and clinical programs. There are a number of unanswered questions related to the combinations of medical diagnoses and social conditions as potential risk factors for overdose, particularly among populations with evidence of abuse or misuse. To date, there have been a limited number of studies that examined the etiology of repeated opioid overdoses or compared them with characteristics associated with fatal overdose. [9-11]. Similarly, little is known about the patterns of cause-specific mortality risk among those with history of at least one nonfatal overdose $[12,13]$. Understanding risk factors for repeated overdose and mortality following a nonfatal overdose could inform healthcare interventions and in turn, better patient outcomes. 


\subsubsection{Risk Factors for Overdose}

Individual-level risk factors for opioid overdose include sex (male), age (particularly 18 to 45 years), race/ethnicity (non-Hispanic white), and residence in a rural area; particularly the Appalachian region [2, 3, 14-18]. Physical health conditions associated with an increased risk of overdose include diagnoses associated with chronic pain, liver disease, renal disease, chronic pulmonary disease, cardiovascular disease, musculoskeletal injury, cancer, and skin and softtissue infections [19-22]. Mental health diagnoses and related factors associated with overdose risk include depression, anxiety, history of suicide attempt or ideation, post-traumatic stress disorder (PTSD), bipolar disorder, attention deficit disorder (ADD), frequent or severe psychological distress, and substance use disorder (SUD) [19-21, 23-27]. While many risk factors for overdoses have been previously studied, they have largely examined risk factors among people who inject drugs (PWID) or individuals taking prescription opioids; primarily due to chronic non-cancer pain $[17,22,26,28-32]$. Moreover, a majority of studies have focused on identifying risk factors using information obtained from cross-sectional surveys. Risk factors associated with opioid overdose are detailed in Table 1.

\subsubsection{Epidemiology of Overdose and Veterans Who Use VHA Services}

Evidence suggests that risk factors associated with opioid overdose among veterans who have utilized Veterans Health Administration (VHA) services are similar to those identified among the general U.S. population. Risk factors assessed in previous studies include dosage of prescribed opioids, duration of prescribed opioids [20, 22, 25, 33], medical conditions associated with chronic pain, and diagnoses or symptoms associated with psychiatric disorders [25, 34, 35]. Although risk factors for overdose are similar to those in the general population, research suggests that more veterans who use VHA services have history of some risk factors associated 
with overdose morbidity and mortality, such as chronic pain and mental health diagnoses, which in turn may be associated with higher overdose mortality rate among members of this population $[24,36,37]$. Further, previous research among veterans found that over $60 \%$ of patients who experienced an unintentional opioid overdose were seen in an outpatient setting in the month prior to their overdose and approximately $30 \%$ of those were for mental health treatment [ 38 , 39]. While many risk factors for fatal overdose have been previously identified, existing studies largely examined unintentional overdose death or risk factors for overdose among those with access to prescription opioid pain relievers; primarily due to chronic pain $[18,20,22,25,29,35$, 40, 41]. Although medical diagnoses capture a variety of risk factors associated with overdose mortality, they do not capture all potential risk factors or information available from electronic medical records. Environmental and social stressors have been previously identified as risk factors for substance abuse, yet little is understood about the unique contribution of these factors or the combined influence of environmental and social stressors and medical/psychiatric diagnoses.

Numerous studies have found that social determinants of health $(\mathrm{SDoH})$ are often significantly associated with negative outcomes [42-44]. SDoH that are the most significant for health outcomes are often those associated with socioeconomic status, such as economic instability or inadequate housing $[42,45]$. Factors such as homelessness and early life adversity, have also been shown to influence risk for drug use and mental health disorders [46, 47]. Indicators of social determinants of health can be assessed in electronic health records (EHR) through certain $\mathrm{V}$ codes (ICD-9) and Z codes (ICD-10). Although these social codes can be used in any healthcare setting, studies have shown they are generally underutilized by most healthcare professionals other than mental health professionals [44, 48]. 
Looking beyond the primary and secondary diagnostic codes may provide an opportunity to describe the social, behavioral, and environmental factors, also known as contextual factors, which may be associated with overdose risk [48-52]. Such findings could inform additional strategies designed to reduce overdose deaths attributed to opioids. Although studies have examined outpatient visits prior to an overdose, no existing study has examined contextual factors prior to an overdose and few have identified these factors in conjunction with health diagnosis in the veteran population $[38,39]$.

It is possible that previously identified risk factors may be exaggerated among veteran populations, such as mental health diagnoses (i.e. post-traumatic stress disorder (PTSD) or chronic pain $[24,25,33,34,53]$. Studies conducted using data from VHA records have consistently found that veterans have a high rate of mental health diagnoses, including substance use disorder (SUD),[20, 34, 53-55]; a potentially important risk factor to overdose morbidity and mortality[20, 24, 25, 36].

\subsubsection{VHA and Electronic Health Records}

Data from EHRs can be used in addition to mortality and prescribing surveillance systems to monitor trends as well as identify clinical characteristics associated with a myriad of health outcomes in a timely manner. EHRs hold a comprehensive list of healthcare factors such as diagnosis codes, procedure codes and medication data, allowing for a deeper understanding of various health outcomes. Linking clinical and death records together can leverage data between these two sources to enhance the understanding of corresponding risk for health outcomes. Findings from rich data sources like EHRs can inform future healthcare efforts targeting patients at risk for overdose. 
Given the growing concern for opioid overdoses across the U.S., there is a need to enhance information used to understand risk for and prevention of overdose morbidity and mortality. Further, the majority of risk factors identified have focused on single episodes (either fatal or nonfatal) and comparatively little is known regarding the risk factors for repeated overdose.

\subsubsection{VHA population}

The VHA is one of the largest integrated healthcare system in the United States and collects data on clinical diagnosis, procedures, medications, and sociodemographic information from more than six million patients annually. Currently, the largest proportion of veterans receiving VHA medical care served in the Vietnam Era [56].

Serving more than six million patients annually, the VHA provides an array of comprehensive healthcare services for a myriad of health conditions. VHA services are provided in 170 medical centers and 1,243 outpatient clinics throughout the U.S. [56]. Available data suggests that patients seeking care from the VHA often have poorer health outcomes, such as chronic pain and psychiatric comorbidities, and multi-system diagnoses, which could increase risk of negative health outcomes [57, 58]. In 2003, it was estimated that more than one million veterans who use VHA services have been diagnosed with either a substance abuse disorder or other mental health condition [59]. Accordingly, mental health and substance use disorders are considered a significant issue among the veteran population [60, 61]. Previous research suggests that more than 55,000 veterans who use VHA services have been diagnosed with an opioid use disorder (OUD)[62]. The breadth of data collected by the VHA coupled with the evidence of elevated risk factors among the patient population provides a unique opportunity to use information from this health care system to identify previously unexplored risk factors and targeted strategies to reduce opioid-related morbidity and mortality. 


\subsubsection{Current Prevention Efforts}

Primary prevention strategies for opioid abuse and overdose prevention have largely focused on reducing the excess supply of prescription opioids, including the development and support of safe prescribing guidelines and the implementation of prescription drug monitoring programs (PDMP). Secondary and tertiary efforts have been primarily focused on addressing the gap in treatment and distribution of naloxone, a rapid acting opioid antagonist [63-65]. Importantly, one consequence of the increased distribution and resulting availability of naloxone is the associated increase in probability of surviving an overdose and related history of multiple overdoses.

In recent years, the VHA has amplified efforts to reduce risk of opioid overdose among patients receiving care from clinicians in its facilities. In an effort to promote safer prescribing the VHA introduced the Opioid Safety Initiative (OSI) which leverages prescription data within the VHA and helps clinicians identify patients at risk for adverse risks from opioids. In addition to the OSI, the VHA developed a dashboard to identify patients at risk for an adverse event related to opioids $[63,66]$. Furthermore, the VHA has developed academic detailing on opioid abuse and overdose prevention in an effort to provide health care professionals with evidence-based educational tools [66]. To further reduce the burden of opioid overdose among veterans, the U.S. Department of Veterans Affairs also developed the Opioid Overdose Education and Naloxone Distribution (OEND) program. This program primarily focuses on educating health care professionals and high-risk patients on strategies to prevent, identify, and reverse an opioid overdose. Veterans with a history of injection drug use, substance use such as heroin, a diagnosis of opioid use disorder (OUD), or those with a high likelihood of opioid overdose or witnessing an overdose are targeted for the OEND program. These patients' are often identified in medical 
settings including but not limited to treatment programs such as Medication-Assisted Treatment (MAT), inpatient withdrawal management, syringe access programs, emergency departments, homeless shelters and other primary health care settings[67].

\subsection{Purpose Statement}

Given increases in overdose deaths, there is a need to identify opportunities for intervention and prevention services informed by a better understanding of risk for repeat overdose and mortality. The primary aim of this study is to identify and assess the risk factors such as demographic characteristics, medical diagnoses and indicators of social determinants of health associated with risk for repeat overdose and all-cause mortality among patients with a history of one opioid overdose.

The proposed project seeks to expand upon existing efforts using data from VHA administrative records to inform strategies for clinical interventions and preventive services targeting veteran groups at increased risk for a fatal opioid overdose or repeat opioid overdose.

Results from this project will specifically add to the literature in the following ways:

1. Increase understanding of potential differences in risk for nonfatal, repeated and fatal overdose.

2. Calculate associations between an increasing number of nonfatal overdoses and risk for mortality or repeated events.

3. Assess all-cause and cause-specific mortality risk among veterans with a documented opioid overdose. 


\subsection{Specific Aims}

\section{Sample design}

Veterans with a documented opioid-related overdose were identified using clinical and administrative records from the Veterans Health Administration (VHA) Corporate Data Warehouse (CDW) and the VA/DoD Suicide (all-cause) Data Repository (SDR) respectively. The process flow of data into the CDW is shown in Figure 1 and specific ICD-9 and ICD-10 codes used for the opioid overdose is in Appendix A and corresponding variables of interest are listed in Appendix B (demographic and diagnostic variables), C (codes which serve as indicators of social determinants of health) and D (codes used to define cause-specific mortality). Underlying cause of death codes used to identify cause-specific mortality can be found in Appendix D.

We identified all veterans who utilized VHA services between calendar years 2011 through 2015 by accessing patient information available from VHA's administrative and EMR data files. Social Security Numbers (SSNs) were used to link to the CDW and SDR records. We extracted potential predictor variables including demographic information such as sex and age, procedural codes and diagnostic codes for the study period (2011-2015). An additional year of data was extracted if the index overdose occurred in the first year of the study period. For instance, if an individual had an opioid overdose (nonfatal or fatal) in January 2011, procedural and diagnosis codes were pulled from one year prior (January 2010) to index overdose.

\section{Inclusion/Exclusion criteria}

The cohort was restricted to veterans over 18 years or under 90 years. We excluded patients that did not have a follow-up visit within one year of a non-fatal overdose event. Patients with a death 
date prior to an overdose diagnosis date were also excluded from analysis ( $\mathrm{n}=145,0.89 \%)$. Given that repeated overdose occurred on average more than one month after the index overdose (mean $=36$ days), patients were excluded if the first nonfatal overdose occurred in the last three months of the study period (October 1, 2015 to December 31, 2015). This mitigated potential bias among those with less than three months of documented time at risk following an overdose event.

\section{Opioid overdose cohort}

A nonfatal opioid overdose was identified using International Classification of Disease, Ninth Edition (ICD-9) 965.00-965.02, 965.09, E850.0-E850.2. Similarly, ICD Tenth Edition (ICD-10) codes were used to identify opioid overdose: X40-X44, X60-X64, X85, and Y10-Y14 and secondary-axis codes T40.0- T40.4, and T40.6 (Appendix A). The first opioid overdose documented in the compiled records was coded as the index overdose. Multiple opioid overdoses that occurred during an inpatient treatment stay were counted as a single overdose event, based on admission and discharge date. Repeat overdoses were identified among veterans with more than one opioid overdose recorded during the study period. A repeat overdose was defined as a second documented overdose that occurred a) two days after the index event with principal diagnosis of an overdose or b) 3 days or more after a prior overdose. Any record of an overdose within one day of a previous overdose was treated as the same event.

We identified 13,333 patients with a record of an opioid overdose between the calendar years 2011 through 2015. Of those, there were 4,949 (37.1\%) opioid overdose deaths, with a majority occurring on the first documented overdose $(n=4,890,98.8 \%)$. Furthermore, among these overdose deaths, $85.0 \%$ were unintentional $(n=4,206), 6.4 \%$ were undetermined $(n=315), 8.5 \%$ 
were intentional $(\mathrm{n}=422)$ and $0.1 \%$ were homicide $(\mathrm{n}=6)$. Figure 2 depicts the specific inclusion and exclusion criteria for each of the specific aims.

\section{Predictors}

Demographic characteristics were extracted using clinical and administrative rules set by the VHA. For instance, sex was based on last entered value for analysis. Age was static and based on the patient's age on the start of the study period, January 1, 2011.

Date of diagnosis was based on the day of visit for the outpatient population or the date of discharge for the inpatient records. Potential predictors were examined one year prior to first documented overdose and at any point during the study period.

All predictors were dummy coded and additional variables were created based on time of diagnosis, particularly in relation to index overdose. This helped describe the potential relationship between diagnosis and type of overdose experienced.

This study was reviewed and approved by the Institutional Review Board at the Syracuse VA Medical Center, New York.

Analysis plan

For all aims, data management and analysis were conducted using SAS Enterprise Grid software (version 5.1, SAS Institute Inc.). Descriptive analysis for all variables were completed using cross tabulations, column percentages were reported for each outcome of interest. Alpha was set to 0.05 for tests unless otherwise specified.

Specific Aim 1: Characterize differences between those with a fatal index overdose and those with repeated nonfatal overdoses from those with only one nonfatal index overdose. 
Based on results from existing studies, we hypothesize that those who experienced repeated overdoses would have a greater number of psychiatric diagnoses and social health indicators than those who died on their first documented overdose [24, 68-71].

Bivariate analyses were conducted using chi-square test of difference among all sociodemographic and diagnostic variables by overdose category: fatal index overdose, repeated nonfatal overdoses, and only one nonfatal overdose. The primary hypotheses was tested using multinomial logistic regression given the polytomous outcome includes three mutually exclusive groups without order. As an extension of logistic regression models, this approach is flexible and allowed three overdose outcome levels using a generalized logit link. In addition, this approach provided a more direct option for interpreting the relationship between the predictors and outcome groups [72], is more robust to violating the assumptions of normality and does not assume a linear relationship between the predictors and outcome [72, 73]. Conversely, this method required additional comparative statements given that this method produced multiple odds ratios for each predictor; which could lead to issues with interpretability [72, 74]. A major limitation of this method may result from the independence of irrelevant alternatives (IIA) assumption which presumes that changing the number of outcomes (e.g. three to five levels) would not affect the odds of the remaining outcomes $[75,76]$. Model fit for this multinomial logistic regression model was first assessed by using a series of logistic regression models, controlling for age and gender, which is known to influence overdose risk[74, 77]. Assumptions for multinomial logistic regression models were tested. For example, multicollinearity was assessed by calculating variance inflation factors (VIF). Predictors with a VIF greater than 10 were reassessed for strength of relationship with the outcome. Of those predictors where collinearity was suspected, Wald chi-square tests were conducted to determine which variable 
was more appropriate for inclusion in the final models. Weaker predictors were dropped and the model was rerun to only include significant predictors that were not collinear. Goodness of fit indices such as the Type 3 Analysis of Effects and Wald chi-square test were examined for all predictors with the null that all of the coefficients were equal to zero in the model[72].

Interactions between significant predictor variables were tested and significant interactions were left in the model. Odds ratios with a 95\% Confidence Interval (CI) were calculated by exponentiating the estimate. The adjusted odds ratio indicate the odds of experiencing a fatal overdose compared to those with one nonfatal overdose as well as the odds of experiencing a repeated nonfatal overdose compared to those with one nonfatal overdose, adjusted for all other predictors in the model.

\section{Specific Aim 2: Calculate the conditional probability of a repeat opioid overdose event} (fatal and nonfatal) among those with record of a nonfatal opioid overdose. We expect that the conditional probability for repeated overdose and mortality will increase linearly with each overdose event.

The frequency and conditional probability of nonfatal and fatal overdose was calculated among the VHA patient population with at least one overdose event during the study period (20112015). We excluded overdoses that were classified as homicides or suicides. To describe the magnitude of repeated overdose and corresponding mortality for each overdose event, the conditional probability of repeated overdose and associated mortality was calculated for patients with at least one documented overdose in the VHA clinical records. Conditional probability of an overdose was calculated by dividing the proportion of patients experiencing the event by the number of patients at risk for the event [78-80]. The outcome of interest was mortality at each overdose event (e.g., one, two, three, four, and five or more overdoses) as well as conditional 
probability for repeated overdose event. Conditional probabilities for overdose death and repeat overdose at each disease event were estimated and $95 \%$ CI were extrapolated using the normal approximation method.

Specific Aim 3: Determine the 5-year cause-specific mortality rate of those who experienced a nonfatal opioid overdose. We hypothesize that the mortality rate will be markedly higher among veterans with a prior nonfatal overdose. Further, we hypothesize that select categories of mortality, including suicide and substance-related mortality, will be significantly higher among patients with one or more previously documented overdose events.

The number of person-years at risk of dying and relative frequencies of overall and causespecific causes of death were compared between those who experienced a nonfatal opioid overdose and a control group. Those who died from a fatal index overdose were excluded from the analysis. We also excluded those with a nonfatal overdose in the last three months of the study period. We evaluated vital status for the nonfatal overdose group and comparison group from the start of the study period, January 1, 2011. Continuous variables were examined to determine overall distribution and bivariate analysis was used to examine bivariate relationships. A 5\% stratified random sample was pulled to compare mortality with the nonfatal overdose group. Pulling a stratified random sample allowed the control group to be similar in composition to those with a nonfatal overdose [81]. Given that VHA users are commonly older male with poorer health outcomes, we stratified by sex and age to reduce potential bias that may influence mortality among the control group $[56,58]$. This method, using a stratified random sample, has been used in previous VHA research using clinical data due to the large sample size of the population [82-85]. This method allowed for controls to be pulled from a heterogeneous population based on specific strata, specifically sex and age [86-88]. The control group was 
constructed to compare differences in mortality between those who experience a nonfatal opioid overdose to those with no documented overdose and allowed for outcome measures to be easily extrapolated for each stratum. We hypothesized that the mortality rate would be markedly higher among the nonfatal overdose group in comparison to the control group, given previous mortality research among a clinical population with a prior nonfatal overdose[12]/

We evaluated mortality from the start of the study period (January 1,2011) through the end of the study period (December 31, 2015). Follow-up for the study ended the day the patient died or the end of the study period, whichever occurred first. In addition to all-cause mortality, causespecific mortality was extrapolated for the following categories: external causes of death, suicide, homicide, accidents, substance-related deaths, drug-related deaths, alcohol-related deaths, infectious, viral hepatitis, human immunodeficiency virus (HIV), circulatory system, respiratory system, influenza, chronic respiratory disease, digestive system, cirrhosis and alcoholic liver disease and cancers. Specific types of cancers were categorized into the following groups using the International Classification of Diseases for Oncology [89]: lung and bronchus, liver and intrahepatic bile duct, digestive system cancers, which included esophageal, stomach, small intestine, colon, rectal, anal, gallbladder and pancreatic cancers, lymphoma and leukemia and other cancers. (See Appendix D for the full list of cause-specific mortality and corresponding ICD-10 codes).

To test study hypotheses, cox proportional hazard models were used to calculate relative risk estimates and included demographic factors (e.g. sex and age) as covariates. Using this type of analysis we assumed the following: 1) the hazard ratio remained constant over time, 2) the independence of survival was different between each veteran in the cohort and 3) there was a multiplicative relationship between the predictors [90]. This semi-parametric method has been 
used in similar research to elucidate the relationship between multiple predictors and mortality $[12,83,91]$. We assessed the proportional hazard assumption by comparing the observed with the predicted survival curves for categories of the variables in the model, curves that were relatively close indicated the hazard ratio remained constant over time [92]. Significant predictors were identified using Wald Z-tests which evaluated whether hazard ratio was equal to one or equivalently that the slope was equal to zero [92]. Given that a cox proportional hazard model is a likelihood-based method, the overall model fit was evaluated through likelihood ratio (LR) tests. Given the large sample size of the cohort, results from the LR test were close to Wald test. Interactions between two different variables were assessed to determine significance by examining Akaike information criteria (AIC) levels in comparison to the model without interaction terms. We detected violations of the hazard assumption by examining the Schoenfeld residuals [93]. Hazard ratios and corresponding 95\% CI were extrapolated for cause-specific mortality.

We identified person-years of follow-up and mortality rates per 10,000 person-years for the cohort. Crude death rates were calculated and adjusted mortality rates were calculated using Cox proportional hazard models, adjusting for age and sex.

Mortality rates among veterans with a nonfatal overdose were compared to mortality rates in the US population. Standardized mortality rate ratios (SMRs) were calculated using data from the Centers for Disease Control and Prevention Wide-Ranging Online Data for Epidemiologic Research (CDC WONDER). In order to obtain approximate estimates, age-adjusted mortality rates were pull for the cause specific deaths of interest among individuals between 15 and 84 years using data from CDC WONDER. SMRs were calculated for specific causes of death by dividing the observed number of deaths to the expected deaths $[94,95]$. 


\section{Limitations}

Although the VHA is the largest healthcare system in the United States, a major limitation of this study is that it only examines individuals who access healthcare through the VHA. Moreover, these study results may not generalize to the US population given the homogeneity of the veteran population. Moreover, veterans using VHA healthcare often experience a number of physical and mental health conditions compared to the general population which could result in a higher number of comorbidities or utilization of health care services [57]. These estimates may suffer from Berksonian bias, which appears when the sample is different than the general population leading to biased findings and is common among studies that use electronic health records [95]. However, the use of comparison groups and controlling for potential confounding will reduce potential bias that may occur. In addition, health services could be utilized outside of the VHA which could alter findings, showing a lower utilization of actual health care services. The CDW only captures overdoses documented in the VHA system which may lead to an underestimate on the true number of overdoses. Another potential limitation could occur when linking datasets (CDW and SDR) resulting in missed overdose deaths resulting in an underestimate of total deaths. However, records were required to match fully on SSN and $80-90 \%$ based of the additional characteristics including name, date of birth and sex. 


\section{References}

1. Rudd, R.A., et al., Increases in Drug and Opioid Overdose Deaths--United States, 20002014. MMWR Morb Mortal Wkly Rep, 2016. 64(50-51): p. 1378-82.

2. $\quad$ Rudd, R.A., et al., Increases in Drug and Opioid-Involved Overdose Deaths - United States, 2010-2015. MMWR Morb Mortal Wkly Rep, 2016. 65(5051): p. 1445-1452.

3. Hedegaard, H., M. Warner, and A.M. Minino, Drug Overdose Deaths in the United States, 1999-2016. NCHS Data Brief, 2017(294).

4. Centers for Disease Control and Prevention, C., CDC WONDER online database. 2018.

5. Weiss, A.J., et al., Opioid-Related Inpatient Stays and Emergency Department Visits by State, 2009-2014: Statistical Brief \#219, in Healthcare Cost and Utilization Project (HCUP) Statistical Briefs. 2017: Rockville (MD).

6. BlueShield, B., America's opioid epidemic and its effect on the nation's commerciallyinsured population. 2017.

7. Inocencio, T.J., et al., The economic burden of opioid-related poisoning in the United States. Pain Med, 2013. 14(10): p. 1534-47.

8. Ronan, M.V. and S.J. Herzig, Hospitalizations Related To Opioid Abuse/Dependence And Associated Serious Infections Increased Sharply, 2002-12. Health Aff (Millwood), 2016. 35(5): p. 832-7.

9. Boyes, A.P., Repetition of overdose: a retrospective 5-year study. J Adv Nurs, 1994. 20(3): p. 462-8.

10. Finkelstein, Y., et al., Repetition of intentional drug overdose: a population-based study. Clin Toxicol (Phila), 2016. 54(7): p. 585-9.

11. Ambrose, G., A. Amlani, and J.A. Buxton, Predictors of seeking emergency medical help during overdose events in a provincial naloxone distribution programme: a retrospective analysis. BMJ Open, 2016. 6(6): p. e011224.

12. Olfson, M., et al., Risks of fatal opioid overdose during the first year following nonfatal overdose. Drug and Alcohol Dependence, 2018. 190: p. 112-119.

13. Larochelle, M.R.M.D.M.P.H., et al., Medication for Opioid Use Disorder After Nonfatal Opioid Overdose and Association With Mortality: A Cohort Study. Annals of Internal Medicine, 2018. 169(3): p. 137-145.

14. Rossen, L.M., D. Khan, and M. Warner, Trends and geographic patterns in drugpoisoning death rates in the U.S., 1999-2009. Am J Prev Med, 2013. 45(6): p. e19-25.

15. Meit M, H.M., Tanenbaum E, Hoffman T, Appalachian Disesases of Despair. 2017, NORC at the University of Chicago: The Walsh Center for Rural Health Analysis. p. 128.

16. Paulozzi, L.J., Prescription drug overdoses: A review. Journal of Safety Research, 2012. 43(4): p. 283.

17. Hall, A.J., et al., Patterns of abuse among unintentional pharmaceutical overdose fatalities. JAMA, 2008. 300(22): p. 2613-20.

18. Bohnert, A.S.B., et al., Trends and Regional Variation in Opioid Overdose Mortality Among Veterans Health Administration Patients, Fiscal Year 2001 to 2009. The Clinical Journal of Pain, 2014. 30(7): p. 605-612.

19. Bonar, E.E., et al., Associations among pain, non-medical prescription opioid use, and drug overdose history. Am J Addict, 2014. 23(1): p. 41-7. 
20. Zedler, B., et al., Risk factors for serious prescription opioid-related toxicity or overdose among Veterans Health Administration patients. Pain Med, 2014. 15(11): p. 1911-29.

21. Bohnert, A.S., K. Roeder, and M.A. Ilgen, Unintentional overdose and suicide among substance users: a review of overlap and risk factors. Drug Alcohol Depend, 2010. 110(3): p. 183-92.

22. Dunn, K.M., et al., Opioid prescriptions for chronic pain and overdose: a cohort study. Ann Intern Med, 2010. 152(2): p. 85-92.

23. Nadpara, P.A., et al., Risk Factors for Serious Prescription Opioid-Induced Respiratory Depression or Overdose: Comparison of Commercially Insured and Veterans Health Affairs Populations. Pain Med, 2017.

24. Bohnert, A.S., et al., Risk of death from accidental overdose associated with psychiatric and substance use disorders. Am J Psychiatry, 2012. 169(1): p. 64-70.

25. Seal, K.H., et al., Association of mental health disorders with prescription opioids and high-risk opioid use in US veterans of Iraq and Afghanistan. JAMA, 2012. 307(9): p. 940-7.

26. Tobin, K.E.M. and C.A.D. Latkin, The relationship between depressive symptoms and nonfatal overdose among a sample of drug users in Baltimore, Maryland. Journal of Urban Health : Bulletin of the New York Academy of Medicine, 2003. 80(2): p. 220-229.

27. Hulse, G.K., S.I. Robertson, and R.J. Tait, Adolescent emergency department presentations with alcohol- or other drug-related problems in Perth, Western Australia. Addiction (Abingdon, England), 2001. 96(7): p. 1059-67.

28. Caudarella, A., et al., Non-fatal overdose as a risk factor for subsequent fatal overdose among people who inject drugs. Drug and alcohol dependence, 2016. 162: p. 51-5.

29. Paulozzi, M.P.H.L.J., et al., A History of Being Prescribed Controlled Substances and Risk of Drug Overdose Death. Pain Medicine, 2012. 13(1).

30. Havens, J.R., et al., Individual and network factors associated with non-fatal overdose among rural Appalachian drug users. Drug and Alcohol Dependence, 2011. 115(1-2): p. 107-112.

31. Darke, S., J. Ross, and W. Hall, Overdose among heroin users in Sydney, Australia: I. Prevalence and correlates of non-fatal overdose. Addiction, 1996. 91(3): p. 405-11.

32. Coben, J.H., et al., Hospitalizations for poisoning by prescription opioids, sedatives, and tranquilizers. Am J Prev Med, 2010. 38(5): p. 517-24.

33. Bohnert, A.S., et al., Association between opioid prescribing patterns and opioid overdose-related deaths. JAMA, 2011. 305(13): p. 1315-21.

34. Painter, J.M., et al., High inpatient utilization among Veterans Health Administration patients with substance-use disorders and co-occurring mental health conditions. Am J Drug Alcohol Abuse, 2017: p. 1-9.

35. Turner, B.J. and Y. Liang, Drug Overdose in a Retrospective Cohort with Non-Cancer Pain Treated with Opioids, Antidepressants, and/or Sedative-Hypnotics: Interactions with Mental Health Disorders. Journal of general internal medicine, 2015. 30(8): p. 108196.

36. Bohnert, A.S., et al., Accidental poisoning mortality among patients in the Department of Veterans Affairs Health System. Med Care, 2011. 49(4): p. 393-6.

37. Bohnert, A.S., et al., Trends and regional variation in opioid overdose mortality among Veterans Health Administration patients, fiscal year 2001 to 2009. Clin J Pain, 2014. 30(7): p. 605-12. 
38. Lin, L.A., et al., Outpatient Provider Contact Prior to Unintentional Opioid Overdose Among VHA Service Users. Psychiatr Serv, 2015. 66(11): p. 1149-54.

39. Lin, L.A., et al., Opioid Overdose: Risk Assessment and Mitigation in Outpatient Treatment. J Addict Med, 2016. 10(6): p. 382-386.

40. Lanier, W.A., et al., Risk Factors for Prescription Opioid-Related Death, Utah, 20082009. Pain Medicine, 2012. 13(12): p. 1580-1589.

41. Wilder, C.M., et al., Risk factors for opioid overdose and awareness of overdose risk among veterans prescribed chronic opioids for addiction or pain. J Addict Dis, 2016. 35(1): p. 42-51.

42. Marmot, M. and R.G. Wilkinson, Social determinants of health. Second edition. ed. Books@Ovid.2006, Oxford: Oxford University Press.

43. Berkman, L.F., I. Kawachi, and M.M. Glymour, Social epidemiology. Second edition. ed. 2014, Oxford: Oxford University Press.

44. Gottlieb, L., et al., Integrating Social And Medical Data To Improve Population Health: Opportunities And Barriers. Health Affairs, 2016. 35(11): p. 2116-2123.

45. Duan-Porter, W., et al., Evidence Review-Social Determinants of Health for Veterans. Journal of general internal medicine, 2018. 33(10): p. 1785-1795.

46. Dube, S.R., et al., Childhood abuse, neglect, and household dysfunction and the risk of illicit drug use: the adverse childhood experiences study. Pediatrics, 2003. 111(3): p. 564-72.

47. Douglas, K.R., et al., Adverse childhood events as risk factors for substance dependence: Partial mediation by mood and anxiety disorders. Addictive Behaviors, 2010. 35(1): p. 713.

48. Torres, J.M., et al., ICD Social Codes: An Underutilized Resource for Tracking Social Needs. Med Care, 2017. 55(9): p. 810-816.

49. Clark, M.A. and D. Gurewich, Integrating Measures of Social Determinants of Health Into Health Care Encounters: Opportunities and Challenges. Med Care, 2017. 55(9): p. 807-809.

50. Bauer, L.K., et al., Characteristics of Homeless Adults Who Died of Drug Overdose: A Retrospective Record Review. Journal of health care for the poor and underserved, 2016. 27(2): p. 846-59.

51. Gossop, M., et al., A prospective study of mortality among drug misusers during a 4-year period after seeking treatment. Addiction, 2002. 97(1): p. 39-47.

52. Marzuk, P.M., et al., Poverty and fatal accidental drug overdoses of cocaine and opiates in New York City: an ecological study. Am J Drug Alcohol Abuse, 1997. 23(2): p. 221-8.

53. Harnish, A., et al., Substance Use and Mental Health Stigma in Veterans With CoOccurring Disorders. J Dual Diagn, 2016. 12(3-4): p. 238-243.

54. Vazan, P., A. Golub, and A.S. Bennett, Substance use and other mental health disorders among veterans returning to the inner city: prevalence, correlates, and rates of unmet treatment need. Subst Use Misuse, 2013. 48(10): p. 880-93.

55. Kerfoot, K.E., I.L. Petrakis, and R.A. Rosenheck, Dual Diagnosis in an Aging Population: Prevalence of Psychiatric Disorders, Comorbid Substance Abuse, and Mental Health Service Utilization in the Department of Veterans Affairs. J Dual Diagn, 2011. 7(1-2): p. 4-13.

56. VA, D.o.V.A., VA utilization profile, FY 2016. 2017. 
57. Selim, A.J., et al., The health status of elderly veteran enrollees in the Veterans Health Administration. Journal of the American Geriatrics Society, 2004. 52(8): p. 1271-1276.

58. Dursa, E.K., et al., Demographic, military, and health characteristics of VA health care users and nonusers who served in or during operation enduring freedom or operation iraqi freedom, 2009-2011. Public Health Reports, 2016. 131(6): p. 839-843.

59. Rosenheck, R., Mental health and substance abuse services for veterans: Experience with mental health performance evaluation in the Department of Veterans Affairs. 2004. Institute of Medicine Committee on Crossing the Quality Chasm: Adaption to mental health and addictive disorders: p. 423-482.

60. Skidmore, W.C. and M. Roy, Practical Considerations for Addressing Substance Use Disorders in Veterans and Service Members. Social Work in Health Care, 2011. 50(1): p. 85-107.

61. Fuehrlein, B.S., et al., The burden of alcohol use disorders in US military veterans: results from the National Health and Resilience in Veterans Study. Addiction, 2016. 111(10): p. 1786-1794.

62. Rhee, T., \& Rosenheck, R., Comparison of opioid use disorder among male veterans and non-veterans: Disorder rates, socio-demographics, co-morbidities, and quality of life. The American journal on addictions, 2019.

63. Oliva, E.M., et al., Development and applications of the Veterans Health Administration's Stratification Tool for Opioid Risk Mitigation (STORM) to improve opioid safety and prevent overdose and suicide. Psychol Serv, 2017. 14(1): p. 34-49.

64. Chinman, M., et al., Protocol for evaluating the nationwide implementation of the VA Stratification Tool for Opioid Risk Management (STORM). Implement Sci, 2019. 14(1): p. 5.

65. Gordon, A.J., et al., Facilitators and barriers in implementing buprenorphine in the Veterans Health Administration. Psychol Addict Behav, 2011. 25(2): p. 215-24.

66. Minegishi, T. and A. Frakt, Reducing Long-term Opioid Use in the Veterans Health Administration. J Gen Intern Med, 2018. 33(6): p. 781-782.

67. Oliva, E.M., et al., Trends in opioid agonist therapy in the Veterans Health Administration: is supply keeping up with demand? The American journal of drug and alcohol abuse, 2013. 39(2): p. 103-7.

68. Beghi, M., et al. Risk factors for fatal and nonfatal repetition of suicide attempts: a literature review. neuropsychiatric disease and treatment, 2013. 2013, 1725-1736.

69. Vallersnes, O.M., et al., Mortality and repeated poisoning after self-discharge during treatment for acute poisoning by substances of abuse: a prospective observational cohort study. BMC Emerg Med, 2019. 19(1): p. 5.

70. Vallersnes, O.M., et al. Factors associated with rapidly repeated acute poisoning by substances of abuse: a prospective observational cohort study. BMC Research Notes, 2018. 11, 1-4 DOI: 10.1186/s13104-018-3834-3.

71. Bohnert, A.S., et al., Misclassification of suicide deaths: examining the psychiatric history of overdose decedents. Inj Prev, 2013. 19(5): p. 326-30.

72. Hosmer Jr, D.W., S. Lemeshow, and R.X. Sturdivant, Applied logistic regression. Vol. 398. 2013: John Wiley \& Sons.

73. Tabachnick, B.G., L.S. Fidell, and J.B. Ullman, Using multivariate statistics. Vol. 5. 2007: Pearson Boston, MA. 
74. Bursac, Z., et al., Purposeful selection of variables in logistic regression. Source code for biology and medicine, 2008. 3(1): p. 17.

75. Hosmer, D. and S. Lemeshow, Applied Logistic Regression Second Editon John Willey \& Sons. New York, New York, 2000.

76. Agresti, A., An introduction to categorical data analysis. 2018: Wiley.

77. Agresti, A. and M. Kateri, Categorical data analysis. 2011: Springer.

78. Pepe, M.S. and M. Mori, Kaplan-Meier, marginal or conditional probability curves in summarizing competing risks failure time data? Stat Med, 1993. 12(8): p. 737-51.

79. Cabarrou, B., et al., Focus on an infrequently used quantity in the context of competing risks: The conditional probability function. Comput Biol Med, 2018. 101: p. 70-81.

80. Rajeswaran, J. and E.H. Blackstone, Competing risks: Competing questions. J Thorac Cardiovasc Surg, 2017. 153(6): p. 1432-1433.

81. Gebregziabher, M., et al., Fitting parametric random effects models in very large data sets with application to VHA national data. BMC Medical Research Methodology, 2012. 12(1): p. 1-14.

82. Park, T.W., et al., Benzodiazepine prescribing patterns and deaths from drug overdose among US veterans receiving opioid analgesics: case-cohort study. BMJ, 2015. 350: p. h2698.

83. Barth, S.K., H.K. Kang, and T. Bullman, All-Cause Mortality Among US Veterans of the Persian Gulf War: 13-Year Follow-up. Public health reports (Washington, D.C. : 1974), 2016. 131(6): p. 822-830.

84. Han, K.K., B. Tim, and K.B. Shannon, All-Cause Mortality Among US Veterans of the Persian Gulf War : 13-Year Follow-up. Public Health Reports, 2016. 131(6): p. 822-830.

85. Gradus, J.L., et al., Predictors of suicidal ideation in a gender-stratified sample of OEF/OIF veterans. Suicide \& life-threatening behavior, 2013. 43(5): p. 574-88.

86. Cochran, W.G., Sampling techniques. $3 \mathrm{~d}$ ed. ed. Wiley series in probability and mathematical statistics. 1977, New York: Wiley.

87. Cochran, W.G., Relative Accuracy of Systematic and Stratified Random Samples for a Certain Class of Populations. The Annals of Mathematical Statistics, 1946. 17(2): p. 164177.

88. Gabler, S. and H. Stenger, Design effect of randomized systematic sampling. Statistics, 2012. 46(1): p. 131-148.

89. Fritz, A.G., International classification of diseases for oncology. 3rd ed. ed. 2000, Geneva, Switzerland: U.S. Dept. of Health and Human Services ;World Health Organization.

90. Allison, P.D. and S.A.S. Institute, Survival analysis using $S A S$ : a practical guide. 2010, SAS Institute: Cary, NC.

91. Kang, H.K. and T.A. Bullman, Mortality among U.S. veterans of the Persian Gulf War. The New England journal of medicine, 1996. 335(20): p. 1498-504.

92. Kleinbaum, D.G. and M. Klein, Survival analysis : a self-learning text. 2012, Springer: New York, NY.

93. Hess, K.R., Graphical methods for assessing violations of the proportional hazards assumption in Cox regression. Stat Med, 1995. 14(15): p. 1707-23.

94. Le, C.T. and L.E. Eberly, Introductory biostatistics. 2016: John Wiley \& Sons.

95. Szklo, M. and F.J. Nieto, Epidemiology: beyond the basics. 2014: Jones \& Bartlett Publishers. 
Tables and Figures 
Table 1. Risk factors for opioid overdose

\begin{tabular}{|l} 
Population characteristics \\
\hline Demographics \\
$\bullet$ Male \\
$\bullet$ Ages 18-45 \\
- Non-Hispanic white \\
$\bullet$ Appalachian region \\
Physical health conditions
\end{tabular}

- Chronic pain

- Liver disease

- Renal disease

- Chronic pulmonary disease

- Cardiovascular disease

- Traumatic injury

- Cancer

- Soft skin and tissue infections

Mental health conditions

- Mental distress

- Depression

- Anxiety

- Previous suicide attempt

- PTSD

- Bipolar disorder

Substance Use

- Substance Use Disorder (SUD)

- History of opioid dependence or abuse 
- Drug use(opioids, specifically heroin)

- High MME/day (e.g. more than 90 MME/day)

- Severity of substance use

- Co-prescribed opioids with benzodiazepines, antidepressants or antipsychotics 
Figure 1. Process Flow of CDW

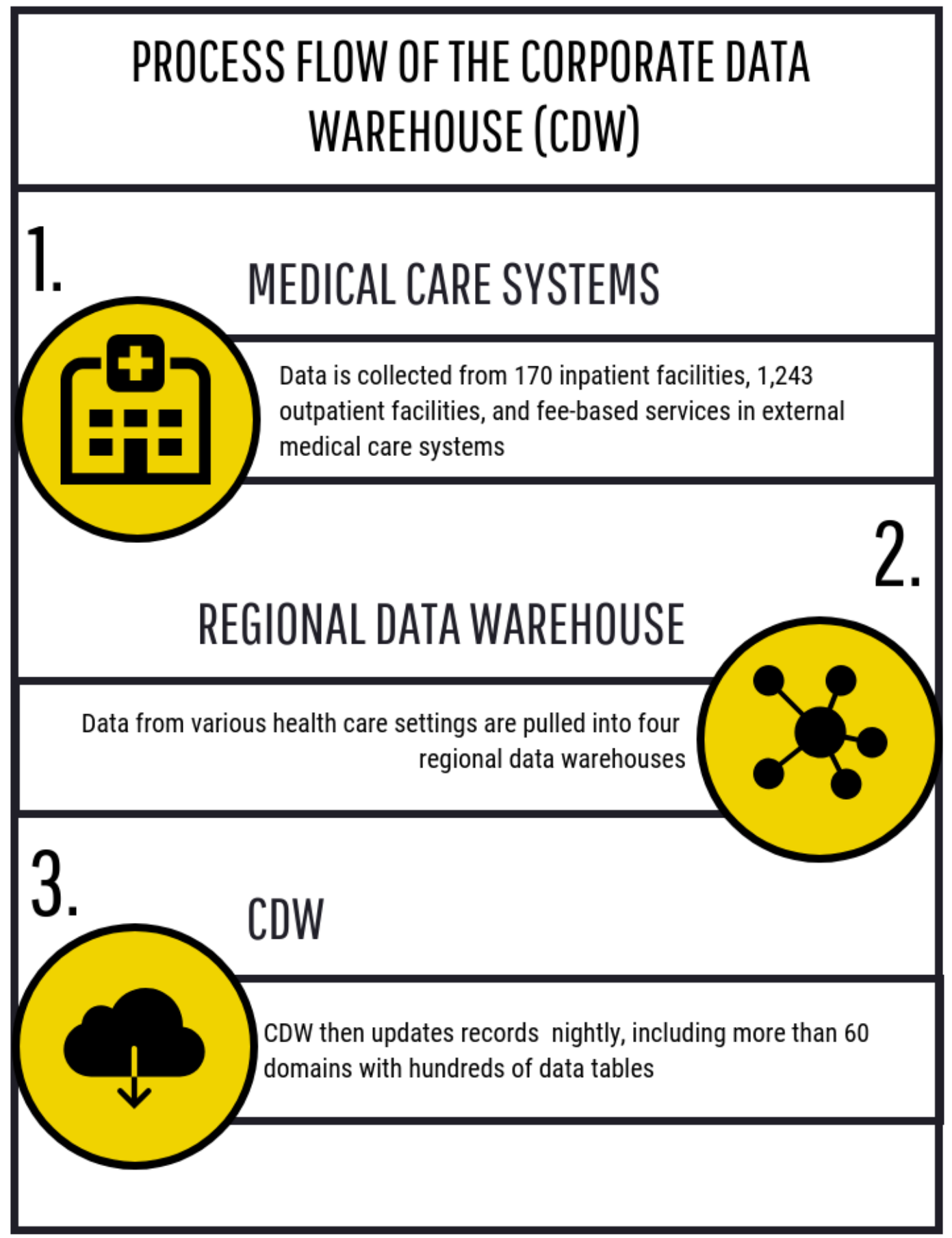

Abbreviations: CDW, Corporate Data Warehouse; VHA, Veterans Health Administration 
Figure 2. Sample Design for the Opioid Overdose Cohort

\section{DEVELOPING THE OPIOID OVERDOSE COHORT}

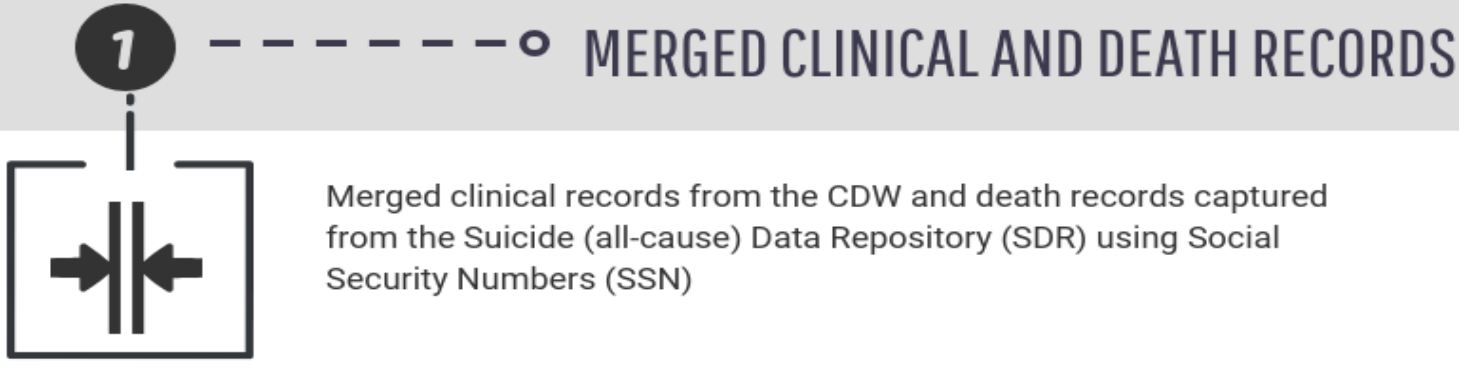

\section{EXTRACTED OPIOID OVERDOSES ○- - - - -}

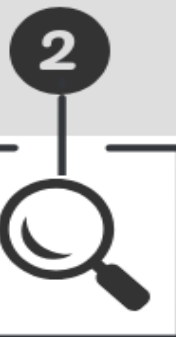

Pulled every recorded overdoses (nonfatal and fatal) among people who use medical services by the Veterans Health Administration (VHA)

\section{CLEANED DATA USING INCLUSION AND EXCLUSION CRITERIA}

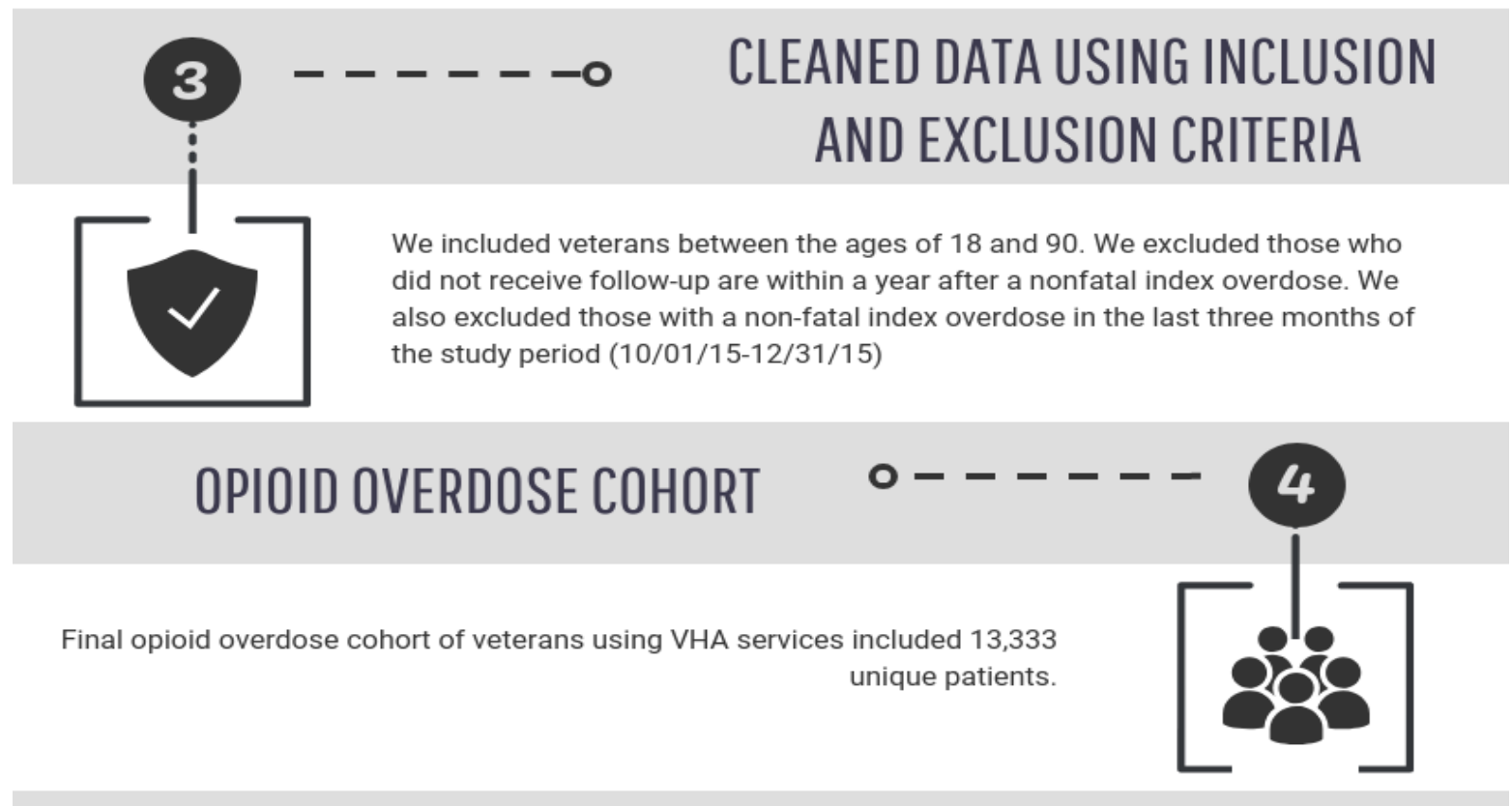

Abbreviations: CDW, Corporate Data Warehouse; SDR, Suicide Data Repository 
Chapter 2 


\subsection{Abstract}

\section{Objective}

To compare demographic and diagnostic criteria associated with different categories of opioid overdoses including: fatal index (i.e. first recorded), single nonfatal, and repeat overdose (nonfatal).

\section{Methods}

Electronic health records (EHR) from the Veterans Health Administration (VHA) and death records from the Department of Veterans Affairs (VA)/Department of Defense (DoD) Joint Suicide (all-cause) Data Repository (SDR) were used to identify veterans with at least one documented opioid overdose between 2011 and 2015. Bivariate analyses were used to describe opioid overdose category and associated variables including sociodemographic characteristics, diagnostic factors such as chronic pain, mental health diagnosis, prior substance use, and codes associated with social determinants of health. Multinomial logistic regression was used to assess factors associated with fatal index overdose versus repeat overdose and one nonfatal overdose.

\section{Results}

A total of 12,848 VHA patients had at least one opioid overdose documented in VHA's EHR between 2011 and 2015. Among them, 34.7\% (n=4,464) died on their first documented overdose, $20.7 \%(n=2,659)$ had at least one additional (i.e. repeat) documented overdose, and $44.6 \%$ $(n=5,725)$ had only one nonfatal overdose in their medical records. Patients who were younger in age (18-44 OR [odds ratio] 7.19, 45-64 OR 4.78) had significantly higher odds of a fatal index overdose and experiencing a repeat overdose (18-44 OR 2.13, 45-64 OR 1.78). Having one or more chronic pain diagnoses was associated with experiencing a fatal index overdose (OR 3.96) 
or repeat overdose (OR 1.15). A mental health or substance abuse or dependence diagnosis was significantly associated with experiencing a repeat overdose, (OR 1.54 and 1.25 respectively). Receipt of medication-assisted therapy (MAT) more than one year prior (OR 1.28) to the first (i.e. index) overdose was significantly associated with increased odds of a fatal overdose whereas receiving counseling services prior to index overdose was protective of experiencing a fatal index overdose.

\section{Conclusion}

To reduce overdose mortality and repeat morbidity, prevention efforts should target younger to middle aged veterans, especially those with a chronic pain diagnosis. Healthcare efforts should focus on treating mental health diagnoses, which are significantly associated with multiple overdoses. Healthcare efforts should consider integrating relapse prevention in primary care settings, to mitigate potential risk among patients with a history of an overdose. 


\subsection{Introduction}

Overdoses are now the leading cause of accidental death in the United States and are a growing concern for public health and clinical medicine. Fatal opioid overdoses have been on the rise since 1999 and have more than quadrupled in the United States during this time period [1-6]. In a similar fashion, nonfatal overdoses have also been increasing. Fatal and nonfatal overdoses are highest among people who inject drugs (PWID) [7-9], have an opioid use disorder (OUD) [10, 11], or consume a high-dose of opioids [12-17].

Prior research has found that risk factors for nonfatal overdose $[13,18-28]$ are similar in nature to those for fatal overdose $[15,17,29-32]$. The most significant risk factors for overdose include those related to mental health such as a diagnosis of anxiety, depression, or a history of suicide ideation or attempt $[7,22,23,28,33-35]$. Diagnostic risk factors such as chronic pain, respiratory disease, renal disease, and cardiovascular disease have also been associated with overdose risk but were not as strong as those associated with mental health diagnoses $[22,23,33$, 34]. Research conducted among PWID suggest that homelessness and early life adversity are also associated with increased risk for substance abuse and overdose [30, 36, 37]. While studies have identified social determinants of health as significant risk factors of overdose, no studies have used EHRs to assess differences across categories of overdoses.

Existing evidence suggests that the number of prior overdoses is directly related to subsequent risk of death from overdose[38]. Furthermore, research suggests there has been a rise in patients hospitalized for repeat overdose events. However, little is known about risk factors for repeat overdose or if they may differ from those identified with increased risk of overdose mortality [39]. The few studies that have examined repeat overdoses have examined intentional overdoses rather than those that were thought to be unintentional or of undetermined intent [40-43]. 
The purpose of this study was to identify diagnostic factors, including codes related to social determinants of health, associated with different opioid overdose categories including fatal index overdose, a single nonfatal overdose, and repeat overdose (nonfatal) using data from the one of the largest integrated health care systems in the U.S.

\subsection{Methods}

\section{Study population}

We pulled a cohort of veterans who received services from the Veteran Health Administration (VHA) in calendar years 2011-2015. Opioid overdoses were extracted using clinical records from the VHA Corporate Data Warehouse (CDW) linked with death records from the VA/DoD Suicide Data Repository using Social Security Numbers (SSNs) [44-47]. To allow for time to risk, patients were excluded if their first overdose occurred in the last three months of the study

(October 1, 2015 through December 31, 2015). Patients were also excluded from the study or if they did not have follow-up records within the year following a nonfatal overdose. This study was restricted to veterans over 18 and under 90 years of age. This cohort identified 13,333 veterans with at least one documented opioid overdose between 2011 through 2015. After excluding those who died from overdoses classified as suicide $(n=422)$ or homicide $(n=6)$, or those that died on a repeat overdose $(n=57)$, the final study cohort was 12,848 .

\section{Opioid overdose}

Opioid overdose was defined using International Classification of Disease, Ninth Edition (ICD9) codes: 965.00-965.02, 965.09, E850.0-E850.2 and ICD Tenth Edition (ICD-10) codes: X40X44, Y10-Y14 and secondary axis codes T40.0- T40.4, and T40.6. Repeat overdose was defined 
as either a) a second documented overdose that occurred two days after the previous overdose, with the overdose documented as the principal diagnosis or b) a second documented overdose that occurred three days or more after the previous overdose. An overdose that occurred one day after a prior overdose was treated as the same event. The outcome of interest was category of opioid overdose: including categories for fatal index overdose, repeated nonfatal overdoses, and only one nonfatal overdose, which were constructed as three mutually exclusive groups.

\section{Predictors}

We extracted information on six domains of predictors for veterans receiving medical care from the VHA $[46,48]$. These domains included demographic, chronic pain, mental health, substance abuse/dependence, MAT, and social codes, which serve as indicators of social determinants of health. Demographic information included age and sex of the patient. Information on race and ethnicity were not included due to limited availability and documented lack of reliability [49, 50]. Age was fixed and determined based on age on the first day of the study period (January 1, 2011). Sex was determined based on last entered value for sex in either the clinical or death records.

\section{Chronic pain}

Chronic pain diagnoses were categorized into seven diagnostic groups: arthritis, back pain, migraines, headaches or tension headaches, psychogenic pain, neuropathy, and fibromyalgia. If a patient had a diagnosis of at least one chronic pain diagnosis, a dummy variable was created to identify the association between any chronic pain diagnosis prior to index overdose and type of subsequent overdose (i.e. any chronic pain diagnosis prior to index overdose). Classifications for chronic pain were guided by previous research [51]. 


\section{Mental health}

A broad definition of mental health diagnosis was identified using ICD-9 codes 290.00 to 319.99 or ICD-10 codes F00 to F99, excluding tobacco codes starting with 305 or F17 [52, 53]. Eight specific types of mental health disorders were categorized and included anxiety, depression, bipolar, PTSD, adjustment disorder, schizophrenia or other psychotic disorders, traumatic stress, and personality disorder. Two combination variables were then created to identify potential interactions between types of mental health diagnoses and included: 1) having either depression, anxiety, or PTSD, and 2) having all three mental health diagnoses (i.e. depression, anxiety, and PTSD). Similar to chronic pain diagnoses, a dummy variable indicating any mental health disorder was used to assess the relationship between mental health diagnoses and type of documented overdose.

\section{Substance abuse or dependence}

Substance abuse or dependence was measured using seven types of substance abuse or dependency groups including alcohol, opioid, cannabis, sedative, hypnotic, or anxiolytic, cocaine, other stimulant, and hallucinogens. Similar to chronic pain and mental health diagnoses, patients with any type of substance abuse or dependence documented in the clinical record were then categorized as having any type of substance abuse or dependence. Patients with more than one type of substance abuse or dependence were also identified as having polysubstance abuse or dependence to assess the potential relationship between substance abuse/dependence for multiple substances and type of overdose. Due to limited numbers, three types of substance abuse/dependency disorders were not included in tables but were included in the composite variable identifying any substance abuse/dependence or polysubstance abuse/dependence. Type 
of substances explored but not specifically retained in tables include the three categories:

cannabis, hallucinogens, and sedative, hypnotic, or anxiolytic substances.

MAT

Receiving MAT services was identified by a documented primary or secondary stop code 523, which identifies buprenorphine or methadone treatment in the clinical record [54-56]. Patients who received MAT prior to their index overdose were then further identified as having MAT more than one year prior to overdose. Exploratory analyses identified more than one year as a critical time point for last MAT rather than one, three or six months prior to index overdose.

\section{Social determinants of health}

Codes that are indicators of social determinants of health were collapsed into the following 13 categories guided by previous literature (Torres et al., 2017; Gottlieb et al., 2016): 1) problems related to employment or unemployment, 2) problems related to education and literacy, 3) problems related to housing or economic circumstances, 4) problems related to mental or behavioral health, 5) problems related to upbringing, 6) problems related to social environment, 7) problems related to primary support group, 8) problems related to psychosocial circumstances, 9) problems related to environmental psychosocial circumstances, 10) problems related to abuse, 11) problems related to lifestyle or lifestyle management, 12) receipt of counseling services, and 13) receipt of counseling services for substance abuse.

The specific diagnostic codes (ICD-9 and ICD-10) used for the predictor variables can be found in a Supplemental Table 1.

This study was reviewed and approved by the Institutional Review Board at the Syracuse VA Medical Center, New York. 
Analysis

Data for this study was analyzed using SAS Enterprise Grid software (version 5.1, SAS Institute Inc.). Descriptive analysis for all potential predictors were completed using cross tabulations for all outcomes and alpha was set to 0.05 for tests unless otherwise specified.

Bivariate analyses were conducted using chi-square test of difference, for all predictor variables with each overdose outcome: fatal index overdose and repeated nonfatal overdoses (Table 1). The reference group for all analyses was a single nonfatal opioid overdose.

Using multinomial logistic regression, the odds ratios for repeat overdose and fatal index overdose were calculated for sociodemographic and diagnostic factors such as chronic pain, mental health diagnosis, prior substance use, and codes associated with social determinants of health. Multinomial regression was used to provide a more direct interpretation for the relationship between the predictors and category of overdose [57, 58]. As an extension of logistic regression, this method was selected because it is more robust to violating assumptions of normality and ability to compare across multiple outcome groups $(57,58)$. Model fit for this multinomial logistic regression model was assessed by using a series of logistic regression models, controlling for age and gender [59,60]. Assumptions for this method were testing by assessing multicollinearity among predictors with a variance inflation factor (VIF) with a critical value greater than ten. If evidence of collinearity was identified among predictors, Wald chisquare tests were conducted to determine which variable was best suited for inclusion in the final model. Goodness of fit indices such as the Type 3 Analysis of Effects and Wald chi-square test were examined for all predictors [61]. Interactions between significant predictor variables were tested. 
Adjusted odds ratios (OR) with 95\% Confidence Intervals (CIs) were calculated for each of the significant predictors in the final model (Table 2). Adjusted odds ratios indicate the odds of experiencing a fatal overdose compared to those with one nonfatal overdose as well as the odds of experiencing a repeated nonfatal overdose compared to those with one nonfatal overdose, adjusted for all other predictors in the model.

\subsection{Results}

Our cohort consisted of 12,848 veterans with at least one documented overdose between calendar years 2011 to 2015 . This retrospective cohort consisted primarily of men $(91.5 \%, \mathrm{n}=11,070)$ between the ages of 45-64 $(61.3 \%, \mathrm{n}=7,874)$. More than half had at least one chronic pain diagnosis $(69.6 \%, \mathrm{n}=8,941)$ the most common types of chronic pain among our cohort was arthritis $(55.5 \%, \mathrm{n}=7,129)$ and back pain $(50.8 \%, \mathrm{n}=6,521)$. Among our study cohort more than $90 \%$ had a mental health diagnosis during the study period $(91.6 \%, \mathrm{n}=11,768)$. The most common mental health diagnoses were depression $(75.5 \%, \mathrm{n}=9,703)$ followed by anxiety $(60.8 \%, n=7,807)$, and PTSD $(47.8 \%, n=6,146)$. In fact, $84.9 \%(n=10,906)$ of our cohort had at least one of those mental health diagnoses and $32.8 \%(n=4,208)$ had record of all three. A majority of the cohort $(64.6 \%, \mathrm{n}=8,303)$ had at least one diagnosis associated with substance abuse or dependence and $40.5 \%(n=5,203)$ had more than one substance abuse or dependence diagnosis. Among our entire cohort, $11.1 \%(n=1,424)$ received MAT during the study period and among those $76.1 \%(n=1,084)$ had MAT before their index overdose. Of those who received MAT prior to their index overdose, $64.9 \%(\mathrm{n}=704)$ last received MAT more than one year before the first overdose recorded in their VHA medical record.

Diagnostic codes that are known as indicators of social determinants of health, or social codes, were present in the EHR for $92.4 \%$ of our cohort $(n=11,867)$. The most common social code 
documented for this cohort was receipt of counseling services, with $88.3 \%(\mathrm{n}=11,338)$ having at least one counseling code on record prior to their index overdose. The other social codes which were frequent among this cohort were those indicating problems with housing or economic circumstances $(39.6 \%, \mathrm{n}=5,082)$ and problems associated with psychosocial circumstances $(44.7 \%, \mathrm{n}=5,739) .($ Table 1$)$

Bivariate analyses showed notable differences in group compositions between those who died on their first overdose, those with repeat nonfatal overdoses, and those with only one nonfatal overdose (Table 2). There were significant differences in the age distribution for those with repeat overdose and fatal overdose $(\mathrm{p}<0.01)$. While males more often experienced a fatal index overdose there were no significant differences in sex distribution for those with repeated nonfatal overdose when compared to those with only one nonfatal overdose. Bivariate analysis also suggests that those with repeated overdose events were significantly more likely to have had a mental health or substance abuse diagnosis when compared to those with only one nonfatal overdose $(\mathrm{p}<0.01)$. Similarly, those who died on their index overdose less frequently had any documented social code $(\mathrm{p}<0.01)$. Those who died on their first overdose were more likely to have a diagnosis for chronic pain in comparison to those with one nonfatal overdose $(\mathrm{p}<0.01)$.

A multivariable analysis assessing factors associated with category of overdose is provided in Table 3. Males were more than $50 \%$ more likely to experience a fatal overdose when compared to those with a single nonfatal overdose (OR [Odds ratio] 1.57, 95\% CIs [confidence interval]: 1.34-1.83). Patients between the ages of 18-44 years were more likely to experience a fatal index overdose (OR 7.19, 95\% CI: 5.88-8.78) or repeat overdose (OR 2.13, 95\% CI 1.76-2.58) when compared to those who only had record of one single nonfatal overdose. Similarly, patients with a chronic pain diagnosis prior to their first recorded overdose were significantly more likely to 
experience a fatal overdose (OR 3.96, 95\% CI: 3.56-4.42) or repeat overdose (OR 1.15, 95\% CI 1.04-1.27). However, patients with a prior history of polysubstance abuse or dependence were more likely to experience a repeat overdose (OR 1.25, 95\% CI: 1.13-1.38) and less likely to experience a fatal index overdose (OR 0.75, 95\% CI: 0.68-0.82) compared to those with one nonfatal overdose. Patients who were last received MAT was more than one year prior to their index overdose were $28 \%$ more likely to experience a fatal index overdose (OR $1.28,95 \%$ CI: 1.05-1.55). Lastly, the odds of fatal index overdose were significantly lower among those receiving counseling services prior to their first known overdose (OR 0.35, 95\% CI: 0.30-0.40).

\subsection{Discussion}

Overall, these findings suggest that men were more likely to experience a fatal index overdose and younger and middle-aged patients (aged 18-64 years) were more likely to experience either a fatal index overdose or repeat overdose; results that are similar to previously identified associations $[4,5,15]$. These findings suggest the need for targeted overdose prevention programs targeting younger to middle aged men.

Similarly, those who experienced either a fatal index or repeat overdose were also more likely to have a chronic pain diagnosis prior to their index event, underscoring the need for integrated health care, which is consistent with other research findings $[22,23]$ and supports the need for continued efforts to identify and support alternative approaches to management of chronic pain [62-64]. While the CDC has developed Chronic Pain Guidelines, these findings suggest the need to amplify risk management of chronic pain patients by additional education or co-prescription of naloxone [65]. 
Interestingly, patients with a mental health diagnosis or polysubstance abuse/dependence were more likely to experience a repeat overdose and less likely to experience a fatal index overdose when compared to those with a single nonfatal overdose. Although there is evidence that mental health diagnoses are more prevalent among those who experience an overdose, this is the first study to identify a difference in magnitude in the associations between mental health diagnosis and category of opioid overdoses $[33,66]$. This is an interesting and important finding considering previous reports that suggests repeat overdose trends are increasing [39]. Healthcare systems should be ready for the potential for a higher number of patients and consider integrating mental health services with emergency care and substance abuse treatment.

In addition to one or more mental health diagnoses, receiving counseling services prior to the index overdose was protective against experiencing a fatal index overdose. Conversely, those who received their last MAT services a year or more ago were more likely to experience a fatal index event during our study period. These findings highlight the need for healthcare systems to treat OUD using a disease model approach and suggest the need for relapse prevention in primary care settings [67]. Substance use disorder (SUD) is a chronic disease with relapse rates comparable to other common health conditions, such as hypertension [68-72]. Future clinical efforts should be supported to identify and address SUD in primary care settings similar to other chronic diseases.

\section{Strengths and limitations}

To the best of our knowledge, this is the first study to compare risk factors by category of opioid overdose history. This study used data from one of the largest integrated healthcare systems in the United States. However, this study is not without limitations. The information collected on category of overdose which relies on clinical recording and may not be present if an individual 
does not seek medical care for an overdose or a clinician does not document the event.

Therefore, the true number of overdoses may be underestimated. This analysis was conducted among the veteran population and results from this study may not be generalizable to the general population. The associations with measures of social determinants of health explored in this study may be biased given that there is evidence that they are more likely to be entered by mental health professionals, particularly psychiatrists, when compared to other medical specialties [73, 74]. The decision to omit patients who die on a repeat overdose could systematically exclude characteristics associated with death after multiple overdoses. However, the small number of cases prevent inclusion as a second category and characteristics among these patients may be different when compared to those who died on their index overdose. Future research should consider characteristics associated with mortality among those with multiple overdose events.

It is important to note that various public health interventions have been implemented to reduce overdose among people at highest risk [16, 75-78]. These efforts have largely been focused on reducing the excess supply of opioids through education programs, surveillance systems designed to reduce the availability of prescription opioids (e.g. prescription drug monitoring programs), and prevention of overdose-related mortality through broad availability of naloxone. In general, nonfatal and fatal overdoses appear to be impacting younger and middle aged veterans, suggesting that primary prevention efforts in the future may want to tailor the programs to this audience. Chronic pain, psychiatric diagnoses, and contextual factors appear differentially associated with fatal index overdose in comparison to those with repeated nonfatal overdoses. These findings underscore the need for integrated healthcare to address mental health and chronic pain among patients at risk for an opioid overdose.

\section{References:}


1. Jones, C.M., E.B. Einstein, and W.M. Compton, Changes in Synthetic Opioid Involvement in Drug Overdose Deaths in the United States, 2010-2016. JAMA, 2018. 319(17): p. 1819-1821.

2. Centers for Disease Control and Prevention, C., CDC WONDER online database. 2018.

3. Rudd, R.A., et al., Increases in Drug and Opioid Overdose Deaths--United States, 20002014. MMWR Morb Mortal Wkly Rep, 2016. 64(50-51): p. 1378-82.

4. $\quad$ Rudd, R.A., et al., Increases in Drug and Opioid-Involved Overdose Deaths - United States, 2010-2015. MMWR Morb Mortal Wkly Rep, 2016. 65(5051): p. 1445-1452.

5. $\quad$ Scholl, L., et al., Drug and Opioid-Involved Overdose Deaths - United States, 20132017. MMWR. Morbidity and Mortality Weekly Report, 2018. 67(5152).

6. Hedegaard, H., M. Warner, and A.M. Minino, Drug Overdose Deaths in the United States, 1999-2016. NCHS Data Brief, 2017(294).

7. $\quad$ Coffin, P.O., et al., Identifying Injection Drug Users at Risk of Nonfatal Overdose. Academic Emergency Medicine, 2007. 14(7): p. 616-623.

8. Davoli, M., et al., Risk factors for overdose mortality: a case-control study within a cohort of intravenous drug users. Int J Epidemiol, 1993. 22(2): p. 273-7.

9. Ochoa, K.C., et al., Overdosing among young injection drug users in San Francisco. Addictive Behaviors, 2001. 26(3): p. 453-460.

10. Davoli, M., et al., Risk of fatal overdose during and after specialist drug treatment: the VEdeTTE study, a national multi-site prospective cohort study. Addiction, 2007. 102(12): p. 1954-1959.

11. Webster, L.R., Risk Factors for Opioid-Use Disorder and Overdose. Anesthesia and analgesia, 2017. 125(5): p. 1741-1748.

12. Dasgupta, N., et al., Cohort Study of the Impact of High-Dose Opioid Analgesics on Overdose Mortality. Pain medicine (Malden, Mass.), 2016. 17(1): p. 85-98.

13. Dunn, K.M., et al., Opioid prescriptions for chronic pain and overdose: a cohort study. Ann Intern Med, 2010. 152(2): p. 85-92.

14. Park, T.W., et al., Understanding Risk Factors for Opioid Overdose in Clinical Populations to Inform Treatment and Policy. J Addict Med, 2016. 10(6): p. 369-381.

15. Paulozzi, L.J., Prescription drug overdoses: A review. Journal of Safety Research, 2012. 43(4): p. 283.

16. Paulozzi, L.J., E.M. Kilbourne, and H.A.B.A.H.A.G.U.S.A. Desai, Prescription Drug Monitoring Programs and Death Rates from Drug Overdose. Pain Medicine, 2011. 12(5): p. 747-754.

17. Paulozzi, M.P.H.L.J., et al., A History of Being Prescribed Controlled Substances and Risk of Drug Overdose Death. Pain Medicine, 2012. 13(1).

18. Coben, J.H., et al., Hospitalizations for poisoning by prescription opioids, sedatives, and tranquilizers. Am J Prev Med, 2010. 38(5): p. 517-24.

19. Havens, J.R., et al., Individual and network factors associated with non-fatal overdose among rural Appalachian drug users. Drug and Alcohol Dependence, 2011. 115(1-2): p. 107-112.

20. Silva, K., et al., Factors associated with history of non-fatal overdose among young nonmedical users of prescription drugs. Drug and Alcohol Dependence, 2013. 128(1-2): p. 104-110. 
21. Hulse, G.K., S.I. Robertson, and R.J. Tait, Adolescent emergency department presentations with alcohol- or other drug-related problems in Perth, Western Australia. Addiction (Abingdon, England), 2001. 96(7): p. 1059-67.

22. Seal, K.H., et al., Association of mental health disorders with prescription opioids and high-risk opioid use in US veterans of Iraq and Afghanistan. JAMA, 2012. 307(9): p. 940-7.

23. Zedler, B., et al., Risk factors for serious prescription opioid-related toxicity or overdose among Veterans Health Administration patients. Pain Med, 2014. 15(11): p. 1911-29.

24. Dilokthornsakul, P., et al., Risk Factors of Prescription Opioid Overdose Among Colorado Medicaid Beneficiaries. Journal of Pain, 2016. 17(4): p. 436-443.

25. Hartung, D.M., et al., Rates of adverse events of long-acting opioids in a state Medicaid program. The Annals of pharmacotherapy, 2007. 41(6): p. 921-8.

26. Turner, B.J. and Y. Liang, Drug Overdose in a Retrospective Cohort with Non-Cancer Pain Treated with Opioids, Antidepressants, and/or Sedative-Hypnotics: Interactions with Mental Health Disorders. Journal of general internal medicine, 2015. 30(8): p. 108196.

27. Darke, S., J. Ross, and W. Hall, Overdose among heroin users in Sydney, Australia: I. Prevalence and correlates of non-fatal overdose. Addiction, 1996. 91(3): p. 405-11.

28. Tobin, K.E.M. and C.A.D. Latkin, The relationship between depressive symptoms and nonfatal overdose among a sample of drug users in Baltimore, Maryland. Journal of Urban Health : Bulletin of the New York Academy of Medicine, 2003. 80(2): p. 220-229.

29. Hall, A.J., et al., Patterns of abuse among unintentional pharmaceutical overdose fatalities. JAMA, 2008. 300(22): p. 2613-20.

30. Bauer, L.K., et al., Characteristics of Homeless Adults Who Died of Drug Overdose: A Retrospective Record Review. Journal of health care for the poor and underserved, 2016. 27(2): p. 846-59.

31. Whitmire J.T., A.G.W., Unintentional overdose deaths in the North Carolina Medicaid population: prevalence, prescription drug use, and medical care services. 2010. Center for Health Statistics.

32. Lanier, W.A., et al., Risk Factors for Prescription Opioid-Related Death, Utah, 20082009. Pain Medicine, 2012. 13(12): p. 1580-1589.

33. Bohnert, A.S., et al., Risk of death from accidental overdose associated with psychiatric and substance use disorders. Am J Psychiatry, 2012. 169(1): p. 64-70.

34. Bohnert, A.S., et al., Accidental poisoning mortality among patients in the Department of Veterans Affairs Health System. Med Care, 2011. 49(4): p. 393-6.

35. Bohnert, A.S., et al., A Detailed Exploration Into the Association of Prescribed Opioid Dosage and Overdose Deaths Among Patients With Chronic Pain. Med Care, 2016. 54(5): p. 435-41.

36. Dube, S.R., et al., Childhood abuse, neglect, and household dysfunction and the risk of illicit drug use: the adverse childhood experiences study. Pediatrics, 2003. 111(3): p. 564-72.

37. Douglas, K.R., et al., Adverse childhood events as risk factors for substance dependence: Partial mediation by mood and anxiety disorders. Addictive Behaviors, 2010. 35(1): p. 713.

38. Caudarella, A., et al., Non-fatal overdose as a risk factor for subsequent fatal overdose among people who inject drugs. Drug and alcohol dependence, 2016. 162: p. 51-5. 
39. Warfield, S., et al., Opioid-Related Outcomes in West Virginia, 2008-2016. American Journal of Public Health, 2019. 109(2): p. 303-305.

40. Beghi, M., et al. Risk factors for fatal and nonfatal repetition of suicide attempts: a literature review. neuropsychiatric disease and treatment, 2013. 2013, 1725-1736.

41. Martin, C.A., et al., A retrospective descriptive study of the characteristics of deliberate self-poisoning patients with single or repeat presentations to an Australian emergency medicine network in a one year period. BMC Emerg Med, 2014. 14: p. 21.

42. Vallersnes, O.M., et al., Mortality and repeated poisoning after self-discharge during treatment for acute poisoning by substances of abuse: a prospective observational cohort study. BMC Emerg Med, 2019. 19(1): p. 5.

43. Vallersnes, O.M., et al. Factors associated with rapidly repeated acute poisoning by substances of abuse: a prospective observational cohort study. BMC Research Notes, 2018. 11, 1-4 DOI: 10.1186/s13104-018-3834-3.

44. Dursa, E.K., et al., Demographic, military, and health characteristics of VA health care users and nonusers who served in or during operation enduring freedom or operation iraqi freedom, 2009-2011. Public Health Reports, 2016. 131(6): p. 839-843.

45. Statistics, N.C.f.H., National Death Index user's guide. 2013.

46. VHA, Veterans Health Administration inpatient and outpatient care data: an overview. Effective Clinical Practice, 2002.

47. Bossarte, R.M., An overview of VA/DoD joint mortality data repository and data from studies conducted by the epidemiology program in VA's Office of Public Health. 2014.

48. VA, D.o.V.A., VA utilization profile, FY 2016. 2017.

49. Long, J.A., et al., Missing Race/Ethnicity Data in Veterans Health Administration Based Disparities Research: A Systematic Review. Journal of Health Care for the Poor and Underserved, 2006. 17(1): p. 128-140.

50. Sohn, M.W., et al., Transition to the new race/ethnicity data collection standards in the Department of Veterans Affairs. Population health metrics, 2006. 4: p. 7.

51. Ilgen, M.A., et al., Noncancer pain conditions and risk of suicide. JAMA Psychiatry, 2013. 70(7): p. 692-7.

52. Hoge, C.W., J.L. Auchterlonie, and C.S. Milliken, Mental health problems, use of mental health services, and attrition from military service after returning from deployment to Iraq or Afghanistan. JAMA, 2006. 295(9): p. 1023-32.

53. Frances, A., Essentials of Psychiatric Diagnosis: Responding to the Challenge of DSM-5. Revised Edition. CANADIAN JOURNAL OF PSYCHIATRY, 2013. 58(12): p. 705.

54. Harris, A.H., et al., Are VHA administrative location codes valid indicators of specialty substance use disorder treatment? Journal of rehabilitation research and development, 2010. 47(8): p. 699-708.

55. Oliva, E.M., et al., Receipt of opioid agonist treatment in the Veterans Health Administration: facility and patient factors. Drug and alcohol dependence, 2012. 122(3): p. 241-6.

56. Oliva, E.M., et al., Trends in opioid agonist therapy in the Veterans Health Administration: is supply keeping up with demand? The American journal of drug and alcohol abuse, 2013. 39(2): p. 103-7.

57. Press, S.J. and S. Wilson, Choosing between logistic regression and discriminant analysis. Journal of the American Statistical Association, 1978. 73(364): p. 699-705.

58. Agresti, A., An introduction to categorical data analysis. 2018: Wiley. 
59. Bursac, Z., et al., Purposeful selection of variables in logistic regression. Source code for biology and medicine, 2008. 3(1): p. 17.

60. Agresti, A. and M. Kateri, Categorical data analysis. 2011: Springer.

61. Hosmer Jr, D.W., S. Lemeshow, and R.X. Sturdivant, Applied logistic regression. Vol. 398. 2013: John Wiley \& Sons.

62. Foster, N.E., et al., Prevention and treatment of low back pain: evidence, challenges, and promising directions. Lancet, 2018. 391(10137): p. 2368-2383.

63. Niknejad, B., et al., Association Between Psychological Interventions and Chronic Pain Outcomes in Older Adults: A Systematic Review and Meta-analysis. JAMA internal medicine, 2018. 178(6): p. 830-839.

64. Turk, D.C., H.D. Wilson, and A. Cahana, Treatment of chronic non-cancer pain. Lancet, 2011. 377(9784): p. 2226-35.

65. Dowell, D., T.M. Haegerich, and R. Chou, CDC Guideline for Prescribing Opioids for Chronic Pain - United States, 2016. MMWR Recomm Rep, 2016. 65(1): p. 1-49.

66. Oliva, E.M., et al., Development and applications of the Veterans Health Administration's Stratification Tool for Opioid Risk Mitigation (STORM) to improve opioid safety and prevent overdose and suicide. Psychol Serv, 2017. 14(1): p. 34-49.

67. Friedmann, P.D., R. Saitz, and J.H. Samet, Management of Adults Recovering From Alcohol or Other Drug Problems Relapse Prevention in Primary Care. JAMA, 1998. 279(15): p. 1227.

68. O'Brien, C.P. and A.T. McLellan, Myths about the treatment of addiction. Lancet (London, England), 1996. 347(8996): p. 237-40.

69. Compton, W.M. and N.D. Volkow, Improving Outcomes for Persons With Opioid Use Disorders: Buprenorphine Implants to Improve Adherence and Access to Care. JAMA, 2016. 316(3): p. 277-9.

70. Volkow, N.D. and F.S. Collins, The Role of Science in Addressing the Opioid Crisis. N Engl J Med, 2017. 377(4): p. 391-394.

71. Volkow, N.D., et al., Medication-assisted therapies--tackling the opioid-overdose epidemic. N Engl J Med, 2014. 370(22): p. 2063-6.

72. Hunt, W.A., L.W. Barnett, and L.G. Branch, Relapse rates in addiction programs. Journal of clinical psychology, 1971. 27(4): p. 455-6.

73. Torres, J.M., et al., ICD Social Codes: An Underutilized Resource for Tracking Social Needs. Med Care, 2017. 55(9): p. 810-816.

74. Gottlieb, L., et al., Integrating Social And Medical Data To Improve Population Health: Opportunities And Barriers. Health Affairs, 2016. 35(11): p. 2116-2123.

75. Frieden, T.R. and D. Houry, Reducing the Risks of Relief--The CDC Opioid-Prescribing Guideline. N Engl J Med, 2016. 374(16): p. 1501-4.

76. Brady, J.E., et al., Prescription drug monitoring and dispensing of prescription opioids. Public health reports (Washington, D.C. : 1974), 2014. 129(2): p. 139-47.

77. Paulozzi, L.J., et al., Controlled Substance Prescribing Patterns--Prescription Behavior Surveillance System, Eight States, 2013. MMWR Surveill Summ, 2015. 64(9): p. 1-14.

78. Walley, A.Y., et al., Opioid overdose rates and implementation of overdose education and nasal naloxone distribution in Massachusetts: interrupted time series analysis. BMJ, 2013. 346: p. f174. 
Tables and Figures 
Table 1. Demographic and diagnostic characteristics of veterans with a documented opioid overdose, 2011-2015

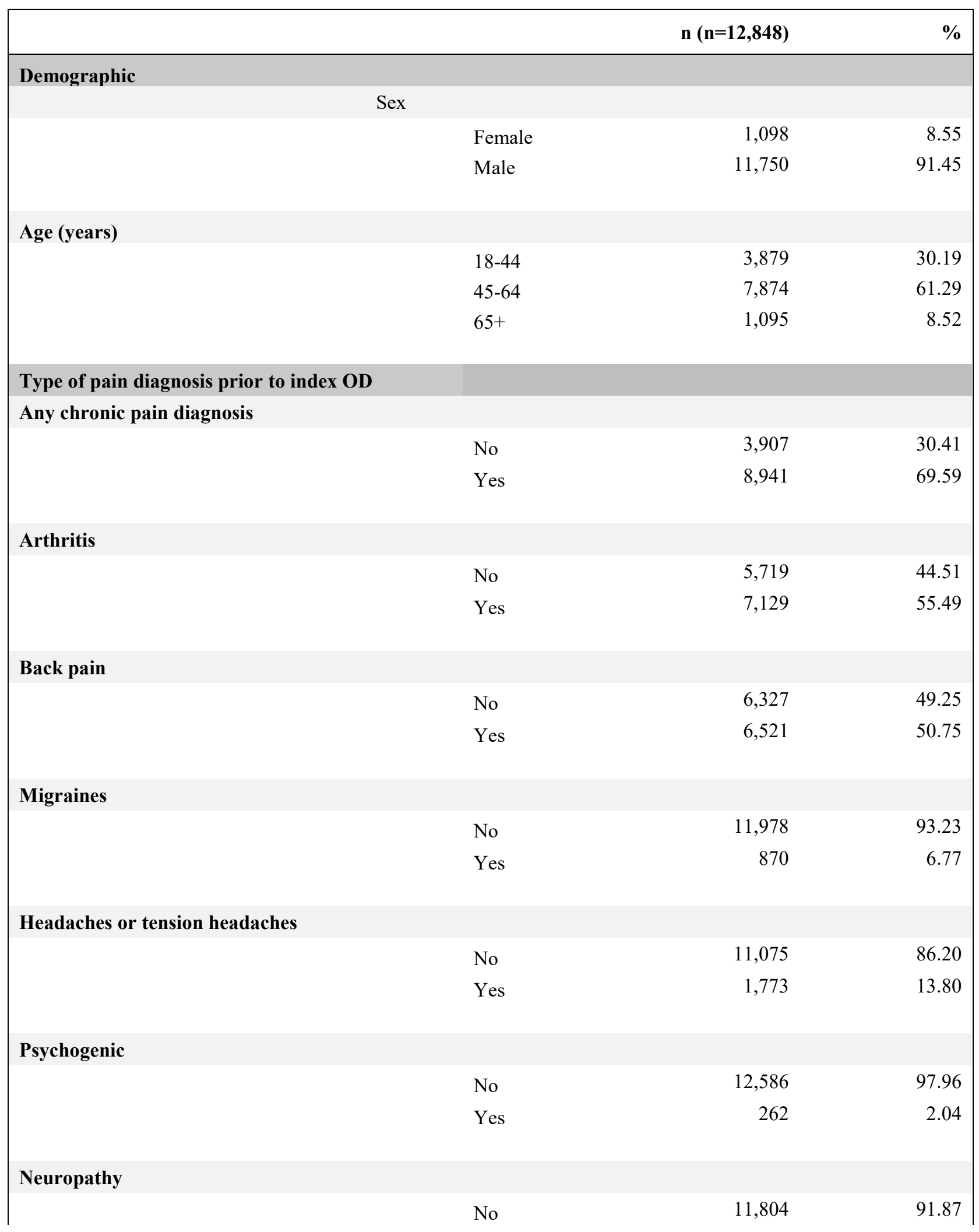



Yes
1,044

Fibromyalgia

No
Yes

12,187

94.86

661

\section{Mental health diagnosis}

Any mental health diagnosis

$\begin{array}{lrr}\text { No } & 1,080 & 8.41 \\ \text { Yes } & 11,768 & 91.59\end{array}$

Anxiety

$$
\text { No }
$$

5,041

39.24

Yes

\section{Depressive disorder}

$$
\text { No }
$$

Yes

\section{Bipolar}

\section{No}

9,764

76.00

Yes

3,084

24.00

\section{PTSD}

$\begin{array}{lll}\text { No } & 6,702 & 52.16 \\ \text { Yes } & 6,146 & 47.84\end{array}$

\section{Adjustment disorder}

Schizophrenia or other psychotic disorder

No
Yes

10,334

2,514

80.43

Traumatic stress

$$
\text { No }
$$

11,071

1,777

86.17

Yes

(1,777

Personality disorder 
Either depression, anxiety, or PTSD diagnosis

$\begin{array}{lrr}\text { No } & 1,942 & 15.12 \\ \text { Yes } & 10,906 & 84.88\end{array}$

All three diagnosis (depression, anxiety, \& PTSD)

$\begin{array}{lll}\text { No } & 8,640 & 67.25 \\ \text { Yes } & 4,208 & 32.75\end{array}$

\section{Substance abuse/dependence}

Any substance abuse/dependence diagnosis

$\begin{array}{lll}\text { No } & 4,545 & 35.38 \\ \text { Yes } & 8,303 & 64.62\end{array}$

Polysubstance abuse/dependence diagnosis ${ }^{a}$

$\begin{array}{lll}\text { No } & 7,645 & 59.50 \\ \text { Yes } & 5,203 & 40.50\end{array}$

Alcohol abuse or dependence diagnosis

$\begin{array}{lll}\text { No } & 6,968 & 54.23 \\ \text { Yes } & 5,880 & 45.77\end{array}$

Opioid abuse or dependence diagnosis

$\begin{array}{lll}\text { No } & 7,137 & 55.55 \\ \text { Yes } & 5,711 & 44.45\end{array}$

Cocaine abuse or dependence diagnosis

$\begin{array}{lrr}\text { No } & 10,052 & 78.24 \\ \text { Yes } & 2,796 & 21.76\end{array}$

Other stimulant abuse or dependence diagnosis

$\begin{array}{lrr}\text { No } & 11,873 & 92.41 \\ \text { Yes } & 975 & 7.59\end{array}$

\section{Medication-Assisted Treatment}

\section{Ever had MAT}

$\begin{array}{lrr}\text { No } & 11,424 & 88.92 \\ \text { Yes } & 1,424 & 11.08\end{array}$

MAT before index overdose

$\begin{array}{lrr}\text { No } & 11,764 & 91.56 \\ \text { Yes } & 1,084 & 8.44\end{array}$


MAT more than 1 year before index OD

$\begin{array}{lrr}\text { No } & 12,144 & 94.52 \\ \text { Yes } & 704 & 5.48\end{array}$

\section{Social determinants of health (SDoH)}

Any code related to SDoH

$\begin{array}{lrr}\text { No } & 981 & 7.64 \\ \text { Yes } & 11,867 & 92.36\end{array}$

\section{Counseling services}

$\begin{array}{lrr}\text { No } & 1,510 & 11.75 \\ \text { Yes } & 11,338 & 88.25\end{array}$

Problems related to housing and economic circumstances

$\begin{array}{lll}\text { No } & 7,766 & 60.45 \\ \text { Yes } & 5,082 & 39.55\end{array}$

Problems related to education and literacy

$\begin{array}{lrr}\text { No } & 11,689 & 90.98 \\ \text { Yes } & 1,159 & 9.02\end{array}$

Problems related to environmental psychosocial circumstances

$\begin{array}{lll}\text { No } & 7,109 & 55.33 \\ \text { Yes } & 5,739 & 44.67\end{array}$

Problems related to mental and behavioral

$\begin{array}{lrr}\text { No } & 12,690 & 98.77 \\ \text { Yes } & 158 & 1.23\end{array}$

Problems related to social environment

$\begin{array}{lll}\text { No } & 9,686 & 75.39 \\ \text { Yes } & 3,162 & 24.61\end{array}$

Other problems related to primary support group

$\begin{array}{lrr}\text { No } & 11,794 & 91.80 \\ \text { Yes } & 1,054 & 8.20\end{array}$

Problems related to upbringing

$\begin{array}{lrr}\text { No } & 12,620 & 98.23 \\ \text { Yes } & 228 & 1.77\end{array}$


Abbreviations: OD, overdose; PTSD, post-traumatic stress disorder, SDoH, social determinants of health; MAT, medication-assisted treatment

a. Polysubstance use or dependence refers to a patient having a diagnosis for more than one substance during the study period (2011-2105). 
Table 2. Bivariate analysis of demographic and diagnostic characteristics by type of opioid overdose among veterans, $2011-2015^{\text {a }}$

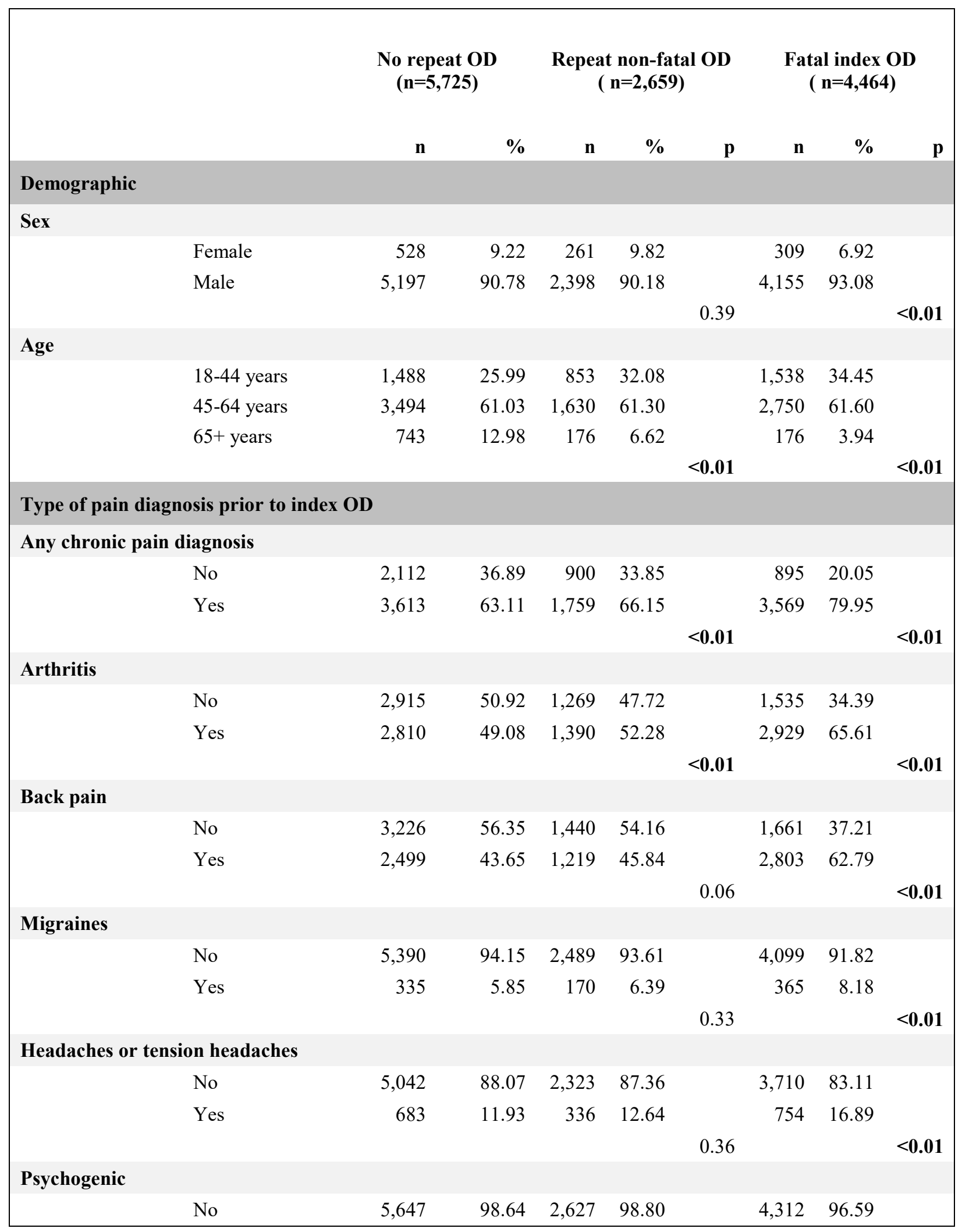




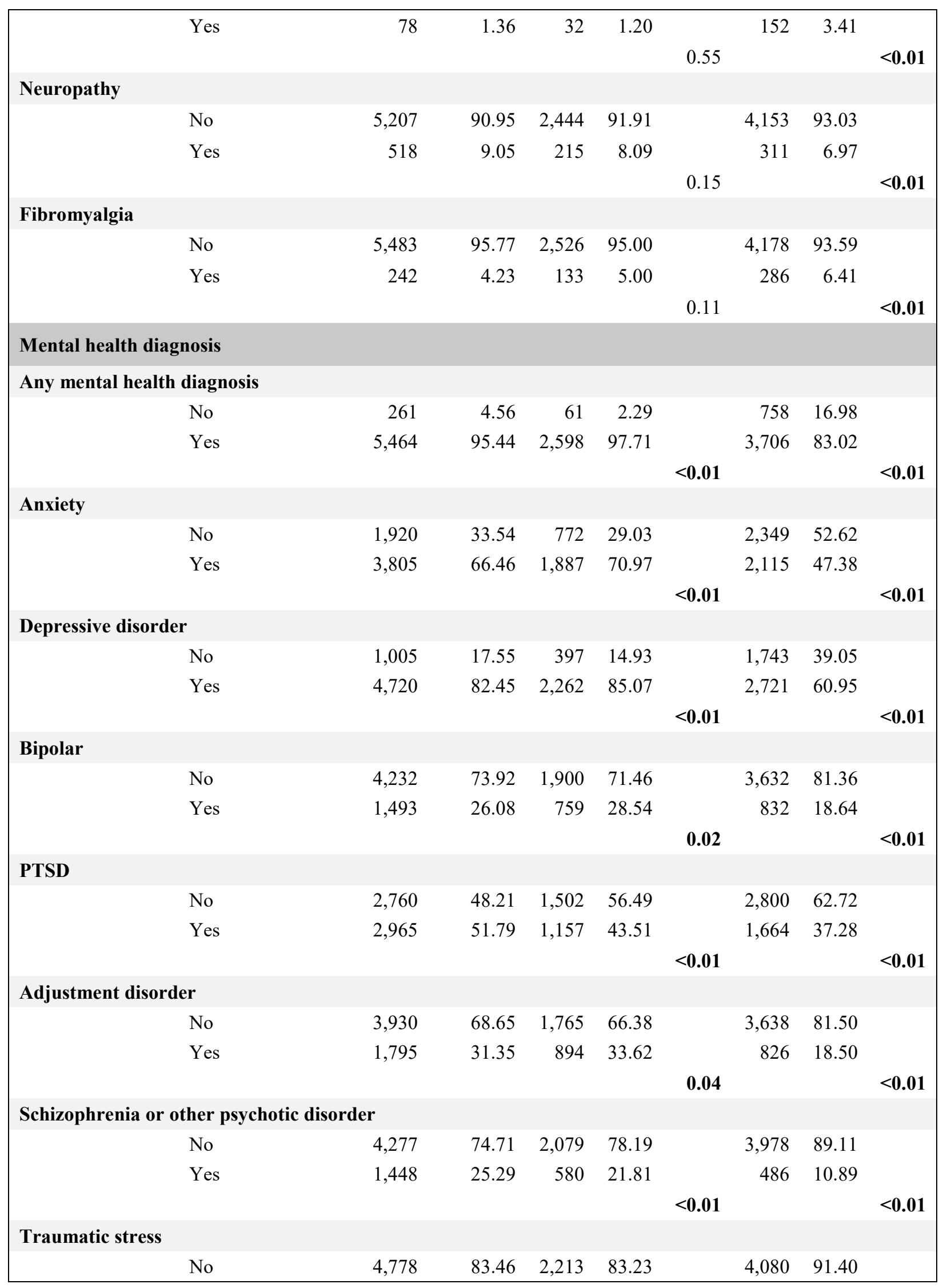




\begin{tabular}{|c|c|c|c|c|c|c|c|c|c|}
\hline & Yes & 947 & 16.54 & 446 & 16.77 & & 384 & 8.60 & \\
\hline & & & & & & 0.80 & & & $<\mathbf{0 . 0 1}$ \\
\hline \multicolumn{10}{|c|}{ Personality disorder } \\
\hline & No & 4,316 & 75.39 & 1,934 & 72.73 & & 3,840 & 86.02 & \\
\hline & Yes & 1,409 & 24.61 & 725 & 27.27 & & 624 & 13.98 & \\
\hline & & & & & & $<0.01$ & & & $<0.01$ \\
\hline \multicolumn{10}{|c|}{ Either depression, anxiety, or PTSD diagnosis } \\
\hline & No & 575 & 10.04 & 197 & 7.41 & & 1,170 & 26.21 & \\
\hline & Yes & 5,150 & 89.96 & 2,462 & 92.59 & & 3,294 & 73.79 & \\
\hline & & & & & & & & & $<0.01$ \\
\hline \multicolumn{10}{|c|}{ All three diagnosis (depression, anxiety, \& PTSD) } \\
\hline & No & 3,573 & 62.41 & 1,512 & 56.86 & & 3,555 & 79.64 & \\
\hline & Yes & 2,152 & 37.59 & 1,147 & 43.14 & & 909 & 20.36 & \\
\hline & & & & & & $<0.01$ & & & $<0.01$ \\
\hline \multicolumn{10}{|c|}{ Substance abuse/dependence } \\
\hline \multicolumn{10}{|c|}{ Any substance abuse/dependence diagnosis } \\
\hline & No & 1,897 & 33.14 & 661 & 24.86 & & 1,977 & 44.29 & \\
\hline & Yes & 3,828 & 66.86 & 1,998 & 75.14 & & 2,487 & 55.71 & \\
\hline & & & & & & $<0.01$ & & & $<0.01$ \\
\hline \multicolumn{10}{|c|}{ Polysubstance abuse/dependence diagnosis ${ }^{b}$} \\
\hline & No & 3,337 & 58.29 & 1,323 & 49.76 & & 2,985 & 66.87 & \\
\hline & Yes & 2,388 & 41.71 & 1,336 & 50.24 & & 1,479 & 33.13 & \\
\hline & & & & & & $<0.01$ & & & $<0.01$ \\
\hline \multicolumn{10}{|c|}{ Alcohol abuse or dependence diagnosis } \\
\hline & No & 2,993 & 52.28 & 1,239 & 46.60 & & 2,736 & 61.29 & \\
\hline & Yes & 2,732 & 47.72 & 1,420 & 53.40 & & 1,728 & 38.71 & \\
\hline & & & & & & $<0.01$ & & & $<0.01$ \\
\hline \multicolumn{10}{|c|}{ Opioid abuse or dependence diagnosis } \\
\hline & No & 3,070 & 53.62 & 1,189 & 44.72 & & 2,878 & 64.47 & \\
\hline & Yes & 2,655 & 46.38 & 1,470 & 55.28 & & 1,586 & 35.53 & \\
\hline & & & & & & $<0.01$ & & & $<0.01$ \\
\hline \multicolumn{10}{|c|}{ Cocaine abuse or dependence diagnosis } \\
\hline & No & 4,509 & 78.76 & 1,945 & 73.15 & & 3,598 & 80.60 & \\
\hline & Yes & 1,216 & 21.24 & 714 & 26.85 & & 866 & 19.40 & \\
\hline & & & & & & $<0.01$ & & & 0.02 \\
\hline \multicolumn{10}{|c|}{ Other stimulant abuse or dependence diagnosis } \\
\hline & No & 5,225 & 91.27 & 2,371 & 89.17 & & 4,277 & 95.81 & \\
\hline & Yes & 500 & 8.73 & 288 & 10.83 & & 187 & 4.19 & \\
\hline & & & & & & $<0.01$ & & & $<\mathbf{0 . 0 1}$ \\
\hline \multicolumn{10}{|c|}{ Medication-Assisted Treatment } \\
\hline Ever had MAT & & & & & & & & & \\
\hline
\end{tabular}




\begin{tabular}{|c|c|c|c|c|c|c|c|c|}
\hline No & 5,097 & 89.03 & 2,264 & 85.14 & & 4,063 & 91.02 & \\
\hline Yes & 628 & 10.97 & 395 & 14.86 & & 401 & 8.98 & \\
\hline & & & & & $<0.01$ & & & $<0.01$ \\
\hline OD & & & & & & & & \\
\hline No & 5,297 & 92.52 & 2,398 & 90.18 & & 4,069 & 91.15 & \\
\hline Yes & 428 & 7.48 & 261 & 9.82 & & 395 & 8.85 & \\
\hline & & & & & $<0.01$ & & & 0.01 \\
\hline year b & & & & & & & & \\
\hline No & 5,433 & 94.90 & 2,476 & 93.12 & & 4,235 & 94.87 & \\
\hline Yes & 292 & 5.10 & 183 & 6.88 & & 229 & 5.13 & \\
\hline & & & & & $<0.01$ & & & 0.95 \\
\hline s of he & & & & & & & & \\
\hline deter & & & & & & & & \\
\hline No & 237 & 4.14 & 120 & 4.51 & & 624 & 13.98 & \\
\hline Yes & 5,488 & 95.86 & 2,539 & 95.49 & & 3,840 & 86.02 & \\
\hline & & & & & 0.43 & & & $<0.01$ \\
\hline & & & & & & & & \\
\hline No & 450 & 7.86 & 200 & 7.52 & & 860 & 19.27 & \\
\hline Yes & 5,275 & 92.14 & 2,459 & 92.48 & & 3,604 & 80.73 & \\
\hline & & & & & 0.59 & & & $<0.01$ \\
\hline hous & ic circu & ances & & & & & & \\
\hline No & 3,482 & 60.82 & 1,535 & 57.73 & & 2,749 & 61.58 & \\
\hline Yes & 2,243 & 39.18 & 1,124 & 42.27 & & 1,715 & 38.42 & \\
\hline & & & & & $<0.01$ & & & 0.43 \\
\hline educ & & & & & & & & \\
\hline No & 5,143 & 89.83 & 2,398 & 90.18 & & 4,148 & 92.92 & \\
\hline Yes & 582 & 10.17 & 261 & 9.82 & & 316 & 7.08 & \\
\hline & & & & & 0.25 & & & $<0.01$ \\
\hline envir & losocial & umstan & & & & & & \\
\hline No & 2,901 & 50.67 & 1,396 & 52.50 & & 2,812 & 62.99 & \\
\hline Yes & 2,824 & 49.33 & 1,263 & 47.50 & & 1,652 & 37.01 & \\
\hline & & & & & 0.12 & & & $<0.01$ \\
\hline ment & & & & & & & & \\
\hline No & 5,653 & 98.74 & 2,618 & 98.46 & & 4,419 & 98.99 & \\
\hline Yes & 72 & 1.26 & 41 & 1.54 & & 45 & 1.01 & \\
\hline & & & & & 0.29 & & & 0.24 \\
\hline socia & & & & & & & & \\
\hline No & 4,111 & 71.81 & 1,975 & 74.28 & & 3,600 & 80.65 & \\
\hline Yes & 1,614 & 28.19 & 684 & 25.72 & & 864 & 19.35 & \\
\hline & & & & & 0.02 & & & $<0.01$ \\
\hline ted $t$ & rt grou & & & & & & & \\
\hline
\end{tabular}




\begin{tabular}{|crrrrrrrl|}
\hline No & 5,193 & 90.71 & 2,427 & 91.27 & & 4,174 & 93.50 & \\
Yes & 532 & 9.29 & 232 & 8.73 & & 290 & 6.50 & \\
& & & & & 0.40 & & & $<\mathbf{0 . 0 1}$ \\
Problems related to upbringing & & & & & & & & \\
No & 5,603 & 97.87 & 2,611 & 98.19 & & 4,406 & 98.70 & \\
Yes & 122 & 2.13 & 48 & 1.81 & & 58 & 1.30 & \\
& & & & & 0.33 & & & $<\mathbf{0 . 0 1}$ \\
\hline
\end{tabular}

Abbreviations: OD, overdose; PTSD, Post-Traumatic Stress Disorder; MAT, Medication-Assisted Treatment

a. Bivariate analysis examined patient characteristics that were different among those with a repeated overdose and fatal index overdose in comparison to those with only non-fatal overdose.

b. Polysubstance use or dependence refers to a patient having a diagnosis for more than one substance during the study period (2011-2105). 
Table 3. Multinomial regression analysis of factors associated with type of opioid overdoses among Veterans, 2011-2015

\begin{tabular}{|c|c|c|c|c|c|}
\hline & & \multicolumn{2}{|c|}{ Repeat OD $(n=2,659)$} & \multicolumn{2}{|c|}{ Fatal index OD $(n=4,464)$} \\
\hline & & OR & $95 \%$ CI & OR & $95 \% \mathrm{CI}$ \\
\hline \multicolumn{6}{|l|}{ Sex } \\
\hline Male & & 0.98 & $(0.83-1.14)$ & 1.57 & $(1.34-1.83)$ \\
\hline Female & & 1.00 & Ref & 1.00 & Ref \\
\hline \multicolumn{6}{|c|}{ Age (years) } \\
\hline & $18-44$ & 2.13 & $(1.76-2.58)$ & 7.19 & $(5.88-8.78)$ \\
\hline & $45-64$ & 1.78 & $(1.49-2.13)$ & 4.78 & $(3.95-5.78)$ \\
\hline & $65+$ & 1.00 & Ref & 1.00 & Ref \\
\hline \multicolumn{6}{|c|}{ Chronic pain diagnosis } \\
\hline Yes & & 1.15 & $(1.04-1.27)$ & 3.96 & $(3.56-4.42)$ \\
\hline No & & 1.00 & Ref & 1.00 & Ref \\
\hline \multicolumn{6}{|c|}{ Mental health diagnosis } \\
\hline Yes & & 1.54 & $(1.15-2.07)$ & 0.18 & $(0.15-0.22)$ \\
\hline No & & 1.00 & Ref & 1.00 & Ref \\
\hline \multicolumn{6}{|c|}{ Polysubstance abuse or dependence ${ }^{a}$} \\
\hline Yes & & 1.25 & $(1.13-1.38)$ & 0.75 & $(0.68-0.82)$ \\
\hline No & & 1.00 & Ref & 1.00 & Ref \\
\hline \multicolumn{6}{|c|}{ MAT more than 1 year prior to index OD } \\
\hline Yes & & 1.18 & $(0.97-1.44)$ & 1.28 & $(1.05-1.55)$ \\
\hline No & & 1.00 & Ref & 1.00 & Ref \\
\hline \multicolumn{6}{|c|}{ Received counseling services } \\
\hline Yes & & 0.93 & $(0.78-1.12)$ & 0.35 & $(0.30-0.40)$ \\
\hline No & & 1.00 & Ref & 1.00 & Ref \\
\hline
\end{tabular}

Abbreviations: OR, Odds Ratio; CI, Confidence Interval; OD, overdose; MAT, Medication-Assisted Treatment

a. Polysubstance use or dependence refers to a patient having a diagnosis for more than one substance during the study period (2011-2105). 
Supplement Table 1. Corresponding ICD-9 and ICD-10 Codes for Variables

\begin{tabular}{|c|c|}
\hline Characteristic & ICD-9 and ICD-10 code \\
\hline \multicolumn{2}{|c|}{ Psychosocial \& related mental health diagnoses } \\
\hline Any mental health diagnosis & $\begin{array}{l}\text { ICD-9: } 290.00 \text { to } 319.99 \text {, excluding tobacco codes starting with } 305 \\
\text { ICD-10: F00 to F99, excluding tobacco codes starting with F17 }\end{array}$ \\
\hline Anxiety & $\begin{array}{l}\text { ICD-9: } 300 \\
\text { ICD-10: } \mathrm{F} 40, \mathrm{~F} 41\end{array}$ \\
\hline Depression & $\begin{array}{l}\text { ICD-9: } 296.2,296.3,300.4,311 \\
\text { ICD-10: F32, F33, F34.1 }\end{array}$ \\
\hline Bipolar & $\begin{array}{l}\text { ICD-9: } 296.0,296.1,296.4,296.5,296.6,296.7,296.8 \\
\text { ICD-10: F31 }\end{array}$ \\
\hline PTSD & $\begin{array}{l}\text { ICD-9: } 309.81 \\
\text { ICD-10: F43.1 }\end{array}$ \\
\hline Adjustment disorder & $\begin{array}{l}\text { ICD-9: } 309.0,309.24,309.28,309.3,309.4,309.9 \\
\text { ICD-10: F43.20- F43.25 }\end{array}$ \\
\hline $\begin{array}{l}\text { Schizophrenia or other psychotic } \\
\text { disorders }\end{array}$ & $\begin{array}{l}\text { ICD-9: 295.90, 295.40, 295.70, 297.1, 297.3, 298.8, 293.81, 293.82, } \\
298.9 \\
\text { ICD-10: F20.9, F20.81, F25.0, F25.1, F22, F24, F23, F06.2, F06.0, F29) }\end{array}$ \\
\hline Traumatic stress & $\begin{array}{l}\text { ICD-9: } 308.9,309.89,309.9 \\
\text { ICD-10: F43.0 F43.8, F43.9 }\end{array}$ \\
\hline Personality disorder & $\begin{array}{l}\text { ICD-9: } 301.83,301.7,301.81,301.50,301.4,301.82,301.6,301.0, \\
\text { 301.20, } 310.1301 .9 \\
\text { ICD-10: F60, F61 }\end{array}$ \\
\hline Opioid abuse/dependence & $\begin{array}{l}\text { ICD-9 codes: } 304.0,304.7,305.5 \\
\text { ICD-10 codes: } F 11\end{array}$ \\
\hline Alcohol abuse/dependence & $\begin{array}{l}\text { ICD-9: } 303,305.0 \\
\text { ICD-10: F10 }\end{array}$ \\
\hline Cannabis abuse/dependence & $\begin{array}{l}\text { ICD-9: } 304.3,305.2 \\
\text { ICD-10: F12 }\end{array}$ \\
\hline $\begin{array}{l}\text { Sedative, hypnotics, or anxiolytic } \\
\text { abuse/dependence }\end{array}$ & $\begin{array}{l}\text { ICD-9: } 304.1,305.4 \\
\text { ICD-10: } \mathrm{F} 13\end{array}$ \\
\hline Cocaine abuse/dependence & $\begin{array}{l}\text { ICD-9: } 304.2,305.6 \\
\text { ICD-10: F14 }\end{array}$ \\
\hline Other stimulant abuse/dependence & $\begin{array}{l}\text { ICD-9: } 304.4,305.7 \\
\text { ICD-10: F15 }\end{array}$ \\
\hline Hallucinogen abuse/dependence & $\begin{array}{l}\text { ICD-9: } 304.5,305.3 \\
\text { ICD-10: } F 16\end{array}$ \\
\hline Any substance abuse/dependence & Any diagnosis for substance abuse/dependence \\
\hline Polysubstance abuse/dependence & At least two combinations of the substance abuse/dependence diagnosis \\
\hline TBI & $\begin{array}{l}\text { ICD-9: 800.0-801.9, 803.0-804.9, 850.0-854.1, 950.1-950.3, 995.55, } \\
\text { 959.01 } \\
\text { ICD-10: S02.0, S02.1, S02.8, S02.91, S04.02, S04.03, S04.04, S06, } \\
\text { S07.1, T74.4 }\end{array}$ \\
\hline
\end{tabular}




\begin{tabular}{|c|c|}
\hline \multicolumn{2}{|c|}{ Medication-Assisted Treatment (MAT) } \\
\hline Record of MAT & $\begin{array}{l}\text { Using stop code } 523 \text { (primary or secondary stop code) to identify MAT } \\
\text { services }\end{array}$ \\
\hline \multicolumn{2}{|l|}{ Chronic pain before index $O D$} \\
\hline Back pain & $\begin{array}{l}\text { ICD-9: 720.0-724.9 } \\
\text { ICD-10: M45.9- M46.1, M46.90, M47.812, M47.12, M47.814, M47.817, } \\
\text { M48.20, M48.10, M48.30, M48.9, M50.20, M51.9, M50.30, M51.34- } \\
\text { M51.37, M48.02, M54.2, M53.0, M53.1, M54.12, M54.13,M43.6, } \\
\text { M54.02, M67.88, M53.82, M54.6, M54.5, M54.30, M54.14-M54.17, } \\
\text { M54.89-M54.9, M43.27, M43.28, M53.2X7, M53.3, M54.08, M43.8X9, } \\
\text { M53.9 }\end{array}$ \\
\hline Arthritis & $\begin{array}{l}\text { ICD-9: 710.0-739.9, excluding back pain codes } \\
\text { ICD-10: M00-M02, M36.2, M36.3, M12, M35.3, M15, M16-M19, M05- } \\
\text { M08, M1A, M10-M14 }\end{array}$ \\
\hline Migraines & $\begin{array}{l}\text { ICD-9: } 346.0-346.9 \\
\text { ICD-10:G43.0, G43.1, G43.4, G43.5, G43.6, G43.7, G43.8, G43.9, } \\
\text { G43.A, G43.B, G43.C, G43.D }\end{array}$ \\
\hline Headaches or tension headaches & $\begin{array}{l}\text { ICD-9: } 784.0 \text { and } 307.81 \\
\text { ICD-10: G44.1, R51, G44.209 }\end{array}$ \\
\hline Psychogenic & $\begin{array}{l}\text { ICD-9: } 307.80 \text { and } 307.89 \\
\text { ICD-10: F45.41, F45.42 }\end{array}$ \\
\hline Neuropathy & $\begin{array}{l}\text { ICD-9: } 355.0,355.9,356.0,357.2,357.9 \\
\text { ICD-10:G57.00, G58.9, G60, E08.42, E09.42, E10.42, E11.42, E13.42, } \\
\text { G61.9 }\end{array}$ \\
\hline Fibromyalgia & $\begin{array}{l}\text { ICD-9: } 729.1 \\
\text { ICD-10: M60.9, M79.1, M79.7 }\end{array}$ \\
\hline Any chronic pain diagnosis & Any of the diagnoses for chronic pain \\
\hline \multicolumn{2}{|c|}{ Social determinants of health $(\mathrm{SDoH})$ codes prior to index $O D$} \\
\hline $\begin{array}{l}\text { Problems related to housing and } \\
\text { economic circumstances }\end{array}$ & $\begin{array}{l}\text { ICD-9: V60.0, V60.1, V60.89, V60.6, V60.2, V60.9 } \\
\text { ICD-10: Z59 (Z59.0-Z59.9) }\end{array}$ \\
\hline $\begin{array}{l}\text { Problems related to support group, } \\
\text { including family and relationships }\end{array}$ & $\begin{array}{l}\text { ICD-9: V61.0, V61.05, V61.8, V61.01, V61.06, V61.07, V61.08, } \\
\text { V62.82, V61.03, V61.49, V61.02, V61.41, V61.3, V61.04, V61.09, } \\
\text { V61.8, V61.9 } \\
\text { ICD-10: Z63 (Z63.0-Z63.9) }\end{array}$ \\
\hline $\begin{array}{l}\text { Problems related to social } \\
\text { environment }\end{array}$ & $\begin{array}{l}\text { ICD-9: V60.3, V62.4, V62.89 } \\
\text { ICD-10: Z60.0, Z60.2, Z60.3, Z60.4, Z60.5, Z60.8, Z60.9 }\end{array}$ \\
\hline Problems related to upbringing & $\begin{array}{l}\text { ICD-9: V61.29, V61.8, V60.81 } \\
\text { ICD-10: Z62.0, Z62.1, Z62.2, Z62.3, Z62.6, Z62.8 }\end{array}$ \\
\hline $\begin{array}{l}\text { Problems related to environmental } \\
\text { psychosocial circumstances }\end{array}$ & $\begin{array}{l}\text { ICD-9: V62.5, V62.89, V62.81, V62.9 } \\
\text { ICD-10: Z65.0, Z65.1, Z65.2, Z65.3, Z65.4, Z65.5, Z65.8, Z65.9 }\end{array}$ \\
\hline Problems related to abuse & $\begin{array}{l}\text { ICD-9: V61.21, V61.22, V62.83, V61.11, V61.12, V65.49 } \\
\text { ICD-10: Z69.0, Z69.01, Z69.02, Z69.1, Z69.8 }\end{array}$ \\
\hline Counseling services & $\begin{array}{l}\text { ICD-9: V65.49, V61.2, V61.1, V65.40, V65.9 } \\
\text { ICD-10: Z71.81, Z71.89, Z71.9 }\end{array}$ \\
\hline $\begin{array}{l}\text { Other problems related to mental } \\
\text { and behavior }\end{array}$ & $\begin{array}{l}\text { ICD-9: V40.0, V40.2, V40.3, V40.31, V40.39, V40.9 } \\
\text { ICD-10: F48.9, F69 }\end{array}$ \\
\hline
\end{tabular}


Abbreviations: ICD, International Classification of Disease; ICD-9, International Classification of Disease, Ninth Edition; ICD-10, International Classification of Disease, Tenth Edition; PTSD, Post-traumatic stress disorder; TBI, Traumatic Brian Injury; MAT, Medication-Assisted Treatment; OD, overdose; SDoH, social determinant of health 


\section{Chapter 3}




\subsection{Abstract}

\section{Objective}

To determine the conditional probability of repeat overdose among patients with one or more prior overdose events and corresponding probability of overdose mortality.

\section{Methods}

Clinical records were extracted between 2011 through 2015 for veterans receiving medical care from the Veterans Health Administration (VHA). Vital status was determined by linking data from the patient's medical record to information contained in the VA/DoD Joint Suicide (allcause) Data Repository (SDR). Conditional probability of repeated overdose and mortality was calculated among patients with at least one recorded overdose.

\section{Results}

There were 12,905 veterans with at least one opioid overdose between 2011 and 2015. Among this study sample, one fifth $(n=2,716)$ had a repeated opioid overdose during the study period. The conditional probability for repeated overdose more than doubled for each overdose event from $21.1 \%$ for a second overdose to $43.2 \%$ for five or more overdoses. Mortality was highest for the first documented overdose $(34.6 \%)$.

\section{Conclusion}

Overdose prevention efforts should be expanded and include primary prevention efforts targeting those at highest risk for overdose morbidity and mortality; including those not currently receiving treatment for opioid abuse or misuse. Additional research is needed to identify risk factors for repeated overdose and corresponding mortality to curtail the current opioid crisis. 


\subsection{Introduction}

Opioid overdoses are a growing public health concern. In the United States, the opioid overdose mortality rate increased by $413 \%$ since 1999 , from a rate of 2.9 to 14.9 per 100,000 [1-5]. In addition to fatal overdoses, nonfatal overdoses resulting in either inpatient admission or emergency department visits have been substantially increasing in the past decade [6, 7]. Despite the observed rise in overdoses, little is known about the risk of repeated overdose events and corresponding mortality. Prior research suggests that a history of overdose and psychiatric diagnoses are risk factors for repeat overdose among persons who engage in self-harm behavior or inject drugs [8-11]. However little is understood regarding the risks associated with repeat overdose among patients in a general patient population.

The overall objective of this study was to calculate the conditional probability of a repeat opioid overdose event and mortality for each overdose event among veterans who use VHA services. This research is important because it will elucidate the number of documented opioid overdose events a patient experiences and will identify the overdose event associated with highest overdose mortality using data from the largest integrated health care system in the U.S..

\subsection{Methods}

Sample design

This study cohort included 13,333 veterans with at least one documented opioid overdose between January 1, 2011 and December 31, 2015. Opioid overdoses were extracted using clinical records from the VHA Corporate Data Warehouse (CDW) [12]. CDW records were linked with mortality records from the VA/DoD Suicide (all-cause) Data Repository using Social Security Numbers (SSNs) [13, 14]. Vital status was determined for these patients through the 2015 
calendar year. Sex and age were extracted from clinical and mortality files. Age was static and determined on the start of the study period (January 1, 2011).

\section{Opioid overdose}

An opioid overdose was identified using International Classification of Disease, Ninth Edition (ICD-9) codes: 965.00-965.02, 965.09, E850.0-E850.2 and ICD Tenth Edition (ICD-10) codes: X40-X44, Y10-Y14 and secondary axis codes T40.0- T40.4, and T40.6. The first opioid overdose documented in the clinical records between calendar years 2011 to 2015 was used as the index overdose. Repeat overdose was defined as a second documented overdose that either occurred two days after the previous overdose with the overdose documented as the principal diagnosis or a second documented overdose that occurred or more than three days after the prior overdose.

The study sample was restricted to veterans between 18 and 90 years old. To allow time for repeated events, we excluded patients that had no follow-up visits within one year of the first overdose event or had their first overdose in the last three months of the study period (October 1, 2015-December 1, 2015). For this study, we excluded patients with an opioid overdose death that was classified as intentional or homicide, yielding a total of 12,905 patients.

This study was reviewed and approved by the Institutional Review Board at the Syracuse VA Medical Center, New York.

\section{Analysis plan}

The frequency and conditional probability of nonfatal and fatal overdose were estimated among the total VHA patient population with at least one overdose event during the study period (20112015). Conditional probability of an overdose was calculated by dividing the proportion of 
patients experiencing the event by the number of patients at risk for the event [15-17]. The conditional probability of interest was mortality at each overdose event for each disease event (e.g., one, two, three, four or more overdoses) as well as conditional probability for repeated nonfatal overdose event. Conditional probabilities for overdose death and repeat overdose at each disease event were estimated and $95 \%$ confidence intervals were extrapolated using the normal approximation method.

\subsection{Results}

There were 12,905 veterans with at least one overdose event documented in VHA's electronic medical record (EMR). The conditional probability of repeated overdose increased directly with the number of overdose events. The conditional probability for repeated overdoses more than doubled from $21.1 \%$ following one nonfatal overdose event to $43.2 \%$ for experiencing four or more overdoses (Table 1). In total, 4,521 veterans experienced a fatal overdose; accounting for $35.0 \%$ of the VHA patients with a recorded overdose. The proportion of deaths was highest for the first documented overdose (98.8\%) compared to subsequent fatal overdose events (Figure 1).

\subsection{Discussion}

More than twenty percent of patients with a documented opioid overdose had at least one repeated overdose documented in the records during the five year study period (January 1, 2011December 31, 2015). With every overdose event, the probability of experiencing an additional overdose continued to increase but the probability of overdose death was consistently low.

Patients were 17 times more likely to die from an opioid overdose on their first documented overdose event during the study period. Given that overdose mortality was highest among patients with no prior overdose during this time period, prevention efforts should be focused on 
amplifying resources to those without documented overdose risk. Additional research is needed to understand the risks associated with repeat overdose to inform future clinical and public health interventions directed at those with history of multiple overdoses.

Although overdose was obtained from one of the nation's largest healthcare records, this study has several limitations. Findings relied on patients seeking medical care for an overdose which could underestimate the true number of overdoses an individual experienced. Data collected was among the veteran population so results may not be generalizable to the general population or users of other health systems. Additional studies are needed to understand if these results hold true in other healthcare populations. Due to the limited scope of this analysis additional factors may be present which in turn increase the risk of repeat overdose and associated fatality. Finally this project only included overdoses that were documented by VHA clinician during the study period. It is possible that previous overdoses outside of the study period or those were otherwise undocumented were not captured. Inclusion of these may change distribution across categories or estimated conditional probabilities.

These results suggest the need for additional research, specifically examining potential unique risk factors for experiencing a repeat overdose. Given the rates of repeat overdose increased in a linear fashion, these findings suggest that healthcare systems should be ready for an influx in patients with opioid overdoses. Furthermore, these findings underscore the urgent need to expand overdose prevention efforts, such as naloxone distribution to patients with no history of an overdose. 


\section{References}

1. Centers for Disease Control and Prevention, C., CDC WONDER online database. 2018.

2. Hedegaard, H., M. Warner, and A.M. Minino, Drug Overdose Deaths in the United States, 1999-2016. NCHS Data Brief, 2017(294).

3. $\quad$ Rudd, R.A., et al., Increases in Drug and Opioid Overdose Deaths--United States, 20002014. MMWR Morb Mortal Wkly Rep, 2016. 64(50-51): p. 1378-82.

4. Rudd, R.A., et al., Increases in Drug and Opioid-Involved Overdose Deaths - United States, 2010-2015. MMWR Morb Mortal Wkly Rep, 2016. 65(5051): p. 1445-1452.

5. Scholl, L., et al., Drug and Opioid-Involved Overdose Deaths - United States, 20132017. MMWR. Morbidity and Mortality Weekly Report, 2018. 67(5152).

6. Weiss, A.J., et al., Opioid-Related Inpatient Stays and Emergency Department Visits by State, 2009-2014: Statistical Brief \#219, in Healthcare Cost and Utilization Project (HCUP) Statistical Briefs. 2017: Rockville (MD).

7. BlueShield, B., America's opioid epidemic and its effect on the nation's commerciallyinsured population. 2017.

8. Boyes, A.P., Repetition of overdose: a retrospective 5-year study. J Adv Nurs, 1994. 20(3): p. 462-8.

9. Finkelstein, Y., et al., Repetition of intentional drug overdose: a population-based study. Clin Toxicol (Phila), 2016. 54(7): p. 585-9.

10. Vallersnes, O.M., et al., Mortality and repeated poisoning after self-discharge during treatment for acute poisoning by substances of abuse: a prospective observational cohort study. BMC Emerg Med, 2019. 19(1): p. 5.

11. Vallersnes, O.M., et al. Factors associated with rapidly repeated acute poisoning by substances of abuse: a prospective observational cohort study. BMC Research Notes, 2018. 11, 1-4 DOI: 10.1186/s13104-018-3834-3.

12. VHA, Veterans Health Administration inpatient and outpatient care data: an overview. Effective Clinical Practice, 2002.

13. Bossarte, R.M., An overview of VA/DoD joint mortality data repository and data from studies conducted by the epidemiology program in VA's Office of Public Health. 2014.

14. Statistics, N.C.f.H., National Death Index user's guide. 2013.

15. Cabarrou, B., et al., Focus on an infrequently used quantity in the context of competing risks: The conditional probability function. Comput Biol Med, 2018. 101: p. 70-81.

16. Pepe, M.S. and M. Mori, Kaplan-Meier, marginal or conditional probability curves in summarizing competing risks failure time data? Stat Med, 1993. 12(8): p. 737-51.

17. Rajeswaran, J. and E.H. Blackstone, Competing risks: Competing questions. J Thorac Cardiovasc Surg, 2017. 153(6): p. 1432-1433. 
Tables and Figures 
Table 1. Repeated opioid overdoses and subsequent mortality among patients between 2011-2015

\begin{tabular}{|c|c|c|c|c|c|c|}
\hline No. of overdoses & $\begin{array}{r}\text { No. of } \\
\text { fatal } \\
\text { OD } \\
\end{array}$ & $\begin{array}{r}\text { No. of } \\
\text { OD }^{\mathbf{a}} \\
\end{array}$ & $\begin{array}{r}\text { Conditional } \\
\text { probability } \\
\text { of repeated } \\
\text { OD } \\
\end{array}$ & $\begin{array}{r}95 \% \text { CI of } \\
\text { repeated event } \\
\end{array}$ & $\begin{array}{r}\text { Probability } \\
\text { of overdose } \\
\text { mortality } \\
\end{array}$ & $\begin{array}{l}95 \% \text { CI of } \\
\text { mortality } \\
\end{array}$ \\
\hline One overdose & 4,464 & 12,905 & & & 34.59 & $(33.77-35.42)$ \\
\hline Two overdoses & 30 & 2,716 & 21.05 & $(20.35-21.76)$ & 1.10 & $(0.76-1.59)$ \\
\hline Three overdoses & 15 & 954 & 35.13 & $(33.33-36.96)$ & 1.57 & $(0.92-2.64)$ \\
\hline Four overdoses & 8 & 396 & 41.51 & $(38.37-44.72)$ & 2.02 & $(0.94-4.10)$ \\
\hline More than 5 overdoses & 4 & 171 & 43.18 & $(38.27-48.23)$ & 2.34 & $(0.75-6.26)$ \\
\hline
\end{tabular}

Abbreviations: OD, overdose; CI, confidence interval; No., Number

a. Number of total overdoses indicate the total number of overdoses a patient experienced during the study period. 
Figure 1. Mortality for each opioid overdose event recorded, 2011-2015

Opioid overdose mortality for each recorded opioid overdose, 2011-2015

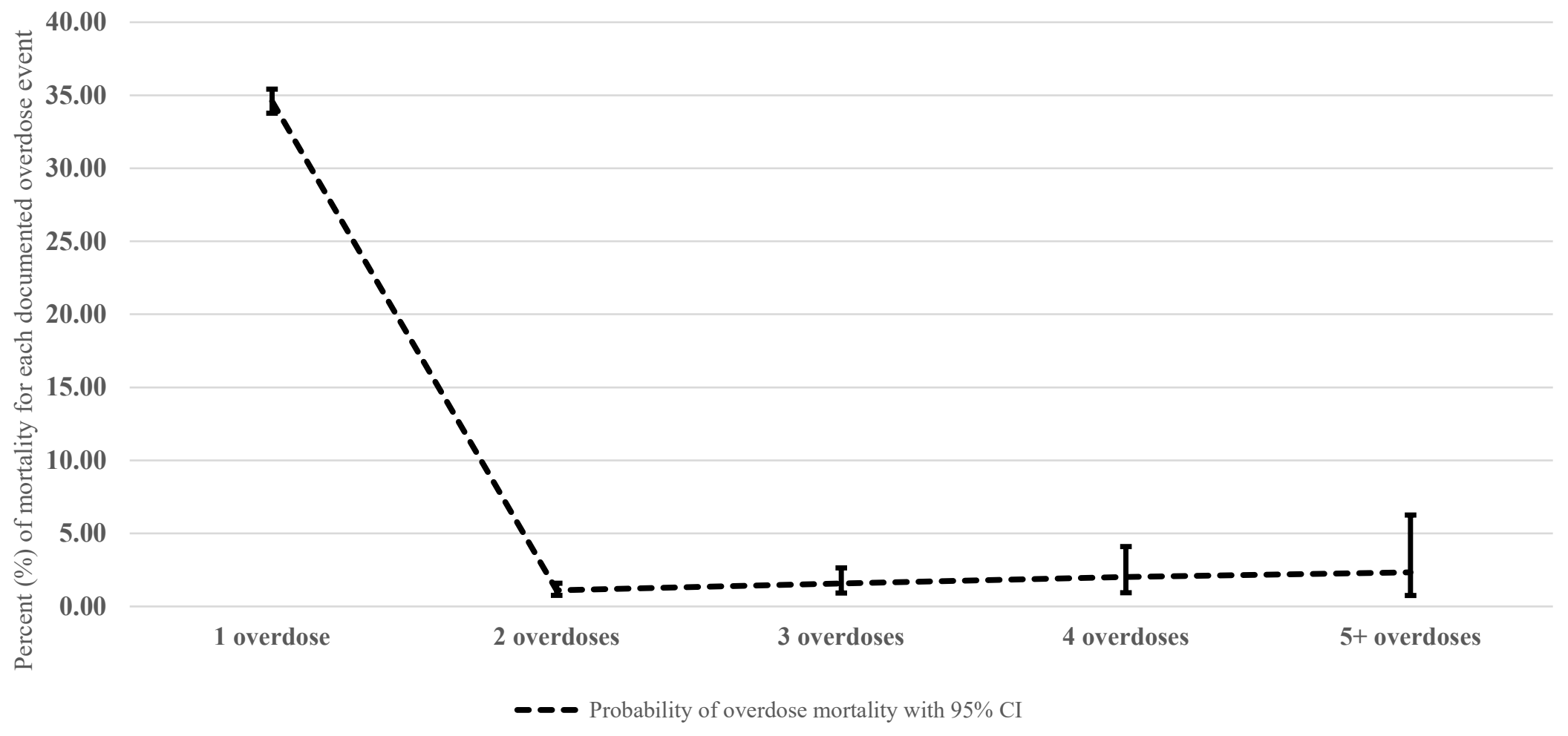

Abbreviations: CI, Confidence Interval 
Chapter 4 


\subsection{Abstract}

\section{Objective}

To identify cause-specific mortality rates and calculate standardized mortality rate ratios (SMRs) among veterans with a prior nonfatal opioid overdose.

\section{Methods}

We followed 8,370 veterans who received medical care for a nonfatal opioid overdose between January 1, 2011 and December 31, 2015 or date of death, whichever occurred first. Mortality records were extracted from the Department of Veteran Affairs (VA)/Department of Defense (DoD) Joint Suicide (all-cause) Data Repository (SDR) and linked to clinical records from the Veterans Health Administration (VHA). We compared the mortality rates among those with a nonfatal opioid overdose to a 5\% stratified random sample of patients accessing services during the same time period $(n=325,073)$. SMRs were calculated using age-adjusted cause-specific mortality rates for the general U.S. population obtained from the Centers for Disease Control and Prevention's Wide-Ranging Online Data for Epidemiologic Research (CDC WONDER).

\section{Results}

The study cohort included 8,370 veterans with history of a nonfatal opioid overdose resulting in a total of 39,207 person-years of follow-up. The crude mortality for veterans with a history of a nonfatal overdose was 370.6 per 10,000 person years and SMR was 26.2 (95\% CI [confidence interval]: 24.6-27.6). The most common causes of death among these veterans of interest were deaths associated with the circulatory system (26.7\%), cancer (19.3\%), deaths associated with the respiratory system $(13.1 \%)$ and drug-related deaths $(11.6 \%)$. Those with a prior nonfatal overdose had a higher risk of substance-related mortality (aHR [adjusted Hazard Ratio] 5.0, 95\% 
CI 4.4-5.8), including a higher risk of death from drugs (aHR 6.9; 95\% CI 5.8-8.1) and alcohol (aHR 2.7, 95\% CI 2.1-3.6). For cause-specific mortalities assessed between veterans and the general U.S. population, SMRs were also highest for deaths associated with substances (114.0, 95\% CI 98.8-128.7), including drugs (139.3, 95\% CI 118.6-160.7) and alcohol (72.7, 95\% CI

53.5-92.4). As expected, SMRs for viral hepatitis (107.4, 95\% CI 65.5-152.7) and liver cancers (68.2, 95\% CI 47.9-88.7) were substantially higher when compared to rates for these outcomes in the U.S. general population. Other cause-specific diseases that were elevated included suicide (29.0, 95\% CI 20.0-38.2) and HIV (34.9, 95\% CI 10.7-58.9). Deaths related to the digestive system (45.2, 95\% CI 36.7-53.7) and respiratory system $(35.4,30.4-40.4)$ were also markedly higher than the general population.

\section{Conclusion}

Veterans with a prior nonfatal overdose experienced a substantially higher mortality rate when compared to other veterans or the general U.S. population. Specific causes of death that were significantly higher include those related to substance use and mental health, highlighting the importance of integrated treatment and recovery services for patients with record of one or more opioid overdose. The significant increase in suicide deaths among veterans, especially among those with history of a prior overdose, supports the need for continued mental health screenings. These findings highlight the need for additional research examining substance use, in particular polysubstance use and associated risk for subsequent mortality among persons with history of one or more nonfatal overdose. Future research should consider whether associations identified in these analyses are different for patients from other health care systems or for those without history of U.S. military service. 


\subsection{Introduction}

Overdoses have surged in the past decade and are now the leading cause of accidental death in the United States. More than $60 \%$ of overdose deaths across the nation can be attributed to opioids[1] [2-5]. Between 2007 and 2017 the opioid overdose death rate more than doubled, from 6.1 per 100,000 to 14.9 per 100,000 [6]. Around the same time, nonfatal opioid overdoses resulting in inpatient and emergency department visits substantially increased, by more than $60 \%$ and $99 \%$ respectively[7]. The rise in opioid overdoses across the United States has been estimated to cost more than $\$ 740$ million annually [8]. Despite the recent surge of nonfatal overdoses and associated mortality associated with opioid abuse/misuse, little is known regarding the patterns of mortality following a nonfatal opioid overdose.

People who inject drugs (PWID), people diagnosed with an opioid use disorder (OUD) and those taking more than 90 morphine milligram equivalent (MME) are at highest risk for experiencing an opioid overdose [9-12]. Although overdoses are the leading cause of death among PWID, research has found that PWID more often die from infection-related causes such as human immunodeficiency virus (HIV), Hepatitis C (HCV), and other substance-related deaths [13-15]. Similarly, research suggests that people with an OUD more often die from infectious disease and liver disease when compared to the general population $[13,16]$. Patients taking a high volume of MME are often suffering from terminal cancer or chronic diseases associated with severe pain $[9,12,17]$. Several public health interventions have been developed to encourage safer prescribing practices and educate patients on opioid use, especially for those with high MME such as those with chronic non-cancer pain $[9,18]$. Although many of these programs have been found to reduce the supply of prescription opioids [11], there is still little known regarding the complex nature of overdose and subsequent mortality. Research among Medicaid enrollees 
suggests that mortality following a nonfatal overdose are often associated with substances, suicide, cancer, and the circulatory system however, cause-specific mortality among veterans using VHA services has yet to be examined [19]. The overarching objective of this study is to assess the cause specific mortality among veterans with a documented nonfatal opioid overdose. In order to describe the mortality for specific causes of deaths among veterans with a nonfatal overdose, we will examine the mortality following a nonfatal overdose to a comparison group comprised of a 5\% random sample of other veterans using VHA services. We will then compare the mortality among veterans with a nonfatal opioid overdose to the general population.

Given previous research examining mortality among veterans with an OUD, we expected substance-related deaths to be significantly higher among this population [13, 16, 19-21]. We also expected suicide death rates to be substantially higher given that veterans have almost double the suicide death rate than the general population and previous research suggest that people with a history of a nonfatal overdose had higher suicide death rates [19, 22, 23]. Similarly, we expected deaths attributed to hepatitis to be significantly higher among our veteran cohort, given that prevalence of hepatitis is two-times higher than non-veterans and is higher among those with a history of drug use [13, 16, 24-26].

\subsection{Methods}

In order to determine mortality following a nonfatal overdose among veterans, we examined causes of death linking clinical and mortality files from the Veterans Health Administration (VHA), which is the largest integrated healthcare provider in the United States. We extracted records on individuals with a documented opioid overdose between January 1, 2011 and September 30, 2015 and identified corresponding causes of death, if any, among this cohort. 
The study cohort examined clinical and death records for $10,522,835$ records to identify veterans with a documented opioid overdose and veterans with no documented overdose for the comparison group. Veterans were identified as having an opioid overdose using clinical records from the VHA Corporate Data Warehouse (CDW)[27]. CDW records were linked with the VA/DoD Suicide Data Repository, using Social Security Numbers (SSNs)[28, 29]. Sex and age were extracted from the SDR and CDW. Age was fixed and determined at the start of the study period. Age-adjusted mortality rates for each cause of death of interest were pulled from the Centers for Disease Control and Prevention Wide-Ranging Online Data for Epidemiologic Research (CDC WONDER) Detailed Compressed Mortality Files from 2011 through 2015 [6]. To more precisely compare age-adjusted mortality rates with the veteran population we pulled age-adjusted rates among 15-84 year old U.S. residents using CDC WONDER.

This study was reviewed and approved by the Institutional Review Board at the Syracuse VA Medical Center, New York.

\section{Study sample}

A nonfatal opioid overdose was identified using International Classification of Disease, Ninth Edition (ICD-9) codes: 965.00-965.02, 965.09, E850.0-E850.2 and ICD Tenth Edition (ICD-10) codes: X40-X44, X60-X64, X85, Y10-Y14 with secondary axis codes: T40.0-T40.4 and T40.6. The first opioid overdose documented in the clinical records was used as the index overdose. Those who died from a fatal index overdose were excluded from analyses.

A control group was constructed by extracting a 5\% random sample of veterans, stratified by sex and age. Age was collapsed into three categories: ages 18-44, 45-64 and over 65 years old. Pulling a stratified random sample allowed the control group to be similar in composition to 
those with a nonfatal overdose[30]. Given that VHA users are primarily older males, we intentionally stratified by sex and age to reduce potential bias that may influence observed mortality among the control group. The use of stratified random sample control populations has been used in previous research among the VHA patient population [20, 31, 32].

\section{Exclusion criteria}

The study cohort was restricted to veterans between 18 and 90 years old. We excluded patients that had no follow-up visits within one year of the first overdose event or had a nonfatal overdose in the last three months of the study period (October 1, 2015 - December 1, 2015). This mitigated potential bias among those with less than three months of risk for mortality. After applying this inclusion and exclusion criteria, 8,370 veterans were identified for the nonfatal overdose group and 325,073 veterans with no documented overdose as the comparison group.

\section{Mortality}

We evaluated mortality from January 1, 2011 through December 31, 2015. Follow-up for the study ended the day the veteran died or the end of the study period, whichever occurred first. In addition to all-cause mortality, cause-specific mortality was considered for the following: all external causes of death, suicide, homicide, accidents, substance-related deaths, drug-related deaths, alcohol-related deaths, infectious, viral hepatitis, human immunodeficiency virus (HIV), circulatory system, respiratory system, influenza, chronic respiratory disease, digestive system, cirrhosis and alcoholic liver disease and cancers. Specific types of cancers were categorized into the following groups using the International Classification of Diseases for Oncology[33]: lung and bronchus, liver and intrahepatic bile duct, digestive system cancers, which included esophageal, stomach, small intestine, colon, rectal, anal, gallbladder and pancreatic cancers, 
lymphoma and leukemia and other cancers. (See Supplement Table 1 for the full list of causespecific mortality and corresponding ICD-10 codes).

Analysis

We identified person-years of follow-up and mortality rates per 10,000 person-years for the entire cohort to compare mortality among veterans with a history of nonfatal overdose to a comparison group of veterans. Crude death rates were calculated and mortality rates were estimated using Cox proportional hazard models, adjusting for age and sex. Survival curves were relatively close, indicating the hazard ratio remained constant over time [34]. Adjusted hazard ratios [aHR] and corresponding 95\% confidence interval [CI] were calculated for cause-specific mortality.

We calculated the standardized mortality rate ratios (SMRs) to compare the observed number of deaths among our overdose cohort to the number of expected number based on rates of mortality among members of the U.S. general population $[35,36]$. The expected number of deaths was calculated using age-adjusted mortality rates from CDC WONDER and corresponding cohort size[6].

Alpha was set to 0.05 for all statistical tests. We analyzed data using SAS Enterprise Grid software (version 5.1, SAS Institute Inc.).

\subsection{Results}

This study identified 8,370 veterans with a history of nonfatal opioid overdose and a total followup of 39,207 person-years. Among this cohort of veterans with history of a nonfatal overdose, approximately $17.4 \%(\mathrm{n}=1,453)$ experienced death during the follow-up period. The proportion of veterans who died following a nonfatal overdose was similar to the proportion of veterans 
who died in the control group $(17.6 \%, \mathrm{n}=57,099)$. Despite the similar proportion of deaths among each group, there were distinct differences in cause-specific mortality rates and corresponding SMRs. The overall crude mortality rate for veterans with a prior overdose was 370.6 per 10,000 person-years and for the control group was 384.1 per 100,000 person-years. Compared to the control group, veterans with a nonfatal opioid overdose had a higher risk of allcause mortality after adjusting for age and gender (aHR 1.5; 95\% CI 1.4-1.5). (Table 1)

The most common causes of death among veterans with a prior nonfatal overdose were disorders of the circulatory system $(26.7 \%)$, cancer $(19.3 \%)$, respiratory disorders $(13.1 \%)$, and drugrelated deaths $(11.6 \%)$. The veteran cohort with a prior nonfatal overdose was more than six times likely to die from substance-related diseases (aHR [Adjusted Hazard Ratio] 5.0, 95\% CI [ Confidence Interval]: 4.4-5.8) and more than six times (aHR 6.9, 95\% CI 5.8-8.1) likely to die from drug-related diseases compared to their veteran peers. These veterans were more than three times as likely to die from hepatitis (aHR 3.2, 95\% CI: 2.1-4.9) and cirrhosis or alcoholic liver disease than their veteran peers (aHR 3.1, 95\% CI: 2.4-3.9). Veterans with a prior overdose were also more than two times more likely to die from suicide than their veteran peers (aHR 2.2, 95\% CI: 1.6-3.1). Further, these veterans were twice as likely to die of diseases associated with the digestive system (aHR 2.3, 95\% CI: 1.9-2.8), chronic respiratory disease (aHR 2.2, 95\% CI: 1.63.1) and HIV (aHR 2.6, 95\% CI: 1.3-5.4).

Similarly, they had an elevated risk of death from viral hepatitis (aHR 3.2, 95\% CI 2.1-4.9) and cirrhosis and alcoholic liver disease (aHR 3.1, 95\% CI 2.4-3.9). These veterans had a higher risk of death attributed to HIV (aHR 2.6, 95\% CI 1.3-5.4), cancer of the liver or intrahepatic bile duct (aHR 2.3, 95\% CI 1.7-3.2), or death associated with the digestive system (aHR 2.3, 95\% CI 2.3, 95\% CI 1.9-2.8). Of note, death from suicide was markedly higher among veterans with a prior 
nonfatal overdose compared to the control group of veterans (aHR 2.2, 95\% CI 1.6-3.1). Conversely, veterans with history of an overdose were significantly less likely to die from lymphoma or leukemia (aHR $0.5,95 \%$ CI 0.2-0.9) compared to veterans in the control group.

Among cause-specific mortalities assessed and compared to the US population, SMRs were more than eight times higher among veterans with a prior overdose. SMRs were highest for deaths associated with substances (114.0, 95\% CI: 98.8-128.7); including drugs (139.3, 95\% CI: 118.6-160.7) and alcohol (72.7, 95\% CI: 53.5-92.4). SMRs for viral hepatitis (107.4, 95\% CI: 65.5-152.7) and liver cancers (68.2, 95\% CI: 47.9-88.7) were substantially higher among veterans with history of a nonfatal opioid overdose. Other cause-specific disease that were elevated in this population include HIV (34.9, 95\% CI: 10.7-58.9), suicide (29.0, 95\% CI: 20.038.2), and deaths related to the digestive system (45.2, 95\% CI: 36.7-53.7). (Table 2)

\subsection{Discussion}

Veterans with a documented nonfatal opioid overdose died at 26 times the rate of the general U.S. population aged 15-84 years. Moreover, mortality was markedly higher among veterans with a prior nonfatal overdose when compared to a comparison population of veterans who use VHA services or the general U.S. population (aHR 1.46, 95\% CI: 1.39-1.54). These findings suggest that excess mortality among veterans with a prior nonfatal overdose may be associated with patterns and consequences of substance use. Mortality associated with substance use for veterans with a prior nonfatal overdose was significantly elevated among those with a prior nonfatal overdose. The rate of alcohol-related deaths was 72 times higher than the rate of alcohol-related deaths in the general population. 
Similarly, veterans with a prior nonfatal overdose had noticeably higher rates of death compared to other veterans, specifically for deaths associated with drugs (aHR 6.85 95\% CI: 5.79-8.09), viral hepatitis (aHR 3.22, 95\% CI: 2.11-4.93), cirrhosis and alcoholic liver disease (aHR 3.05, 95\% CI 2.38-3.90). These findings suggest excess mortality among veterans with a nonfatal overdose can be largely attributed to substance abuse. Although deaths associated with substance use accounted for a majority of deaths, disease of the digestive and respiratory system were elevated in this population as well. Additional research is need to understand the intersection of certain comorbidities related to the digestive system and overdose risk.

There were some distinct differences when comparing results from this study to an existing study examining mortality following a nonfatal overdose among a sample of Medicaid enrollees [19]. The all-cause SMR and drug-related deaths were similar between both the veteran population and Medicaid enrollees. In general, the cause-specific deaths listed in both studies were elevated among the veteran population and HIV was the only cause-specific death in both studies that was lower among the Medicaid population. The most notable difference in our study was the SMR for alcohol-related deaths, the veteran population had an SMR more than seven times higher than the study article. Deaths associated with cirrhosis and alcoholic liver disease were more than four times higher and deaths associated with viral hepatitis were more than three times higher. This finding may be attributed to high rates of HCV among veterans from the Vietnam Era [24-26].

These findings parallel previous research suggesting a deeper understanding of the complex relationship between overdose and self-harm [23, 37-39]. Importantly, deaths from suicide were markedly higher among our cohort of veterans with a prior opioid overdose compared to the general population and a random sample of veterans from the VHA using population. This finding alone suggests the need for continued support and comprehensive services aimed at 
reducing suicide among veterans. Mental health services, such as post-discharge psychiatric care may benefit patients with history a nonfatal overdose [40-42]. A documented overdose may provide opportunities to initiate treatment or other prevention programs such as naloxone distribution or provide mental health screening given the elevated mortality associated with suicide and substance-related deaths.

\section{Strengths and limitations}

Although this study utilized data from one of the nation's largest healthcare networks, analyses were contingent on patients seeking medical care for healthcare needs such as an overdose. The large sample size provided the statistical power needed to detect differences in risk for mortality. Despite the large sample size, this study had several limitations. Previous studies have shown that barriers often impede healthcare treatment for OUD, which could influence findings from this study[43]. Results from this study may underestimate the magnitude of nonfatal overdoses and subsequent mortality among veterans[44]. Furthermore, these results may not be generalizable to the US population given the heterogeneous composition of veterans seeking healthcare [45-47].

\section{Conclusion}

Given the rise in opioid overdoses across the US, there is an urgent need to understand excess mortality among people who experience a nonfatal overdose to inform future clinical and public health efforts. Veterans with a history of nonfatal overdose are significantly more likely to die from any cause, specifically deaths associated with substance use and suicide. Additional research is needed to determine the relationship between psychiatric diagnoses, substance use 
and overdose risk over time. These findings underscore the need for coordinated health care, with particular emphasis on mental health care among those with a prior overdose. 


\section{References}

1. Hedegaard, H., M. Warner, and A.M. Minino, Drug Overdose Deaths in the United States, 1999-2016. NCHS Data Brief, 2017(294).

2. $\quad$ Rudd, R.A., et al., Increases in Drug and Opioid Overdose Deaths--United States, 20002014. MMWR Morb Mortal Wkly Rep, 2016. 64(50-51): p. 1378-82.

3. Rudd, R.A., et al., Increases in Drug and Opioid-Involved Overdose Deaths - United States, 2010-2015. MMWR Morb Mortal Wkly Rep, 2016. 65(5051): p. 1445-1452.

4. Seth, P., et al., Overdose Deaths Involving Opioids, Cocaine, and Psychostimulants United States, 2015-2016. MMWR. Morbidity and mortality weekly report, 2018. 67(12): p. 349-358.

5. Scholl, L., et al., Drug and Opioid-Involved Overdose Deaths - United States, 20132017. MMWR. Morbidity and Mortality Weekly Report, 2018. 67(5152).

6. Centers for Disease Control and Prevention, C., CDC WONDER online database. 2018.

7. Weiss, A.J., et al., Opioid-Related Inpatient Stays and Emergency Department Visits by State, 2009-2014: Statistical Brief \#219, in Healthcare Cost and Utilization Project (HCUP) Statistical Briefs. 2017: Rockville (MD).

8. Hsu, D.J., et al., Hospitalizations, costs and outcomes associated with heroin and prescription opioid overdoses in the United States 2001-12. Addiction, 2017. 112(9): p. 1558-1564.

9. Gwira Baumblatt, J.A., et al., High-risk use by patients prescribed opioids for pain and its role in overdose deaths. JAMA internal medicine, 2014. 174(5): p. 796-801.

10. Hall, A.J., et al., Patterns of abuse among unintentional pharmaceutical overdose fatalities. JAMA, 2008. 300(22): p. 2613-20.

11. Paulozzi, L.J., E.M. Kilbourne, and H.A.B.A.H.A.G.U.S.A. Desai, Prescription Drug Monitoring Programs and Death Rates from Drug Overdose. Pain Medicine, 2011. 12(5): p. 747-754.

12. Paulozzi, M.P.H.L.J., et al., A History of Being Prescribed Controlled Substances and Risk of Drug Overdose Death. Pain Medicine, 2012. 13(1).

13. Degenhardt, L., et al., Causes of death in a cohort treated for opioid dependence between 1985 and 2005. Addiction, 2014. 109(1): p. 90-99.

14. Mathers, Bradley M., et al., Mortality among people who inject drugs: a systematic review and meta-analysis. Bulletin of the World Health Organization, 2013. 91(2): p. 102-123.

15. Tyndall, M.W., et al., Impact of HIV infection on mortality in a cohort of injection drug users. Journal of acquired immune deficiency syndromes (1999), 2001. 28(4): p. 351-7.

16. Larney, S., et al., Mortality among older adults with opioid use disorders in the Veteran's Health Administration, 2000-2011. Drug and Alcohol Dependence, 2015. 147: p. 32-37.

17. Paulozzi, L.J., Prescription drug overdoses: A review. Journal of Safety Research, 2012. 43(4): p. 283.

18. Brady, K.T., J.L. McCauley, and S.E. Back, Prescription Opioid Misuse, Abuse, and Treatment in the United States: An Update. Am J Psychiatry, 2016. 173(1): p. 18-26.

19. Olfson, M., et al., Risks of fatal opioid overdose during the first year following nonfatal overdose. Drug and Alcohol Dependence, 2018. 190: p. 112-119.

20. Bohnert, A.S., et al., Risk of death from accidental overdose associated with psychiatric and substance use disorders. Am J Psychiatry, 2012. 169(1): p. 64-70. 
21. Bohnert, A.S., et al., A Detailed Exploration Into the Association of Prescribed Opioid Dosage and Overdose Deaths Among Patients With Chronic Pain. Med Care, 2016. 54(5): p. 435-41.

22. Administration, V.H., Veteran Suicide Data Report, 2005-2016. 2018. Office of Mental Health and Suicide Prevention.

23. Bohnert, K.M., et al., Substance use disorders and the risk of suicide mortality among men and women in the US Veterans Health Administration. Addiction, 2017. 112(7): p. 1193-1201.

24. Backus, L.I., et al., Hepatitis $C$ virus screening and prevalence among US veterans in Department of Veterans Affairs care. JAMA internal medicine, 2013. 173(16): p. 154952.

25. Dominitz, J.A., et al., Elevated prevalence of hepatitis $C$ infection in users of United States veterans medical centers. Hepatology (Baltimore, Md.), 2005. 41(1): p. 88-96.

26. Mishra, G., et al., Risk Factors for Hepatitis C Virus Infection Among Patients Receiving Health Care in a Department of Veterans Affairs Hospital. Digestive Diseases and Sciences, 2003. 48(4): p. 815-820.

27. VHA, Veterans Health Administration inpatient and outpatient care data: an overview. Effective Clinical Practice, 2002.

28. Bossarte, R.M., An overview of VA/DoD joint mortality data repository and data from studies conducted by the epidemiology program in VA's Office of Public Health. 2014.

29. $\quad$ Statistics, N.C.f.H., National Death Index user's guide. 2013.

30. Gebregziabher, M., et al., Fitting parametric random effects models in very large data sets with application to VHA national data. BMC Medical Research Methodology, 2012. 12(1): p. 1-14.

31. Park, T.W., et al., Benzodiazepine prescribing patterns and deaths from drug overdose among US veterans receiving opioid analgesics: case-cohort study. BMJ, 2015. 350: p. h2698.

32. Gradus, J.L., et al., Predictors of suicidal ideation in a gender-stratified sample of OEF/OIF veterans. Suicide \& life-threatening behavior, 2013. 43(5): p. 574-88.

33. Fritz, A.G., International classification of diseases for oncology. 3rd ed. ed. 2000, Geneva, Switzerland: U.S. Dept. of Health and Human Services ;World Health Organization.

34. Kleinbaum, D.G. and M. Klein, Survival analysis : a self-learning text. 2012, Springer: New York, NY.

35. Le, C.T. and L.E. Eberly, Introductory biostatistics. 2016: John Wiley \& Sons.

36. Szklo, M. and F.J. Nieto, Epidemiology: beyond the basics. 2014: Jones \& Bartlett Publishers.

37. Bohnert, A.S., et al., Misclassification of suicide deaths: examining the psychiatric history of overdose decedents. Inj Prev, 2013. 19(5): p. 326-30.

38. Bohnert, A.S., K. Roeder, and M.A. Ilgen, Unintentional overdose and suicide among substance users: a review of overlap and risk factors. Drug Alcohol Depend, 2010. 110(3): p. 183-92.

39. Rockett, I.R., et al., Suicide and unintentional poisoning mortality trends in the United States, 1987-2006: two unrelated phenomena? BMC public health, 2010. 10: p. 705.

40. Bohnert, A.S.B., et al., Overdose and adverse drug event experiences among adult patients in the emergency department. Addictive Behaviors, 2018. 86: p. 66-72. 
41. Vallersnes, O.M., et al., Mortality and repeated poisoning after self-discharge during treatment for acute poisoning by substances of abuse: a prospective observational cohort study. BMC Emerg Med, 2019. 19(1): p. 5.

42. Vallersnes, O.M., et al. Factors associated with rapidly repeated acute poisoning by substances of abuse: a prospective observational cohort study. BMC Research Notes, 2018. 11, 1-4 DOI: 10.1186/s13104-018-3834-3.

43. Gordon, A.J., et al., Facilitators and barriers in implementing buprenorphine in the Veterans Health Administration. Psychol Addict Behav, 2011. 25(2): p. 215-24.

44. Di Rico, R., et al., Drug overdose in the ED: a record linkage study examining emergency department ICD-10 coding practices in a cohort of people who inject drugs. BMC health services research, 2018. 18(1): p. 945.

45. VA, D.o.V.A., VA utilization profile, FY 2016. 2017.

46. Dursa, E.K., et al., Demographic, military, and health characteristics of VA health care users and nonusers who served in or during operation enduring freedom or operation iraqi freedom, 2009-2011. Public Health Reports, 2016. 131(6): p. 839-843.

47. Young, G.J., M. Meterko, and K.R. Desai, Patient Satisfaction With Hospital Care: Effects of Demographic and Institutional Characteristics. Medical Care, 2000. 38(3): p. 325-334. 
Tables and Figures 
Table 1. Mortality rate (per 10,000 person-years) among veterans with a nonfatal index OD ( $\mathrm{n}=8,370)$ compared to a $5 \%$ stratified random sample of veterans $(\mathrm{n}=325,073)^{\mathrm{a}}$

\begin{tabular}{|c|c|c|c|c|c|c|c|c|c|}
\hline \multirow[b]{2}{*}{ Cause of death } & \multicolumn{2}{|c|}{ Nonfatal OD } & \multicolumn{2}{|c|}{ Control group } & \multirow{2}{*}{$\begin{array}{c}\text { Hazard } \\
\text { ratio of } \\
\text { mortality }\end{array}$} & \multirow{2}{*}{$\begin{array}{r}95 \% \text { CI } \\
\text { Hazard } \\
\text { Ratio }\end{array}$} & \multirow{2}{*}{$\begin{array}{r}\text { Adjusted } \\
\text { Hazard } \\
\text { ratio of } \\
\text { mortality } b\end{array}$} & \multirow{2}{*}{$\begin{array}{r}95 \% \text { CI } \\
\text { Adjusted } \\
\text { Hazard } \\
\text { Ratio }^{b}\end{array}$} & \multirow[b]{2}{*}{ p-value } \\
\hline & $\begin{array}{r}\text { No. of } \\
\text { deaths } \\
\end{array}$ & $\begin{array}{r}\text { Crude mortality } \\
\text { rate }\end{array}$ & $\begin{array}{r}\text { No. of } \\
\text { deaths }\end{array}$ & $\begin{array}{r}\text { mortality } \\
\text { rate } \\
\end{array}$ & & & & & \\
\hline Opioid overdose & 59 & 15.05 & & - & - & - & - & - & - \\
\hline External Cause of death & 69 & 17.60 & 1,509 & 10.15 & $1.74 *$ & $(1.36-2.21)$ & $1.82 *$ & $(1.43-2.32)$ & $<0.001$ \\
\hline Suicide & 39 & 9.95 & 651 & 4.38 & $2.27 *$ & $(1.65-3.14)$ & $2.24 *$ & $(1.62-3.10)$ & $<0.001$ \\
\hline Homicide & 5 & 1.28 & 98 & 0.66 & 1.93 & $(0.79-4.75)$ & 1.71 & $(0.70-4.23)$ & 0.24 \\
\hline Accidents & 25 & 6.38 & 760 & 5.11 & 1.25 & $(0.84-1.86)$ & 1.43 & $(0.96-2.13)$ & 0.08 \\
\hline Substance-related & 223 & 56.88 & 1,474 & 9.91 & $5.74 *$ & $(4.98-6.61)$ & $5.03 *$ & $(4.36-5.80)$ & $<0.001$ \\
\hline Drug-related & 169 & 43.10 & 871 & 5.86 & $7.36^{*}$ & $(6.24-8.68)$ & $6.85^{*}$ & $(5.79-8.09)$ & $<0.001$ \\
\hline Alcohol-related & 54 & 13.77 & 603 & 4.06 & $3.40 *$ & $(2.57-4.49)$ & $2.73 *$ & $(2.06-3.61)$ & $<0.001$ \\
\hline Infectious & 55 & 14.03 & 1,393 & 9.37 & $1.50 *$ & $(1.14-1.96)$ & $1.89 *$ & $(1.44-2.49)$ & $<0.001$ \\
\hline Viral hepatitis & 24 & 6.12 & 203 & 1.37 & $4.48^{*}$ & $(2.94-6.84)$ & $3.22 *$ & $(2.11-4.93)$ & $<0.001$ \\
\hline$H I V$ & 8 & 2.04 & 83 & 0.56 & $3.66^{*}$ & $(1.77-7.56)$ & $2.63 *$ & $(1.27-5.44)$ & 0.01 \\
\hline Circulatory system & 388 & 98.96 & 18,312 & 123.17 & $0.80^{*}$ & $(0.73-0.89)$ & $1.29 *$ & $(1.16-1.42)$ & $<0.001$ \\
\hline Respiratory system & 191 & 48.72 & 6,730 & 45.27 & 1.08 & $(0.93-1.24)$ & $1.87 *$ & $(1.61-2.16)$ & $<0.001$ \\
\hline Influenza \& pneumonia & 23 & 5.87 & 1,219 & 8.20 & 0.72 & $(0.47-1.08)$ & 1.32 & $(0.87-2.00)$ & 0.19 \\
\hline Chronic respiratory disease & 139 & 35.45 & 4,051 & 27.25 & $1.30^{*}$ & $(1.10-1.54)$ & $2.18^{*}$ & $(1.83-2.58)$ & $<0.001$ \\
\hline Digestive system & 109 & 27.80 & 2,036 & 13.69 & $2.03 *$ & $(1.68-2.46)$ & $2.27 *$ & $(1.87-2.75)$ & $<0.001$ \\
\hline Cirrhosis \& alcoholic liver disease & 70 & 17.85 & 763 & 5.13 & $3.48^{*}$ & $(2.72-4.44)$ & $3.05 *$ & $(2.38-3.90)$ & $<0.001$ \\
\hline Cancers & 280 & 71.42 & 14,585 & 98.10 & $0.73 *$ & $(0.65-0.82)$ & 1.00 & $(0.88-1.12)$ & 0.97 \\
\hline Lung \& bronchus & 80 & 20.40 & 4,347 & 29.24 & $0.70^{*}$ & $(0.56-0.87)$ & 0.90 & $(0.72-1.13)$ & 0.38 \\
\hline Liver \& intrahepatic bile duct & 43 & 10.97 & 699 & 4.70 & $2.33 *$ & $(1.71-3.17)$ & $2.31 *$ & $(1.69-3.16)$ & $<0.001$ \\
\hline Digestive system & 42 & 10.71 & 2,780 & 18.70 & $0.57 *$ & $(0.42-0.78)$ & 0.77 & $(0.57-1.05)$ & 0.09 \\
\hline Lymphoma \& leukemia & 9 & 2.30 & 1,116 & 7.51 & $0.31 *$ & $(0.16-0.59)$ & $0.47 *$ & $(0.24-0.90)$ & $\mathbf{0 . 0 3}$ \\
\hline Other cancers & 106 & 27.04 & 5,643 & 37.96 & $0.71 *$ & $(0.59-0.86)$ & 1.06 & $(0.88-1.29)$ & 0.55 \\
\hline Any type of death & 1,453 & 370.59 & 57,099 & 384.06 & 0.97 & $(0.92-1.02)$ & $1.46^{*}$ & $(1.39-1.54)$ & $<0.001$ \\
\hline
\end{tabular}

Abbreviations: No, Number; CI, Confidence Interval; SMR, Standardized Mortality Rate Ratio; OD, overdose; HIV, human immunodeficiency virus

a. For those with a nonfatal OD there were 39,207 person-years follow-up. A control group was constructed using a 5\% random sample of veterans, stratified by sex and age stratum.

b. Adjusted for age and sex. 
Table 2. Standardized Mortality Ratios, observed, and expected number of deaths for veterans with a nonfatal index overdose for all causes and selected causes, $2011-2015$

\begin{tabular}{|c|c|c|c|c|c|}
\hline \multirow[b]{2}{*}{ Cause of death } & \multicolumn{2}{|c|}{ Nonfatal OD } & \multirow{2}{*}{$\begin{array}{r}\text { US Age-adjusted } \\
\text { rates }^{\mathrm{a}} \\
\begin{array}{r}\text { Expected } \\
\text { number of } \\
\text { deaths }^{\mathrm{b}}\end{array} \\
\end{array}$} & \multicolumn{2}{|c|}{$\begin{array}{l}\text { Standardized Mortality Rate Ratio } \\
\text { (95\% CI) }\end{array}$} \\
\hline & No. of deaths & $\begin{array}{r}\text { Crude mortality } \\
\text { rate }\end{array}$ & & $\mathbf{S M R}^{\mathrm{b}}$ & $95 \% \mathrm{CI}$ \\
\hline Opioid overdose & 59 & 15.05 & 0.91 & 64.73 & $(48.29-81.38)$ \\
\hline External Cause of death & 69 & 17.60 & 4.19 & 16.47 & $(12.58-20.35)$ \\
\hline Suicide & 39 & 9.95 & 1.34 & 29.01 & $(19.97-38.24)$ \\
\hline Homicide & 5 & 1.28 & 0.54 & 9.25 & $(1.14-17.38)$ \\
\hline Accidents & 25 & 6.38 & 2.30 & 10.85 & $(6.61-15.13)$ \\
\hline Substance-related & 223 & 56.88 & 1.96 & 113.96 & $(98.84-128.71)$ \\
\hline Drug-related & 169 & 43.10 & 1.21 & 139.25 & $(118.62-160.73)$ \\
\hline Alcohol-related & 54 & 13.77 & 0.74 & 72.65 & $(53.51-92.44)$ \\
\hline Infectious & 55 & 14.03 & 1.65 & 33.36 & $(24.52-42.14)$ \\
\hline Viral hepatitis & 24 & 6.12 & 0.22 & 107.39 & $(65.45-152.74)$ \\
\hline$H I V$ & 8 & 2.04 & 0.23 & 34.88 & $(10.68-58.89)$ \\
\hline Circulatory system & 388 & 98.96 & 15.27 & 25.41 & $(22.88-27.94)$ \\
\hline Respiratory system & 191 & 48.72 & 5.40 & 35.40 & $(30.35-40.39)$ \\
\hline Influenza \& pneumonia & 23 & 5.87 & 0.94 & 24.45 & $(14.47-34.47)$ \\
\hline Chronic respiratory disease & 139 & 35.45 & 3.35 & 41.48 & $(34.59-48.39)$ \\
\hline Digestive system & 109 & 27.80 & 2.41 & 45.15 & $(36.74-53.72)$ \\
\hline Cirrhosis \& alcoholic liver disease & 70 & 17.85 & 1.07 & 65.29 & $(50.09-80.75)$ \\
\hline Cancer & 280 & 71.42 & 15.29 & 18.32 & $(16.17-20.46)$ \\
\hline Lung \& bronchus & 80 & 20.40 & 4.17 & 19.20 & $(14.98-23.39)$ \\
\hline Liver \& intrahepatic bile duct & 43 & 10.97 & 0.63 & 68.23 & $(47.85-88.65)$ \\
\hline Digestive system & 42 & 10.71 & 3.14 & 13.36 & $(9.33-17.42)$ \\
\hline Lymphoma \& leukemia & 9 & 2.30 & 1.06 & 8.47 & $(2.94-14.04)$ \\
\hline Other cancers & 106 & 27.04 & 6.14 & 17.27 & $(13.98-20.55)$ \\
\hline Any type of death & 1,453 & 370.59 & 55.41 & 26.22 & $(24.87-27.57)$ \\
\hline
\end{tabular}

Abbreviations: No, Number; CI, Confidence Interval; SMR, Standardized Mortality Rate Ratio

a. Mortality for US population was from the Centers for Disease Control and Prevention Wide-Ranging Online Data for Epidemiologic Research data (CDC WONDER).

b. Mortality rates and expected counts is by using age-adjusted mortality rates among 15-84 year olds. 
Supplemental Table ICD-10 Codes for cause-specific mortality

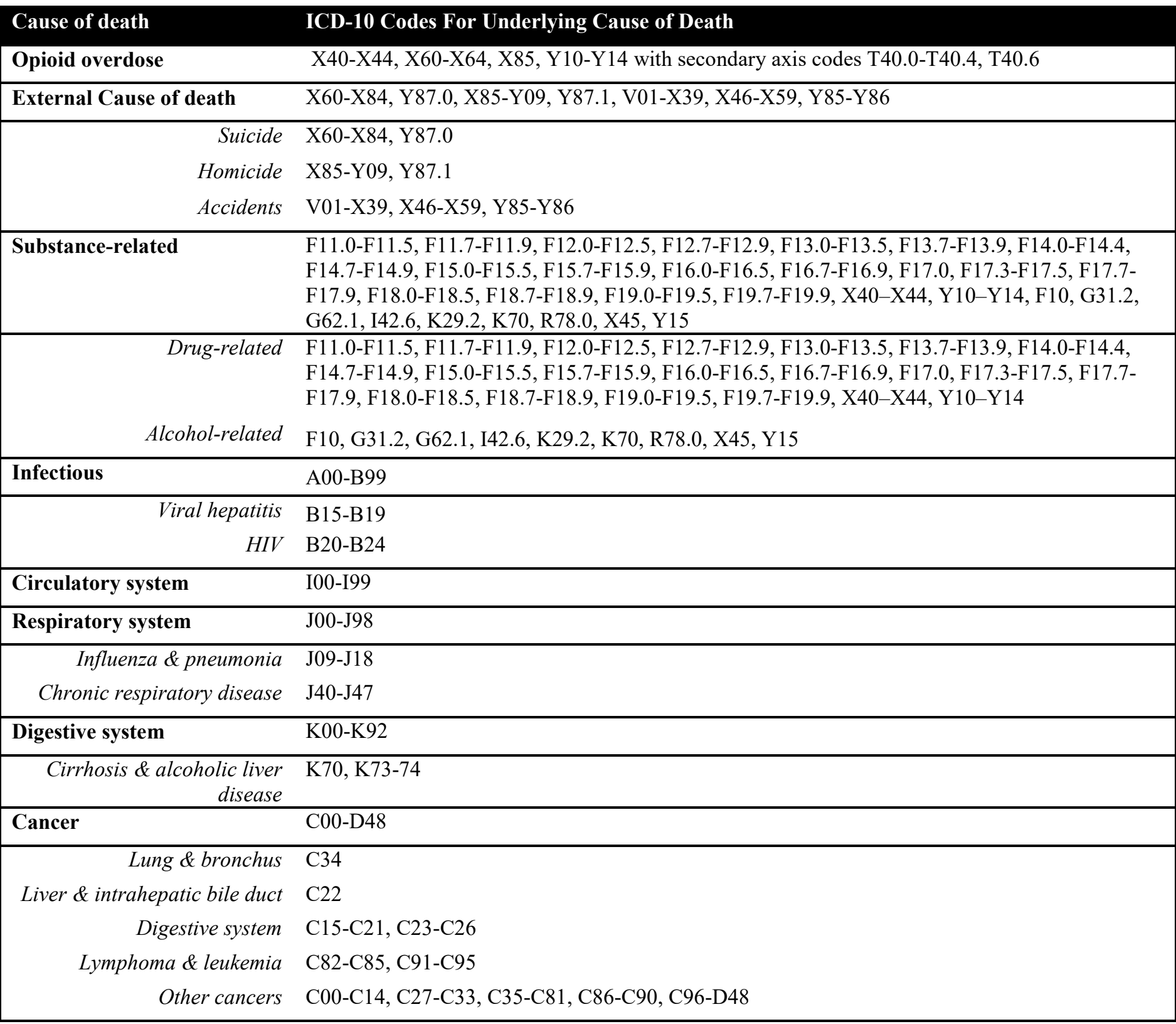

Abbreviations: ICD-10, International Classification of Diseases, Tenth Edition 


\section{Chapter 5}




\subsection{Summary}

This retrospective cohort study consisted of 13,333 patients with a documented opioid overdose, of any type, from January 1, 2011 to December 31, 2015. Among our cohort, 4,949 persons experienced a fatal overdose during the study period. Of note, we found that mortality from an opioid overdose was highest for an individual's index (i.e. first recorded in the electronic medical record) overdose $(98.8 \%, n=4,890)$, with only $1.2 \%(n=59)$ dying on a repeat overdose. Of those who survived their first overdose, $31.5 \%(n=2,659)$ had one or more repeat overdoses. Among those with a repeat overdose, we found that the conditional probability of repeat overdose increased in a linear fashion with the number of additional overdoses in the patient's medical records. In other words, the probability of having a fourth overdose was higher than the probability of having either a third or second overdose.

Although the U.S. has been experiencing an increase in overdoses for more than a decade there is still a limited understanding of risk for repeat overdose or whether factors associated with increased risk for repeat overdose are also associated with risk for overdose mortality. To answer these questions, we identified and compared risk factors for different overdose outcomes, including repeat overdose, available in VHA's electronic health record.

Patients between the ages of 18-64 years were the most likely to have record of a repeat overdose or fatal index overdose compared to those with record of only one non-fatal overdose. Men were more likely than women to die on their index overdose when compared to either repeat or single non-fatal overdose. (OR [odds ratio] 1.57, 95\% CI [confidence interval]: 1.34-1.83). Similarly, those with a chronic pain diagnosis were more likely to experience either a repeat overdose (OR 1.15, 95\% CI: 1.04-1.27) or fatal index overdose (OR 3.96, 95\% CI: 3.56-4.42), when compared to those with report of only one non-fatal overdose. Surprisingly, we found that patients with a 
mental health and substance abuse/dependence diagnosis were more likely to experience a repeat overdose and were less likely to die from a fatal index overdose. We also identified associations between patients receiving counseling prior to an overdose and lower likelihood of experiencing a fatal overdose (OR 0.35, 95\% CI: 0.30-0.40) and those who had been in MAT more than one year prior were more likely to experience a fatal index overdose (OR 1.28, 95\% CI:1.05-1.55). Neither of these factors were significantly associated with repeat overdose. Among those with a non-fatal overdose during the study period, we identified significantly increased rates for all-cause mortality when compared to risk for death among other veterans receiving VHA services. Veterans with record of a non-fatal overdose were five times (aHR 5.03, 95\% CI: 4.36-5.80) more likely to die from substance-related deaths than their veteran peers. Furthermore, they were more than three times as likely to die from viral hepatitis (aHR 3.22, 95\% CI: 2.11-4.93) or cirrhosis and alcohol-related liver disease (aHR 3.05, 95\% CI: 2.383.90). Despite the higher rate of suicide among veterans who use VHA services [1-3], those with a history of an opioid overdose were twice (aHR 2.24, 95\% CI: $1.62-3.10$ ) as likely to die from suicide as their veteran peers who also used VHA services.

Standardized mortality rate ratios (SMR) were calculated to identify differences in the number of observed deaths to the number of expected deaths for cause-specific mortality in the general U.S. population. Of the categories examined, veterans with a non-fatal overdose died at more than 139 times the rate of drug-related deaths, more than 114 times the rate for substance-related deaths and more than 72 times the rate for alcohol-related deaths than the general U.S. population. Moreover, veterans with a history of an opioid overdose died at more than 100 times the rate from viral hepatitis, more than 68 times the rate of liver and intrahepatic bile duct cancer, and more than 65 times the rate for cirrhosis and alcoholic-related liver disease than the general 
population. Overall, we found that veterans with a history of non-fatal overdose died at approximately 26 times the rate of all-cause mortality than observed in the general population.

Overall, these findings highlight the need for additional public health and clinical interventions for those at risk of overdose. Prevention programs designed to reduce opioid overdose mortality should focus on primary prevention efforts, such as reaching veterans who may not have been identified as having a substance abuse or dependence problem and should tailor these programs to engage veterans who are young to middle aged adults. These findings suggest healthcare providers and health system administrators should prepare for a rise in patients with repeat overdose history and should work to coordinate these patients with mental and physical health care as needed. Lastly, these findings suggest a need to address excess mortality risk among people with a history of non-fatal overdose. Findings from this project describe the magnitude of excess mortality among people with a history of a non-fatal overdose, especially causes of death related to substances; including drugs or alcohol.

\subsection{Significance}

In the United States, the opioid overdose death rate nearly doubled in four years between 2013 to 2017 (7.9 to 14.0 per 100,000), highlighting the urgent need to understand ways public health and clinical efforts can address rising morbidity and mortality associated with opioid abuse and misuse [4-9]. This study sought to identify the potential differences in risk for non-fatal, repeated and fatal overdose, which are all of growing concern. To date, little is known about the magnitude of repeat overdoses that occur within a clinical setting and the overdose event that is associated with the highest overdose mortality.

Understanding risk factors for fatal overdose and repeat overdose can inform public health and clinical efforts to combat the rise in mortality and morbidity associated with opioid overdoses. 
The project specifically assessed the number of non-fatal overdoses and risk for mortality or repeated events. Results from this project parallel findings from previous research, which suggests the need for additional mental health programs and treatment for those who experience an opioid overdose. These findings also underscore the need to amplify primary prevention efforts targeted to those who may not have experienced a previous overdose, specifically those between the ages of 18 and 64 years.

This study was not without limitations. First, we were only able to examine opioid overdoses that were documented in VHA's clinical or mortality records. It is possible that the true number of opioid overdoses among this patient population was underestimated. Moreover, patients may have sought health services not associated with VHA, which could also bias results and limit consideration of associated characteristics. This study was conducted using data from veterans using VHA healthcare services, who often report a greater number of physical and mental health conditions compared to the general population $[10,11]$. It is possible that patients with different physical and mental health comorbidities are associated with differential patterns of health care services and likelihood that overdose history is assessed and recorded. These analyses were conducted among patients seeking medical care which could lead to Berksonian bias, due to the difference in overall health among populations studied [12]. However, using comparison groups and stratifying by potential confounding features such as sex and age aided to reduce potential bias that may occur. Lastly, using clinical records with mortality files could have resulted in a missed deaths resulting in an underestimate of true mortality. However, records were required to match fully on SSN and 80-90\% on additional demographics such as name, date of birth, and sex $[2,13,14]$. Diagnostic codes in clinical records are not always a true representation the number of patients meeting diagnostic criteria. Clinical records are reliant on medical professionals 
inputting them into the electronic health records therefore certain diagnostic codes, in particular the social codes, may be underutilized and lead to an underestimate in the patient population [15, $16]$.

Although this study used clinical records which have inherent limitations, to the best of our knowledge, this was the first study to explore multiple overdose outcomes and compare risk factors for category of overdose using a comprehensive list of potential medical and contextual characteristics including demographic, chronic pain diagnoses, mental health diagnoses, and social codes, which served as indicators of social determinants of health. Findings from this study could be useful in informing clinical tools developed by the VA, such as a clinical dashboard, which is used to identify patients at risk for an adverse event related to opioids, by integrating contextual factors that may increase a patients risk for experiencing an overdose [1720].

\subsection{Future research}

These results indicate the need for additional research, specifically among those with cooccurring mental health and substance use disorders. While there are many public health interventions aimed at reducing the morbidity and mortality associated with overdoses, they have primarily focused on reducing the excess supply of prescription opioids. While some public health prevention efforts have demonstrated a reduction in overdose death, such as the implementation of prescription drug monitoring programs or the development of chronic pain guidelines, some researchers suggest this has pushed individuals to seek more potent nonprescription opioid options increasing risk for overdose morbidity and mortality [21-23]. Furthermore, public health and clinical interventions have been primarily developed to reduce the supply of opioids rather than reducing demand. Additional research is needed on initiation of 
substance abuse and misuse and motivation for initial misuse. Findings from this study suggest that additional comorbidities, specifically mental health comorbidities, may be the underlying factors driving the current overdose crisis and in turn may be factors associated initial misuse or abuse. While safer prescribing practices are necessary to mitigate initial abuse or misuse, a highlevel of stigma is present among people with an opioid use disorder (OUD) [24, 25]. Stigmareduction is essential in supporting individuals with a history of substance abuse or dependence, including reducing the stigma surround seeking treatment for the disease [26]. Although there is a prolific amount of research showing the effectiveness of Medication-Assisted Treatment (MAT) for OUD, additional barriers often impede patients from receiving necessary treatment. Infrastructure barriers such as provider willingness and access to providers who can prescribe MAT often deter patients from receiving treatment [20, 26-28]. Given our findings, which show that mortality is highest for the first documented overdose, there is an urgent need to remove potential barriers that may impede patients from seeking medical resources needed.

Future studies should also examine the conditional probability of repeat overdose and identify the overdose event that is associated with highest mortality in other populations. Furthermore, additional research is needed to elucidate the relationship between psychiatric comorbidities and overdose risk. Mental health diagnosis and related conditions, including substance abuse or dependence, are suggested to be the driving factors for the rise in opioid overdoses. Because of this, additional research is also needed to understand the best treatment for individuals with cooccurring mental health diagnoses or a history of polysubstance use.

\subsection{Conclusions}

Understanding risk of experiencing a fatal overdose or repeated overdose is necessary in order to curb the current rise in fatal and non-fatal overdoses. These findings underscore the need for 
amplified prevention efforts targeted to those without a history of overdose. Furthermore, these results suggest that healthcare systems should be ready for a rise in the number of patients seen for a repeat overdose. While these results suggest that patients with a repeat overdose may be in need of additional clinical services, coordinated health care is needed among those with a prior overdose. In order to tackle this multifaceted issue, additional primary care services are needed in conjunction with mental health care to address the potential comorbidities among those with a documented or suspected overdose. In conclusion, this study demonstrates that opioid overdoses remain a significant public health problem with additional research needed however, the current public health crisis is not driven solely by opioids, rather this appears to be mental health needs and associated crises. Health systems, clinical health providers, and others seeking to decrease deaths resulting from opioid overdose, are encouraged to systematically assess for and intervene on symptoms associated with mental health disorders. 


\section{References}

1. Olfson, M., et al., Risks of fatal opioid overdose during the first year following nonfatal overdose. Drug and Alcohol Dependence, 2018. 190: p. 112-119.

2. Administration, V.H., Veteran Suicide Data Report, 2005-2016. 2018. Office of Mental Health and Suicide Prevention.

3. Bohnert, K.M., et al., Substance use disorders and the risk of suicide mortality among men and women in the US Veterans Health Administration. Addiction, 2017. 112(7): p. 1193-1201.

4. Centers for Disease Control and Prevention, C., CDC WONDER online database. 2018.

5. Rudd, R.A., et al., Increases in Drug and Opioid-Involved Overdose Deaths - United States, 2010-2015. MMWR Morb Mortal Wkly Rep, 2016. 65(5051): p. 1445-1452.

6. Hedegaard, H., M. Warner, and A.M. Minino, Drug Overdose Deaths in the United States, 1999-2016. NCHS Data Brief, 2017(294).

7. Scholl, L., et al., Drug and Opioid-Involved Overdose Deaths - United States, 20132017. MMWR. Morbidity and Mortality Weekly Report, 2018. 67(5152).

8. Weiss, A.J., et al., Opioid-Related Inpatient Stays and Emergency Department Visits by State, 2009-2014: Statistical Brief \#219, in Healthcare Cost and Utilization Project (HCUP) Statistical Briefs. 2017: Rockville (MD).

9. Paulozzi, L.J., Prescription drug overdoses: A review. Journal of Safety Research, 2012. 43(4): p. 283.

10. Selim, A.J., et al., The health status of elderly veteran enrollees in the Veterans Health Administration. Journal of the American Geriatrics Society, 2004. 52(8): p. 1271-1276.

11. Dursa, E.K., et al., Demographic, military, and health characteristics of VA health care users and nonusers who served in or during operation enduring freedom or operation iraqi freedom, 2009-2011. Public Health Reports, 2016. 131(6): p. 839-843.

12. Szklo, M. and F.J. Nieto, Epidemiology: beyond the basics. 2014: Jones \& Bartlett Publishers.

13. Bossarte, R.M., An overview of VA/DoD joint mortality data repository and data from studies conducted by the epidemiology program in VA's Office of Public Health. 2014.

14. Statistics, N.C.f.H., National Death Index user's guide. 2013.

15. Torres, J.M., et al., ICD Social Codes: An Underutilized Resource for Tracking Social Needs. Med Care, 2017. 55(9): p. 810-816.

16. Gottlieb, L., et al., Integrating Social And Medical Data To Improve Population Health: Opportunities And Barriers. Health Affairs, 2016. 35(11): p. 2116-2123.

17. Oliva, E.M., et al., Development and applications of the Veterans Health Administration's Stratification Tool for Opioid Risk Mitigation (STORM) to improve opioid safety and prevent overdose and suicide. Psychol Serv, 2017. 14(1): p. 34-49.

18. Oliva, E.M., et al., Receipt of opioid agonist treatment in the Veterans Health Administration: facility and patient factors. Drug and alcohol dependence, 2012. 122(3): p. 241-6.

19. Oliva, E.M., et al., Trends in opioid agonist therapy in the Veterans Health Administration: is supply keeping up with demand? The American journal of drug and alcohol abuse, 2013. 39(2): p. 103-7.

20. Gordon, A.J., et al., Facilitators and barriers in implementing buprenorphine in the Veterans Health Administration. Psychol Addict Behav, 2011. 25(2): p. 215-24. 
21. McRae, I. and M. Islam An inevitable wave of prescription drug monitoring programs in the context of prescription opioids: pros, cons and tensions. BMC Pharmacology and Toxicology, 2014. 15, 1-7 DOI: 10.1186/2050-6511-15-46.

22. Dowell, D., T.M. Haegerich, and R. Chou, CDC Guideline for Prescribing Opioids for Chronic Pain - United States, 2016. MMWR Recomm Rep, 2016. 65(1): p. 1-49.

23. Dowell, D., et al., Mandatory Provider Review And Pain Clinic Laws Reduce The Amounts Of Opioids Prescribed And Overdose Death Rates. Health Aff (Millwood), 2016. 35(10): p. 1876-1883.

24. Kennedy-Hendricks, A., et al., Social Stigma Toward Persons With Prescription Opioid Use Disorder: Associations With Public Support for Punitive and Public Health-Oriented Policies. Psychiatric services (Washington, D.C.), 2017. 68(5): p. 462-469.

25. Davis C., G.T., Beletskey L., Action, Not Rhetoric, Needed to Reverse the Opioid Overdose Epidemic. The Journal of Law, Medicine \& Ethics, 2017. 45(1): p. 20-23.

26. Olsen, Y. and J.M. Sharfstein, Confronting the stigma of opioid use disorder--and its treatment. JAMA, 2014. 311(14): p. 1393-4.

27. Roman, P.M., A.J. Abraham, and H.K. Knudsen, Using medication-assisted treatment for substance use disorders: Evidence of barriers and facilitators of implementation. Addictive Behaviors, 2011. 36(6): p. 584-589.

28. Wyse, J.J., Gordon, A. J., Dobscha, S. K., et al., Medications for opioid use disorder in the Department of Veterans Affairs (VA) health care system: Historical perspective, lessons learned, and next steps. Substance abuse, 2018. 39(2): p. 139-144. 


\section{APPENDIX A}

\section{Diagnostic codes used for opioid overdoses recorded in the EHR}

\begin{tabular}{ll}
$\begin{array}{l}\text { Type of } \\
\text { overdose }\end{array}$ & ICD-9 \\
\hline $\begin{array}{l}\text { Opioid } \\
\text { overdose } \\
\text { hospitalization }\end{array}$ & 965.00 (Opium) \\
& 965.01 (Heroin) \\
& 965.09 (Methadone) \\
& OR \\
& E850.0 (Accidental: Heroin \\
& E850.1 (Accidental: Methadone) \\
& E850.2 (Accidental: Other opiates)
\end{tabular}

ICD-10

T40.0X Opium

T40.1X Heroin

T40.2X Other opioids

T40.3X Methadone

T40.4X Synthetic narcotics

T40.60X Unspecified narcotics

T40.69X Other narcotics

And a 6th character of $1,2,3$,or 4

\section{Opioid} overdose mortality
Underlying cause of death code:

X40-X44 (accidental), X60-X64

(intentional/self-harm), X85

(assault/homicide), Y10-Y14

(undetermined)

And a contribution cause of death code T40.0-T40.4, T40.6

Abbreviations: ICD-9, International Classification of Diseases, Ninth Revision; ICD-10, International Classification of Diseases, Tenth Revision; EHR, electronic health record 


\section{APPENDIX B}

\section{Variables of interest among veterans with an opioid overdose}

$\begin{array}{lll}\text { Characteristic } & \text { Variable } & \text { Related ICD codes } \\ \text { Sex } & \text { Sex }(1=\text { male, } 0=\text { female) } & \text { Used last entered value } \\ \text { Age } & \text { Age (Continuous) } & \text { Age as of January } 1,2011 \\ \text { Date of visit } & \begin{array}{l}\text { V_date (in SAS date9. } \\ \text { format) }\end{array} & \text { Time period } 01 / 01 / 2011-12 / 31 / 2015\end{array}$

\section{Psychosocial \& related mental health diagnoses}

Any mental health

diagnosis

mh_dx $(1=$ yes, $0=$ no $)$

Anxiety

anx_dx $(1=$ yes, $0=$ no $)$

Depression

dep_dx $(1=$ yes, $0=$ no $)$

Bipolar

PTSD

Adjustment disorder

Schizophrenia or other psychotic disorders

Traumatic stress

trst_dx $(1=$ yes, $0=$ no $)$

Personality disorder

Opioid

abuse/dependence

Alcohol

abuse/dependence

Cannabis

abuse/dependence

Sedative, hypnotics, or anxiolytic

abuse/dependence

Cocaine

abuse/dependence

Other stimulant

abuse/dependence

op_dx $(1=$ yes, $0=$ no $)$

alc_dx $(1=$ yes, $0=$ no $)$

can_dx $(1=$ yes, $0=$ no $)$
ICD-9: 290.00 to 319.99 , excluding tobacco codes starting with 305

ICD-10: F00 to F99, excluding tobacco codes starting with F17

ICD-9: 300

ICD-10: F40, F41

ICD-9: 296.2, 296.3, 300.4, 311

ICD-10: F32, F33, F34.1

ICD-9: 296.0, 296.1, 296.4, 296.5, 296.6, 296.7, 296.8

ICD-10: F31

ICD-9: 309.81

ICD-10: F43.1

ICD-9: 309.0, 309.24, 309.28, 309.3, 309.4, 309.9

ICD-10: F43.20- F43.25

ICD-9: 295.90, 295.40, 295.70, 297.1, 297.3, 298.8, 293.81, 293.82, 298.9

ICD-10: F20.9, F20.81, F25.0, F25.1, F22, F24, F23, F06.2, F06.0, F29)

ICD-9: $308.9,309.89,309.9$

ICD-10: F43.0 F43.8, F43.9

ICD-9: 301.83, 301.7, 301.81, 301.50, 301.4, 301.82, 301.6, 301.0, 301.20, 310.1301 .9

ICD-10: F60, F61

ICD-9 codes: $304.0,304.7,305.5$

ICD-10 codes: $F 11$

ICD-9: 303, 305.0

ICD-10: F10

ICD-9: $304.3,305.2$

ICD-10: F12

sha_dx $(1=$ yes, $0=$ no $) \quad$ ICD-9: $304.1,305.4$

ICD-10: F13

coc_dx (1=yes, $0=$ no $) \quad$ ICD-9: 304.2, 305.6

ICD-10: F14

stm_dx $(1=$ yes, $0=$ no $) \quad$ ICD-9: $304.4,305.7$

ICD-10: F15 


\begin{tabular}{|c|c|c|}
\hline $\begin{array}{l}\text { Hallucinogen } \\
\text { abuse/dependence }\end{array}$ & hal_dx $(1=$ yes, $0=$ no $)$ & $\begin{array}{l}\text { ICD-9: } 304.5,305.3 \\
\text { ICD-10: F16 }\end{array}$ \\
\hline $\begin{array}{l}\text { Any substance } \\
\text { abuse/dependence }\end{array}$ & $\begin{array}{l}\text { anysub_dx }(1=\text { yes, } \\
0=\text { no })\end{array}$ & Any diagnosis for substance abuse/dependence \\
\hline $\begin{array}{l}\text { Polysubstance } \\
\text { abuse/dependence }\end{array}$ & $\begin{array}{l}\text { polysub_dx }(1=\text { yes, } \\
0=\text { no })\end{array}$ & More than 1 diagnosis for substance abuse/dependence \\
\hline TBI & tbi_dx $(1=$ yes, $0=$ no $)$ & $\begin{array}{l}\text { ICD-9: } 800.0-801.9,803.0-804.9,850.0-854.1,950.1-950.3 \\
\text { 995.55, } 959.01 \\
\text { ICD-10: S02.0, S02.1, S02.8, S02.91, S04.02, S04.03, S04.04, } \\
\text { S06, S07.1, T74.4 }\end{array}$ \\
\hline \multicolumn{3}{|c|}{ Medication-Assisted Treatment (MAT) } \\
\hline Record of MAT & MAT & $\begin{array}{l}\text { Using stop code } 523 \text { (primary or secondary stop code) to identify } \\
\text { MAT services }\end{array}$ \\
\hline \multicolumn{3}{|c|}{ Chronic pain before index $O D$} \\
\hline Back pain & b_pain $(1=$ yes, $0=$ no $)$ & $\begin{array}{l}\text { ICD-9: 720.0-724.9 } \\
\text { ICD-10: M45.9- M46.1, M46.90, M47.812, M47.12, M47.814, } \\
\text { M47.817, M48.20, M48.10, M48.30, M48.9, M50.20, M51.9, } \\
\text { M50.30, M51.34-M51.37, M48.02, M54.2, M53.0, M53.1, } \\
\text { M54.12, M54.13,M43.6, M54.02, M67.88, M53.82, M54.6, } \\
\text { M54.5, M54.30, M54.14-M54.17, M54.89-M54.9, M43.27, } \\
\text { M43.28, M53.2X7, M53.3, M54.08, M43.8X9, M53.9 }\end{array}$ \\
\hline Arthritis & a_pain $(1=$ yes, $0=$ no $)$ & $\begin{array}{l}\text { ICD-9: 710.0-739.9, excluding back pain codes } \\
\text { ICD-10: M00-M02, M36.2, M36.3, M12, M35.3, M15, M16- } \\
\text { M19, M05-M08, M1A, M10-M14 }\end{array}$ \\
\hline Migraines & $\mathrm{m} \_$pain $(1=$ yes, $0=$ no $)$ & $\begin{array}{l}\text { ICD-9: } 346.0-346.9 \\
\text { ICD-10:G43.0, G43.1, G43.4, G43.5, G43.6, G43.7, G43.8, } \\
\text { G43.9, G43.A, G43.B, G43.C, G43.D }\end{array}$ \\
\hline $\begin{array}{l}\text { Headaches or tension } \\
\text { headaches }\end{array}$ & $\mathrm{h} \_$pain $(1=$ yes, $0=$ no $)$ & $\begin{array}{l}\text { ICD-9: } 784.0 \text { and } 307.81 \\
\text { ICD-10: G44.1, R51, G44.209 }\end{array}$ \\
\hline Psychogenic & p_pain $(1=$ yes, $0=$ no $)$ & $\begin{array}{l}\text { ICD-9: } 307.80 \text { and } 307.89 \\
\text { ICD-10: } F 45.41, \text { F } 45.42\end{array}$ \\
\hline Neuropathy & n_pain $(1=$ yes, $0=$ no $)$ & $\begin{array}{l}\text { ICD-9: } 355.0,355.9,356.0,357.2,357.9 \\
\text { ICD-10:G57.00, G58.9, G60, E08.42, E09.42, E10.42, E11.42, } \\
\text { E13.42, G61.9 }\end{array}$ \\
\hline Fibromyalgia & f_pain $(1=$ yes, $0=$ no $)$ & $\begin{array}{l}\text { ICD-9: } 729.1 \\
\text { ICD-10: } M 60.9, \text { M79.1, M79.7 }\end{array}$ \\
\hline $\begin{array}{l}\text { Any chronic pain } \\
\text { diagnosis }\end{array}$ & chr_dx $(1=$ yes, $0=$ no $)$ & Any of the diagnoses for chronic pain \\
\hline \multicolumn{3}{|c|}{ Social determinants of health $(S D o H)$ codes prior to index $O D$} \\
\hline $\begin{array}{l}\text { Problems related to } \\
\text { housing and economic } \\
\text { circumstances }\end{array}$ & $\begin{array}{l}\text { Prob_econ } \\
(1=\text { yes, } 0=\text { no })\end{array}$ & $\begin{array}{l}\text { ICD-9: V60.0, V60.1, V60.89, V60.6, V60.2, V60.9 } \\
\text { ICD-10: Z59 (Z59.0-Z59.9) }\end{array}$ \\
\hline $\begin{array}{l}\text { Problems related to } \\
\text { support group, } \\
\text { including family and } \\
\text { relationships }\end{array}$ & $\begin{array}{l}\text { Prob_supp } \\
(1=\text { yes, } 0=\text { no })\end{array}$ & $\begin{array}{l}\text { ICD-9: V61.0, V61.05, V61.8, V61.01, V61.06, V61.07, } \\
\text { V61.08, V62.82, V61.03, V61.49, V61.02, V61.41, V61.3, } \\
\text { V61.04, V61.09, V61.8, V61.9 } \\
\text { ICD-10: Z63 (Z63.0-Z63.9) }\end{array}$ \\
\hline $\begin{array}{l}\text { Problems related to } \\
\text { social environment }\end{array}$ & $\begin{array}{l}\text { Prob_soenv } \\
(1=\text { yes, } 0=\text { no })\end{array}$ & $\begin{array}{l}\text { ICD-9: V60.3, V62.4, V62.89 } \\
\text { ICD-10: Z60.0, Z60.2, Z60.3, Z60.4, Z60.5, Z60.8, Z60.9 }\end{array}$ \\
\hline
\end{tabular}




\begin{tabular}{|c|c|c|}
\hline $\begin{array}{l}\text { Problems related to } \\
\text { upbringing }\end{array}$ & $\begin{array}{l}\text { Prob_upbr } \\
(1=\text { yes, } 0=\text { no })\end{array}$ & $\begin{array}{l}\text { ICD-9: V61.29, V61.8, V60.81 } \\
\text { ICD-10: Z62.0, Z62.1, Z62.2, Z62.3, Z62.6, Z62.8 }\end{array}$ \\
\hline $\begin{array}{l}\text { Problems related to } \\
\text { environmental } \\
\text { psychosocial } \\
\text { circumstances }\end{array}$ & $\begin{array}{l}\text { Prob_enpsych } \\
(1=\text { yes, } 0=\text { no })\end{array}$ & $\begin{array}{l}\text { ICD-9: V62.5, V62.89, V62.81, V62.9 } \\
\text { ICD-10: Z65.0, Z65.1, Z65.2, Z65.3, Z65.4, Z65.5, Z65.8, Z65.9 }\end{array}$ \\
\hline $\begin{array}{l}\text { Problems related to } \\
\text { abuse }\end{array}$ & $\begin{array}{l}\text { Prob_abuse } \\
(1=\text { yes, } 0=\text { no })\end{array}$ & $\begin{array}{l}\text { ICD-9: V61.21, V61.22, V62.83, V61.11, V61.12, V65.49 } \\
\text { ICD-10: Z69.0, Z69.01, Z69.02, Z69.1, Z69.8 }\end{array}$ \\
\hline Counseling services & $\begin{array}{l}\text { Prob_coun } \\
(1=\text { yes, } 0=\text { no })\end{array}$ & $\begin{array}{l}\text { ICD-9: V65.49, V61.2, V61.1, V65.40, V65.9 } \\
\text { ICD-10: Z71.81, Z71.89, Z71.9 }\end{array}$ \\
\hline $\begin{array}{l}\text { Other problems related } \\
\text { to mental and behavior }\end{array}$ & $\begin{array}{l}\text { Prob_menbeh } \\
(1=\text { yes, } 0=\text { no })\end{array}$ & $\begin{array}{l}\text { ICD-9: V40.0, V40.2, V40.3, V40.31, V40.39, V40.9 } \\
\text { ICD-10: F48.9, F69 }\end{array}$ \\
\hline Any SDoH & $\begin{array}{l}\text { any_sdoh } \\
(1=\text { yes, } 0=\text { no })\end{array}$ & Any of the above SDoH codes captured before index OD \\
\hline
\end{tabular}

Abbreviations: ICD, International Classification of Disease; ICD-9, International Classification of Disease, Ninth Edition; ICD-10, International Classification of Disease, Tenth Edition; PTSD, Post-traumatic stress disorder; TBI, Traumatic Brian Injury; MAT, Medication-Assisted Treatment; OD, overdose; SDoH, social determinant of health 


\section{APPENDIX C}

\section{Diagnostic codes used to classify indicators of social determinants of health}

\section{Description}

Problems related to housing

and economic circumstances
Description

- Homelessness

- Inadequate housing

- Discord with neighbors, lodgers and landlord

- Problems related to living in residential institution

- $\quad$ Lack of adequate food and safe drinking water

- Extreme poverty

- Low income

- Insufficient social insurance and welfare support

- Other problems related to housing and economic circumstances

- Problem related to housing and economic circumstances, unspecified
Problems related to support group, including family and relationships

- Problems in relationship with spouse or partner

- Problems in relationship with in-laws

- Absence of family member

- Disappearance and death of family member

- Disruption of family by separation and divorce

- Dependent relative needing care at home

- Other stressful life events affecting family and household

- Other specified problems related to primary support group

- Problems related to primary support group, unspecified

Problems related to social environment
- Problems of adjustment to life-cycle transitions

- Problems related to living alone

- Acculturation difficulty

- Social exclusion and rejection

- Target of (perceived) adverse discrimination and persecution

- Other problems related to social environment

- $\quad$ Problem related to social environment, unspecified
ICD code

ICD-9: V60.0, V60.1, V60.89, V60.6, V60.2, V60.9

ICD-10: Z59 (Z59.0-Z59.9)

ICD-9: V61.0, V61.05, V61.8, V61.01, V61.06, V61.07, V61.08, V62.82, V61.03, V61.49, V61.02, V61.41, V61.3, V61.04, V61.09, V61.8, V61.9

ICD-10: Z63 (Z63.0-Z63.9)

ICD-9: V60.3, V62.4, V62.89

ICD-10: Z60.0, Z60.2, Z60.3, Z60.4, Z60.5, Z60.8, Z60.9 


\begin{tabular}{|c|c|c|}
\hline $\begin{array}{l}\text { Problems related to } \\
\text { upbringing }\end{array}$ & $\begin{array}{l}\text { - Inadequate parental supervision and control } \\
\text { - } \quad \text { Parental overprotection } \\
\text { - Upbringing away from parents } \\
\text { - Hostility towards and scapegoating of child } \\
\text { - Inappropriate (excessive) parental pressure } \\
\text { - Other specified problems related to } \\
\text { upbringing }\end{array}$ & $\begin{array}{l}\text { ICD-9: V61.29, V61.8, V60.81 } \\
\text { ICD-10: Z62.0, Z62.1, Z62.2, } \\
\text { Z62.3, Z62.6, Z62.8 }\end{array}$ \\
\hline $\begin{array}{l}\text { Problems related to } \\
\text { environmental psychosocial } \\
\text { circumstances }\end{array}$ & 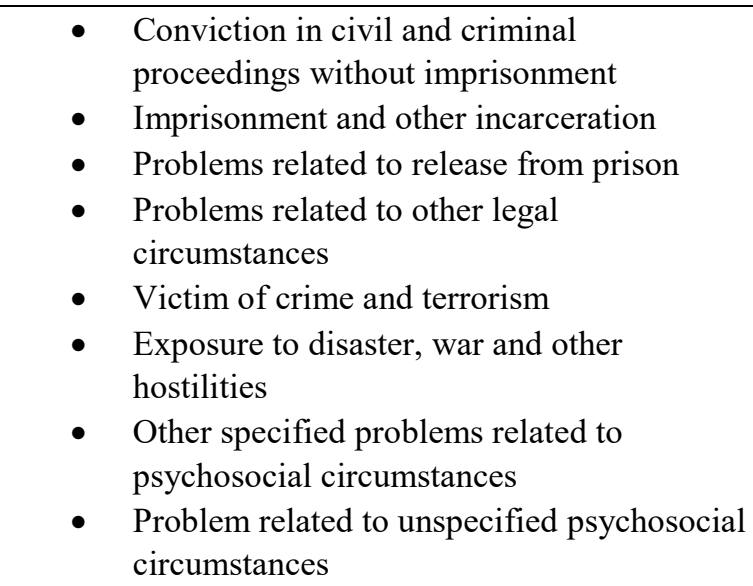 & $\begin{array}{l}\text { ICD-9: V62.5, V62.89, V62.81, } \\
\text { V62.9 } \\
\text { ICD-10: Z65.0, Z65.1, Z65.2, } \\
\text { Z65.3, Z65.4, Z65.5, Z65.8, Z65.9 }\end{array}$ \\
\hline Problems related to abuse & $\begin{array}{l}\text { - } \begin{array}{l}\text { Encounter for mental health services for } \\
\text { child abuse problems }\end{array} \\
\text { - } \quad \text { Encounter for mental health services for } \\
\text { parental child abuse } \\
\text { - Encounter for mental health services for } \\
\text { non-parental child abuse } \\
\text { - Encounter for mental health services for } \\
\text { spousal or partner abuse problems } \\
\text { - Encounter for mental health services for } \\
\text { victim or perpetrator of other abuse }\end{array}$ & $\begin{array}{l}\text { ICD-9: V61.21, V61.22, V62.83, } \\
\text { V61.11, V61.12, V65.49 } \\
\text { ICD-10: Z69.0, Z69.01, Z69.02, } \\
\text { Z69.1, Z69.8 }\end{array}$ \\
\hline Counseling services & $\begin{array}{ll}\text { - } & \text { Spiritual or religious counseling } \\
\text { - } & \text { Other specified counseling } \\
\text { - } & \text { Counseling, unspecified }\end{array}$ & $\begin{array}{l}\text { ICD-9: V65.49, V61.2, V61.1, } \\
\text { V65.40, V65.9 } \\
\text { ICD-10: Z71.81, Z71.89, Z71.9 }\end{array}$ \\
\hline $\begin{array}{l}\text { Other problems related to } \\
\text { mental and behavior }\end{array}$ & $\begin{array}{l}\text { - Nonpsychotic mental disorder, unspecified } \\
\text { - Unspecified disorder of adult personality } \\
\text { and behavior }\end{array}$ & $\begin{array}{l}\text { ICD-9: V40.0, V40.2, V40.3, } \\
\text { V40.31, V40.39, V40.9 } \\
\text { ICD-10: F48.9, F69 }\end{array}$ \\
\hline Any SDoH & \multicolumn{2}{|l|}{ Any of the above SDoH codes captured before index OD } \\
\hline
\end{tabular}

Abbreviations: ICD, International Classification of Disease; ICD-9, International Classification of Disease, Ninth Edition; ICD-10, International Classification of Disease, Tenth Edition; SDoH, social determinant of health 


\section{APPENDIX D}

Underlying cause of death codes used for cause-specific mortality

\begin{tabular}{|c|c|}
\hline Cause of death & ICD-10 Codes Associated With Underlying Cause of Death \\
\hline Opioid overdose & $\mathrm{X} 40-\mathrm{X} 44, \mathrm{X} 60-\mathrm{X} 64, \mathrm{X} 85, \mathrm{Y} 10-\mathrm{Y} 14$ with secondary axis codes T40.0-T40.4, T40.6 \\
\hline External Cause of death & X60-X84, Y87.0, X85-Y09, Y87.1, V01-X39, X46-X59, Y85-Y86 \\
\hline Suicide & $\mathrm{X} 60-\mathrm{X} 84, \mathrm{Y} 87.0$ \\
\hline Homicide & $\mathrm{X} 85-\mathrm{Y} 09, \mathrm{Y} 87.1$ \\
\hline Accidents & V01-X39, X46-X59, Y85-Y86 \\
\hline Substance-related & $\begin{array}{l}\text { F11.0-F11.5, F11.7-F11.9, F12.0-F12.5, F12.7-F12.9, F13.0-F13.5, F13.7-F13.9, } \\
\text { F14.0-F14.4, F14.7-F14.9, F15.0-F15.5, F15.7-F15.9, F16.0-F16.5, F16.7-F16.9, } \\
\text { F17.0, F17.3-F17.5, F17.7-F17.9, F18.0-F18.5, F18.7-F18.9, F19.0-F19.5, F19.7- } \\
\text { F19.9, X40-X44, Y10-Y14, F10, G31.2, G62.1, I42.6, K29.2, K70, R78.0, X45, } \\
\text { Y15 }\end{array}$ \\
\hline Drug-related & $\begin{array}{l}\text { F11.0-F11.5, F11.7-F11.9, F12.0-F12.5, F12.7-F12.9, F13.0-F13.5, F13.7-F13.9, } \\
\text { F14.0-F14.4, F14.7-F14.9, F15.0-F15.5, F15.7-F15.9, F16.0-F16.5, F16.7-F16.9, } \\
\text { F17.0, F17.3-F17.5, F17.7-F17.9, F18.0-F18.5, F18.7-F18.9, F19.0-F19.5, F19.7- } \\
\text { F19.9, X40-X44, Y10-Y14 }\end{array}$ \\
\hline Alcohol-related & F10, G31.2, G62.1, I42.6, K29.2, K70, R78.0, X45, Y15 \\
\hline Infectious & A00-B99 \\
\hline Viral hepatitis & B15-B19 \\
\hline$H I V$ & B20-B24 \\
\hline Circulatory system & I00-I99 \\
\hline Respiratory system & J00-J98 \\
\hline Influenza \& pneumonia & J09-J18 \\
\hline $\begin{array}{r}\text { Chronic respiratory } \\
\text { disease }\end{array}$ & $\mathrm{J} 40-\mathrm{J} 47$ \\
\hline Digestive system & K00-K92 \\
\hline $\begin{array}{r}\text { Cirrhosis \& alcoholic } \\
\text { liver disease }\end{array}$ & K70, K73-74 \\
\hline Cancer & C00-D48 \\
\hline Lung \& bronchus & C34 \\
\hline $\begin{array}{r}\text { Liver \& intrahepatic bile } \\
\text { duct }\end{array}$ & $\mathrm{C} 22$ \\
\hline Digestive system & $\mathrm{C} 15-\mathrm{C} 21, \mathrm{C} 23-\mathrm{C} 26$ \\
\hline Lymphoma \& leukemia & C82-C85, C91-C95 \\
\hline Other cancers & $\mathrm{C} 00-\mathrm{C} 14, \mathrm{C} 27-\mathrm{C} 33, \mathrm{C} 35-\mathrm{C} 81, \mathrm{C} 86-\mathrm{C} 90, \mathrm{C} 96-\mathrm{D} 48$ \\
\hline
\end{tabular}

Abbreviations: ICD-10, International Classification of Diseases, Tenth Edition; HIV, human immunodeficiency virus 